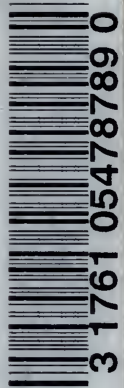

ME NEW KNOWLEDGE

R. K. DUNCAN 



D9124n

\section{THE NEW KNOWLEDGE}

A POPULAR ACCOUNT OF THE NEW PHYSICS AND THE NEW CHEMISTRY IN THEIR RELATION

TO THE NEW THEORY OF MATTER

BY

\section{ROBERT KENNEDY DUNCAN}

PROFESSOR OF CHEMISTRY IN WASHINGTON AND JEFFERSON COLLEGE
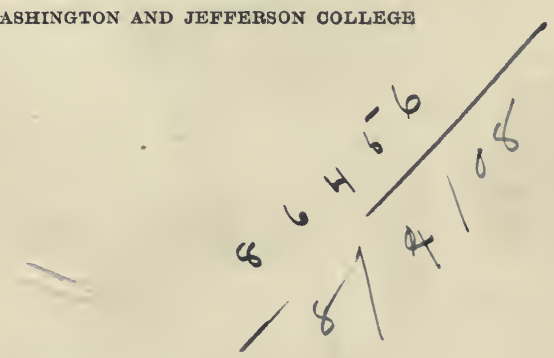

ILLUS'TRATED

HODDER AND STOUGHTON

LONDON MCMVII 
Digitized by the Internet Archive in 2007 with funding from Microsoft Corporation 




\section{PREFACE.}

The historical method of treatment is the death of clear exposition. Consequently, I have given scant consideration to the evolution of the idea in time compared with its evolution from the standpoint of simplicity of apprehension. Furthermore, what a man "wants to know" is less the doer of the work than the work done. I have, therefore, made the workers incidental to their work. Nevertheless, these men represent the very élite of the army of science. It is doubtful whether in any other field of human effort there are to be found so many men of transcendent genius, magnificent training and splendid balance of judgment as are to be found in the science of radioactivity. It often happens in science that when a new Alaska is discovered there is a rush of "tenderfeet" to the district and it becomes difficult to extract from the mass of material presented the pure metal from the "fool's gold." This was notably the case with Röntgen's original discovery, but it has been equally not the case since radio-activity became a distinct science. These men are the pride of their universities; and their names and work will long hold out "against the wreckful siege of battering days." Such are: J. J. Thomson, Becquerel, M. et Mde. Curie, Rutherford, Ramsay, Crookes, Lodge, C. T. R. 
Wilson, H. A. Wilson, Elster and Geitel, Soddy, Debierne, McLennan, Allan, and many others.

Their work consists of facts experimentally obtained and theories based upon these facts. Their statements of fact may, emphatically, be believed, and I trust that I have not trifled with them. Their theories are as they would have them-acceptable so long as they explain the phenomena observed. As these theories are presented in this book, they cannot be said to rest upon any definite concensus of scientific opinion. The science is too new. Each theory is, rather, the work of some one man who is entitled to speak as the authority paramount on that particular subject. I have taken them as so many defensible theses and have presented them as clearly and forcibly as I might.

If any portion of this book seems a little too enthusiastic it is due to a vast admiration for the work of these masters of science.

\section{R. K. D.}

\section{PREFACE TO THE FIFTH EDITION.}

The rapid sequence of editions through which this book has passed has given me scant opportunity of altering it. I take the opportunity, however, in this edition of correcting certain typographical inadvertencies that have caused me to write many grievous letters of explanation to readers who thought that in them they discovered inconsistencies of statement. I wish to thank most cordially my readers both at home and abroad for their letters of thanks and good-will. In a book that appeals solely to the beauty of human reason and not at all to the emotions, such letters are as unlooked for as they are welcome. I wish to thank my critics; it is deeply gratifying to me that they have indicated nothing that I ought to retract. Finally, I wish to thank the workers in radio-activity for their kind expressions of praise and esteem. 


\section{TABLE OF CONTENTS.}

Introduction.

XV

Part 1. Current Conceptions.

Chapter I. The Three Entities.

1

II. Compounds and Elements: MoleCULES AND ATOMS.

8

Part 2. The Periodic Law.

Chapter I. The Mystery of Matter.

II. The Atoms of the Elements. 17 .

III. The Table of the Law.

26

IV. The Testing of the Law.

34

V. The Significance of the Law

39

\section{Part 3. Gaseous Ions.}

Chapter I. Gases from the Standpoint of Physics: How They Conduct Electricity.

II. Discovery of Ions: A New Kind of Particles.

III. Discovery of Corpuscles.

IV. Factors of a Corpuscle: An ExPERIMENT.

V. The Speed of a Corpuscle and How it is Estimated.

VI. The Relation of the Charge on a Corpuscle to its Mass: How Im.PORTANT IT IS. 
Chapter VII. How the Electrical Charge on a Corpuscle is Estimated. A New Use for Clouds.

VIII. How the Mass of a CoRpuscle is Determined: Discovery of the One Thing.

IX. Properties of Corpuscles: Cathode RAYS.

X. Positive Ions: The Other Kind of Particles.

Part 4. Natural Radio-activity: A New Property of Matter. Chapter I. Antecedent Discovery.

II. Discovery of Radio-Activity.

III. Discovery of Radio-ACtive EleMENTS.

IV. RADIUM.

V. Becquerel Rays from Radium.

VI. The Alpha-, Beta-, And Gamma-Rays. 105

VII. Emanations.

VIII. Emanation $\mathrm{X}$ and the Birth of HELIUM.

IX. Thorium, Uranium, Polonium and ACTINIUM.

X. Radio-ACtivity Everywhere.

Part 5. The Resolution of the Atom.

Chapter I. Modern Alchemy: The TransmuTATION OF MATTER.

II. Аtomic Disintegration: An AtTEMPt to Explain the Mystery OF MATTER.

III. INTRA-ATOMIC ENERgY.

IV. The Electrical Nature of Matter. 179 
Part 6. Inorganic Evolution.

Chapter I. Celestial Dissociation.

II. Inorganic Evolution. 206

III. Inorganic Devolution.

Part 7. The New Knowledge and 0ld Problems.

Chapter I. Cosmical Problems.

II. The Mechanical Pressure of Light and Its Consequences.

232

III. The Reconstruction of a UniVERSE.

IV. The Definitions of Science ReDEFINED.

V. The Validity of the New KnowlEDGE. 



\section{ILLUSTRATIONS.}

FIG.

PAGE

1. Radiometer ............................ 4

2. Periodicity of Аtomic Volumes............... 24

3. Periodicity of . Meleting-Points............... 25

4. First Part of Mendeléeffy's Table............. 26

5. The Latest Table of the Periodic Law......... 28

6. Relationship in Group II................. 31

7. Relationship in Group VII................ 32

8. An Electroscope....................... 47

9. Apparatus for Proving the Conductivity of the Air 49

10. Showing the Division of a Flame between Oppositely Charged Plates...................... 50

11. Apparatus for Studying Ions from a Hot Wire..... 51

12. Experiment for Determining the Velocity of a Corpuscle ......................... 56

13. Showing Rays Deflected by Horse-shoe Magnet.... 57

14. Showing Phenomena in Vacuum Tube........... 68

15. Showing that the Phosphorescence Arises from the Cathode........................... 68

16. Photographic Representation of a Vacuum Tube in Action.............................. 69

17. Cathode Rays of Corpuscles Brodght to a Focus.. 71

18. Showing that Corpuscles Will Move a Body Which They Strike....................... 71

19. Niewenglowski's Experiment............... 83

20. The Result of Niewengloski's Experiment....... 84

21. Becquerel's First Experiment............... 87

22. URANiUm RadiograPH.................. 88

23. Photograph of a Section of Pitchblende......... 91

24. Radiograph of a Section of Pitchblende......... 91

25. Comparative Spectra of Radium and Calcium....... 93

26. Radiograph Showing the Penetrative Power of

RAYS FROM RADIUM.................. 96

27. Radiograph by the Curies................. 97

28 (a). Radium Chloride, Photographed by Daylight...... 98 
FIG.

28 (b). Radium Chloride, Photographed by the Light of its

Phosphorescence...................... 98

29 (a). An Electroscope, Charged................. 99

29 (b). The Same Electroscope Discharged by Radium...... 100

30. M. Becquerel and the Experiment With the Magnet 101

31. Magnetic Deviation of the Becquerel Rays....... 102

32. Radiograph Showing the Penetrative Power of

RAYS FROM RADIUM................... 102

33. Becquerel Rays Consist of at Least Two Kinds.... 103

34. Another Proof.......................... 103

35. Section of Crooke's Spinthariscope........... 106

36. Phosphorescence Induced by Induced Radio-Activity 113

37. Curie's Experiment Proving the Existence $、$ of aN

Emanation ........................... 114

38 (a). CURIE's Electros Cope For the StUdy of Radio-ACtivity 117

38 (b). Diagrammatic Representation of Fig. 38 (a)...... 117

59. Curves Showing the Rate of Recovery of the Radium

and the Decay of the Emanation.......... 120

40. The Spectrum of Helium.................. 125

41. Curves Showing the Rate of Recovery of Thorium

ANd the Decay of Thorium X............ 127

42. The Arrangement of Two Corpuscles........... 154

43. The Arrangement of Three Corpuscles.......... 154

44. The Configurations Assumed by Floating Magnets.. 156

45. A Continuous and a Discontinuous Spectrum..... 195

46. Parts of the Spectra of Barium and Iron........ 195

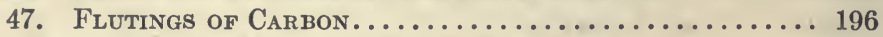

48. Series Spectra in the Cleveite Gases.......... 196

49. Fraunhofer's Lines...................... 198

50. Iron Sun-spot Lines at Kensington Confronted With

Iron Prominence-lines at Palermo.......... 202

51. Different Rates of Motion Registered by Different

Iron Lines.......................... 203

52. Diagram Showing the Duration of Organic Evolu-

tion Compared With Inorganic Evolution..... 215

53. Spectra Showing an Inorganic Devolution....... 219

54. The Progress of a Nebula to a Dark Star........ 223 


\section{INTRODUCTION.}

Laymen in science who wish to follow the trend of modern discovery are limited for the most part to one of two things: Either they must read the pseudo-science of the magazines, which is arranged chiefly for dramatic effect rather than for accurate exposition, or they must turn to specialized and technical works written by the discoverers themselves for their fellow-workers-books in which technical training is taken for granted, and the lay reader, however cultured and thoughtful he may be, becomes utterly and hopelessly lost.

The world is thus divided between men who know and cannot tell, and men who tell and cannot know. The great expositors are dead, Huxley and Tyndall and all the others; and the great expositor of the future, the interpreter of knowledge to the people, has still to be born. The writer of this book, himself, falls under the burden of these difficult conditions. He dares venture the undertaking only because of the need of some interpretation of this new and interesting knowledge and because of his own sincerity. $\mathrm{He}$ expects nothing from the reader but a high school education and a love of contemporary natural knowledge. This love of contemporary natural knowledge is legitimate. There is something peculiarly attractive about this borderline between science and ignorance. It is the fightingline-and it is so pre-eminently human and natural to love the spectacle of a struggle. It is the spectacle of a con- 
temporary struggle that the author places before the reader, the casus belli being neither more nor less than the nature of the chemist's atom. The nature of the atom may seem at first sight to be too abstruse and remote to enter into the sphere of practical interest. Such a hasty judgment would be unwarranted. The atoms of matter are the bricks of the universe, out of which you and we and the Milky Way and the Dog Star are all made up. What affects the atom affects us. As a matter of fact, there is nothing esoteric about it and little that is abstract. The knowledge is apprehendable enough and vastly important. Locked up in it is the cause of the heat of the sun, together with the nature of electricity, the evolution of a universe and the birth and decay of matter. There are also, possibly, a cure for tuberculosis, light without heat, a demonstration of vast stores of energy hitherto unsuspected, beside which the forms of energy with which we are acquainted are absolutely insignificant, and a whole series of radiations heretofore unknown from matter in the natural state. Ten years ago men talked with extreme positiveness about this and that; a famous littérateur, even, wrote a comprehensive treatise on "The Bankruptcy of Science" in which he proved (sic) that everything essential and possible of knowing was known, and that all that remained was mere detail. It is proper to say that the answer of science to this tremendous indictment was in deeds, not words, for there came in rapid succession Hertz' discovery of electro-magnetic waves, Moissan's revolutionary work with the electric furnace, Röntgen's X-rays, Rayleigh's and Ramsay's discovery of the rare gases of the atmosphere, and Dewar's liquefaction of hydrogen. Finally, there has come, as most upsetting to all preconceived ideas, the famous discovery of Becquerel and the Curies, which in itself and in its consequences forms mainly the subject- 
matter of this book. Where before there was solid, walkable ground to the older science, now there is nothing but shifting sand. The last century began with the atom, and the result is the implements of civilization as we have them. This century begins with the atom within the atom, and, if one may judge, the civilization of the coming years will be rapidly modified and eventually transformed into phases of which, now, we have but the barest glimpse.

Since it has been the cardinal desire of the writer to make this book a logical sequence and, to some extent, a synthesis of this new knowledge, he has deemed it advisable to begin with definitions which formulate the fundamental conceptions of the older science and to build the book up to the definitions, re-defined, which sum up the advance. Only in this way can the general reader obtain a reasonably comprehensive grasp of the subject-matter and only in this way, also, can the writer force upon him an intellectual conviction of its validity.

Since there appears to be no text-book which even attempts to cover this field of knowledge it is hoped that this simple gathering together of its most significant facts and theories may prove useful and helpful to the teacher and the student.

The progressive teacher, particularly in the high school or smaller college, finds it, often, exceedingly difficult to gain access to the original sources of knowledge.

The student, whether he is now in school or college or whether he has passed therefrom into his life-work of mechanical or professional activity, generally has not time for and does not desire such original sources, though he may have an eager wish to keep abreast of the march of knowledge.

Teachers and advanced students of branches of knowl- 
edge widely divergent from physical science often wish to correlate their knowledge with its latest thought. To them as well as to general readers it is hoped that the simple exposition and summary offered in this book may prove convenient, acceptable and useful.

R. K. D. 


\section{PART I.}

\section{CURRENT CONCEPTIONS.}


"Now, whether the main outlines of the world-picture which I have just imperfectly presented to you be destined to survive, or whether in their turn they are to be obliterated by some new drawing on the scientific palimpsest, all will, I think, admit that so bold an attempt to unify physical nature excites feelings of the most acute intellectual gratification. The satisfaction it gives is almost oesthetic in its intensity and quality. We feel the same sort of pleasurable shock as when from the crest of some melancholy pass we first see far below us the sudden glories of plain, river, and mountain."

"Reflections Suggested by the New Theory of Matter." Inaugural Address by the Right Hon. A. J. Balfour, President of the British Association. August, 1904. 


\section{THE NEW KNOWLEDGE.}

PART I.

CURRENT CONCEPTIONS.

\section{CHAPTER I.}

The Three Entities.

When a man begins to think, seriously, of the world, or worlds, around about him, he is at first dazed by the seeming complexity of it all. Thousands of phenomena confront him, inextricably tangled, and there seems to be no simple way of co-ordinating them. That the universe must be harmonious, is a fundamental demand of our human nature. Nor is this faith misplaced. Just so soon as we actually begin to sort things out, mattcrs proceed with gratifying smoothness and it soon becomes apparent that one may place all he knows of this universe of space and time into just exactly three compartments. These compartments we shall label:
1. MATTER.
2. ETHER.
3. ENERGY.

These are three physical entities, outside of which, so 
far as we understand the physical universe, there is nothing, and into which the universal content of the mind of man, so far as it concerns things outside itself, may be stowed away. For the sake of our atom, we must define these three entities, and, until the progress of our book warrants it, we must define them by means of the current conceptions.

\section{MATTER.}

What matter is, in itself and by itself, is quite hopeless of answer and concerns only metaphysicians. The "Ding an sich" is forever outside the province of science. If all men stopped to quarrel over the inner inwardness of things, progress, of course, would cease. Science is naïve; she takes things as they come, and rests content with some such practical definition as will serve to differentiate matter from all other forms of non-matter. This may be done, strictly provisionally in this place, by defining matter as that which occupies space and possesses weight. Using these two properties it is readily possible to sift out matter from all the heterogeneous phenomena that present themselves to the senses, and that, in this place, is what we want. Thus, wood, water, copper, oil and air are forms of matter for they evidently possess weight and fill space. But light, heat, electricity and magnetism we cannot consider to fill so many quarts or weigh so many pounds. They are, therefore, forms of non-matter. In like manner, things such as grace, mercy, justice and truth, while they are existing entities as much as matter, are unquestionably non-matter

We have, consequently, in this definition, a ready touchstone for distinguishing matter from non-matter.

Now, governing matter in all its varied forms, there is one great fundamental law which up to this time has been ironclad in its character. 
This law, known as the law of the conservation of mass, states that no particle of matter, however small, may be created or destroyed. All the king's horses and all the king's men cannot destroy a pin's head. We may smash that pin's head, dissolve it in acid, burn it in the electric furnace, employ, in a word, every annihilating agency, and yet that pin's head persists in being. Again, it is as uncreatable as it is indestructible. In other words, we cannot create something out of nothing. The material must be furnished for every existent article. The sum of matter in the universe is $x$ pounds,-and, while it may be carried through a myriad forms, when all is said and done, it is just- $x$ pounds.

In the foregoing statements we have used the conceptions of the older science, and, indeed, the current conceptions; . but to say that throughout all time we never should be able to destroy or create matter, or to say, indeed, that matter is not, to some extent, being created and destroyed to-day, would be to run the risk of profound error. All we can say, to-day, is that we cannot do it. If creation or annihilation is actually going on, we are mere spectators and stand in no causal relation. That this well may be, and probably is, it must be the duty of our book to disclose in certain succeeding pages.

\section{ETHER.}

Any discussion of ether leads out upon the highroad to incredulity. A thing must be defined by its properties and the properties of the ether are for the most part negative; so negative, indeed, are they, that when one says boldly that we cannot see ether, hear it, taste it, smell it, exhaust it, weigh it, or measure it, one feels timid that saneminded people will meet these negative qualities of our 
ether by a decided negation of belief in its existence. But the fact of the matter is that if this thing "ether" is not visible to the eye of sense it is visible to the eye of the mind, which is much less liable to err. To demonstrate this, place a little instrument known as the radiometer up in the

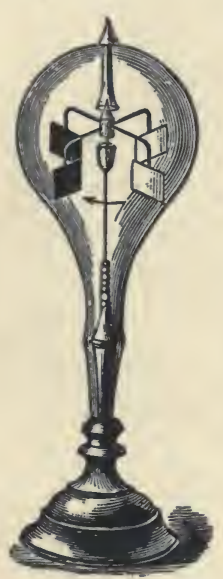

Fig. 1.

sunlight. This instrument consists of a glass bulb containing a partial vacuum in which hangs poised a tiny mill wheel of aluminum. On the impact of the sunlight the wheel at once begins to revolve, and soon attains a velocity so great that the eye is unable to distinguish the separate vanes. Now the eye of the mind is applied: Something, therefore, flies $93,000,000$ of miles from the sun and causes that wheel to revolve, and that something must be the radiations of light and heat. With regard to the nature of these radiations we are positively shut up to one of two explanations.

The light and heat proceeding from the sun consist either of particles or of waves. There is no other explanation conceivable.

The first assumption, that they consist of particles, is known as the "corpuscular theory," and was killed outright and buried years ago after a battle royal. The second assumption, that of waves, known as the undulatory theory, meets with universal acceptance. It is the only complete explanation of all the known facts. The radiations from the sun, therefore, that moved our mill wheel consist of waves; and now comes the inevitable back-thrust of the mind, waves of what?

Once convinced that light consists of waves, the mind 
insists that these waves shall inhere in something. The ocean waves are made of water,-sound waves of air,light waves of, we must say,-something. This something cannot be air or water or any form of matter as we know it, for throughout that great reach of $93,000,000$ of miles between the sun and us there exists but empty space. Filled this empty space is, however, and to the brim. There is no such thing as emptiness. From corner to corner of the universe, wherever a star shines or light darts, there broods this vast circumambient medium-the ether. Not only through interstellar spaces, but through the world also, in all its manifold complexity, through our own bodies; all lie not only encompassed by it but soaking in it as a sponge lies soaked in water. How much we ourselves are matter and how much ether is, in these days, a very moot question.

\section{ENERGY.}

Just as there is no such thing as emptiness, so there is no such thing as rest. It is doubtful that there is such a thing as rest even in a relative sense. The very particles that constitute the materials of our so-solid-seeming earth, that seem so fixed and at rest relatively to one another are in a state of perpetual unremitting quiver-what we call temperature-and that quivering, had we eyes but big enough to see it, is very far, indeed, removed from rest. Now, this motion is continually changing, from one velocity to another, and the same kind of reasoning that led us to believe in the ether leads us to believe that a body can go faster or slower only because of some cause. This cause, or this power to change the state of motion of a body, is energy.

Just as matter may exist in so many different forms, so may energy, a list of the forms of which we append:

$$
\begin{aligned}
& \text { ETHER IS MATTER INFINITELY } \\
& \text { SUBDIVIDED. }
\end{aligned}
$$



1. KINETIC ENERGY.
6. CHEMICAL ENERGY.
2. GRAVITATION ENERGY.
7. ELECTRICAL ENERGY.
3. HEAT.
8. MAGNETIC ENERGY.
4. ENERGY OF ELASTICITY.
9. RADIANT ENERGY.
5. COHESION ENERGY.

This list comprises "forms" of energy and not "different energies," for the reason that they are one and all interconvertible. Energy is protean in its nature for it may be converted, directly or indirectly, into any other form. They are, therefore, different phases of one thing, not different things. For example, the energy of the burning coal is converted consecutively into heat, into mechanical energy, into electrical energy, and, finally, in some far away street, into the radiant energy of the arc lamp. It is possible, even, that these very "forms" may not be distinct from one another, actually, but are simply so many different varieties of motion. OF PARTICLES, NOT OF ETHER

However that may be, energy is not only transformable but transferable. In a word, we may transfer energy from one body to another indefinitely. We may load the energy from a waterfall into a dynamo and from the dynamo into a sewing machine. Matter is but a stepping-stone to energy, here and away, through one form to another and from one body to another, infinitely restless, constant only to one thing,-its total quantity. However much energy may be transformed or transferred, when any quantity of one form disappears, a precisely equal quantity simultaneously appears in some other form or forms. Just as with matter, you cannot create or destroy any quantity of energy however small, and since energy is the great worker of the universe you cannot get something for nothing. No machine can make energy, and it is curious that this fact is 
so little understood of men, that, according to rumour, the Patent Office finds it necessary to employ a special clerk to deal with persons who believe in perpetual motion. ${ }^{8}$ It will readily be seen, then, that since energy may be transformed from one form into another, since it may equally well be transferred from one body to another, and since, moreover, it cannot be created or destroyed, we have precisely the same grounds for believing in its existence as an actual entity as we had for believing in the existence of matter. It is proper for us to hold as reasonable the view that energy is an existing "thing." Concerning the dictum of current science, that it is impossible to create or destroy it, we ought to make the same provision as we did with matter, that while it may not be forever and forever indestructible and uncreatable, and while it may be even now suffering annihilation, we have no control over it. The doctrine of the conservation of energy is receiving some hard knocks nowadays, and whether or not it is weakening will be for the future to determine.

We have, thus, reduced the universe to three terms: matter-ether-energy, and we ought now to consider whether this triune conception may not be capable of a deeper synthesis. We have all, I imagine, a deep-seated conviction of the essential "oneness" of the universe, and to justify it, we must assume, either that these three things are after all but "forms" or phases of an underlying and unknowable reality, or that, separate and distinct as they appear, they are themselves One, in some mysterious way altogether beyond the power of human reason to grasp.

\section{(8) THERE IS PERPETUAL MOTION - THE SUN THE MOON, THE STARS, THEEARTH - HEAT LIFE!}




\section{CHAPTER II.}

Compounds and Elements: Molecules and Atoms.

The number of the forms of matter, that is, of the different weighable; space-filling things, in our world reaches an astonishing total.

Two hundred and fifty thousand would, probably, be a modest estimate of the number of things having properties that sharply demarcate them from every other individual thing. It is a simple fact that if one were to attempt to read all the accounts of the different forms of matter daily discovered, as they appear in the journals of science, one would certainly hopelessly fail, reading twenty-four hours in the day. These substances are known as the "compounds" of matter.

Compounds, however, while they are individual in their properties are not simple in their composition. Common salt may be broken down into a metal that floats on water, called sodium and a greenish-yellow gas called chlorine; prussic acid may be decomposed into two gases called hydrogen and nitrogen and into a solid called carbon. In fact, every one of this vast number of heterogeneous substances may be broken down successively into simpler bodies that weigh less than the substances from which they are abstracted; and these simpler bodies, some seventy in all, constitute the chemist's so-called "elements" of matter. These elements, in their properties, have no relation to the substances which, when united together in various ways, they comprise. Some of them, such as iron, sulphur or phosphorus, may exist free or combined, as the case may 
be, others, such as calcium, cæsium or fluorine, are always combined and you never see them as such. They may be common as dirt or a thousand times rarer than gold. The important point is that, united together by a force called chemical affinity, in various ways and in different quantities, these same seventy things constitute all that is. But these things are found all over. If the world is made of "mud," so are the sun and stars. They consist of the same thing. Iron and hydrogen are found in the sun, together with many an other element; calcium and manganese in the great star Sirius; carbon, the so-called "element of life" in all the stars alike. The chemistry of all parts of space is the same.

A Compound is thus a substance that may be decomposed or separated into other substances.

An Element is a substance that has, so far, resisted all attempts to decompose it.

\section{MOLECULES AND ATOMS.}

A substance is either infinitely divisible, or it is not. There is no mediate possibility. According to the old scholastic conception, you could, at first practically, and then mentally, go on dividing any specific object into parts smaller and smaller forever and forever and forever. In other words, you could never have a thing so small but that it had two halves. Now we need trouble ourselves with this conception no further than to say that it is absolutely incapable of explaining the observed phenomena of the world. The fruitful conception, the one that not only explains the phenomena of matter to an astonishing degree, but even permits the successful prediction of many forms of matter hitherto unknown, assumes that these forms of matter as we know them are not by any means infinitely 
divisible, but that they consist of ultimate particles-that matter is no jelly but that it is made up of grains.

We believe that, taking for example a piece of common salt, if we proceeded to break it up finer and finer, we should eventually, away down in the scale of fineness, arrive at a piece so small, that if it were broken in two we should have no longer two pieces of salt resulting, but, instead, two particles widely different in their properties, namely, a piece of the metal sodium and a piece of the gas chlorine. This piece of salt, so small that if we broke it the pieces would no longer have the properties of salt, is called a molecule of salt. A pound of salt is simply $x$ molecules of salt. We believe that they move about each other, under the influence of heat, as separate bodies and that they are the limit beyond which it is impossible to subdivide matter without destroying its identity.

ATOMS.

We have said that when a molecule of common salt is broken down, there results a particle of sodium and a particle of chlorine. These particles, the constituents of molecules, are the atoms of matter. Instead, therefore, of defining a compound as a substance composed of elements, we may say that a compound is a substance the molecules of which are made up of the atoms of the elements. There are, of course, as many different atoms as there are elements. When atoms of like kind unite together we have the elements of matter, when of unlike kind the compounds of matter. Now, since there are some seventy elements, there are some seventy kinds of atoms, and when we think of the varied number of combinations and permutations, so to speak, that may be brought about by tying together different numbers and different kinds of, 
say, seventy odd marbles, it is no matter for wonder that there are some two hundred and fifty thousand different molecules. A substance is $x$ molecules, and a molecule is a little building of which the atoms are the bricks. We may now re-define our definitions.

A Molecule is the smallest particle of a substance that can exist in a free state, and which has the same composition as any larger mass of the substance.

An Atom is the smallest particle of an element that exists in any molecule.

A Compound is a substance whose molecule contains two or more kinds of atoms.

An Element is a substance whose molecule contains only one kind of atom.

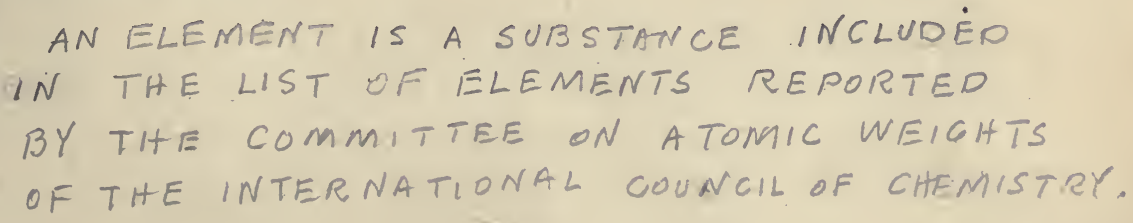





\section{PART II.}

\section{THE PERIODIC LAW.}


v 


\section{PART II.}

\section{THE PERIODIC LAW.}

\section{CHAPTER I. \\ The Mystery of Matter.}

We believe-we must believe, in this day-that everything in God's universe of world and stars is made of atoms, in quantities $x, y$ or $z$ respectively. Men and women, mice and elephants, the red belts of Jupiter and the rings of Saturn are one and all are but ever shifting, ever varying, swarms of atoms. Every mechanical work of earth, air, fire and water, every criminal act, every human deed of love or valor: what is it all, pray, but the relation of one swarm of atoms to another?

Here, for example, is a swarm of atoms, vibrating, scintillant, martial,- they call it a soldier,-and, anon, some thousands of miles away upon the South African veldt, that swarm dissolves,-dissolves, forsooth, because of another little swarm,-they call it lead.

What a phantasmagoric dance it is, this dance of atoms! And what a task for the Master of the Ceremonies. For mark you the mutabilities of things. These same atoms, maybe, or others like them, come together again, vibrating, clustering, interlocking, combining, and there results a woman, a flower, a blackbird or a locust, as the case may be. But to-morrow again the dance is ended and the 
atoms are far away; some of them are in the fever germs that broke up the dance, others are "the green hair of the grave," and others are blown about the antipodes on the winds of ocean. The mutabilities of things, and likewise the tears of things: for one thing after another,

"Like snow upon the Desert's dusty Face Lighting a little hour or two-is gone,"

and the eternal, ever-changing dance goes on.

Now, whether we call the atoms God's little servants or the Devil's agents, one thing is sure-that every action of every thing, living or dead, within this bourne of time and space, is the action of one swarm of atoms on another, for without them there is but empty void.

Consequently, whether we consider the atoms as the starting-place in our search for the One Thing, or whether we think of them only as the foundation of all physical action and being, they are the most important things in the world to us, for they are us, physically at least, and any knowledge concerning them or any relation between them has, therefore, to us poor people they condition, an interest that is tragic. 


\section{CHAPTER II.}

The Atoms of the Elements.

The names of the atoms are these:

International Atomic Weights (1904).

\begin{tabular}{|c|c|c|c|c|c|c|c|}
\hline & & & $\mathrm{O}=16$. & & & $\mathrm{Fe}$ & $\begin{array}{l}\mathrm{O}=16 \\
55.9\end{array}$ \\
\hline & . & $\begin{array}{ll}\text { AI } \\
. . & \text { Sb }\end{array}$ & $\begin{array}{r}2.1 \\
120.2\end{array}$ & $\begin{array}{l}\text { Iron } \\
\text { Krypton }\end{array}$ & . & $\mathrm{Kr}$ & $\begin{array}{l}55.9 \\
81.8\end{array}$ \\
\hline & .. & .. A & 39.9 & Lanthanum & & $\mathrm{La}$ & 138.9 \\
\hline IIC & .. & .. As & 75.0 & & .. & $\mathrm{Pb}$ & 206.9 \\
\hline & .. & $\therefore$ & 137.4 & IIUM & & i i & 7.03 \\
\hline & .. & .. $\mathrm{Bi}$ & 208.5 & am & & $\mathrm{Mg}$ & 24.36 \\
\hline & .. & .. & 11 & JESE & & .. & \\
\hline & .. & .. $\mathrm{Br}$ & 79.96 & $\mathrm{RY}$ & & $\mathrm{Hg}$ & 200.0 \\
\hline & .. & .. & 112 . & & IUM . & O & \\
\hline & 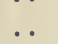 & .. & 132. & ium & .. & $\mathrm{id}$ & 143.6 \\
\hline & .. & .. & & & .. & T. & \\
\hline & .. & .. & 12 & & & $\mathrm{Ni}$ & 58.7 \\
\hline & .. & .. & 140.25 & GEN . & .. & & 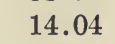 \\
\hline & .. & .. & & & .. & Os & 191 \\
\hline & .. & .. & & & & & 160 \\
\hline & .. & .. & 5 & & & $\mathrm{Pd}$ & 106.5 \\
\hline & .. & & & ORU & US & 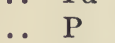 & \\
\hline & .. & .. & & & .. & Pt & 194.8 \\
\hline & $\cdots$ & .. & 166 & & & & 39.15 \\
\hline & .. & .. F & 19 & ium & & $\mathrm{Pr}$ & 140.5 \\
\hline & .. & .. & 156 & & & & 225 \\
\hline & 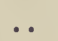 & .. & 70 & & & h & 103.0 \\
\hline & .. & . & & & $\ddot{. .}$ & 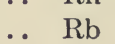 & \\
\hline & & $\because$ & & & & u & 101.7 \\
\hline & & .. & 197. & & . & & 150 \\
\hline & & & 4 & & & $\mathrm{Sc}$ & 44. \\
\hline GEN & & & 1.0 & & & & \\
\hline & & .. & & & .. & $\cdots$ & 28 \\
\hline & & & 126 & & & & 107 \\
\hline & & & & & & & \\
\hline & & & & & & (17) & \\
\hline
\end{tabular}




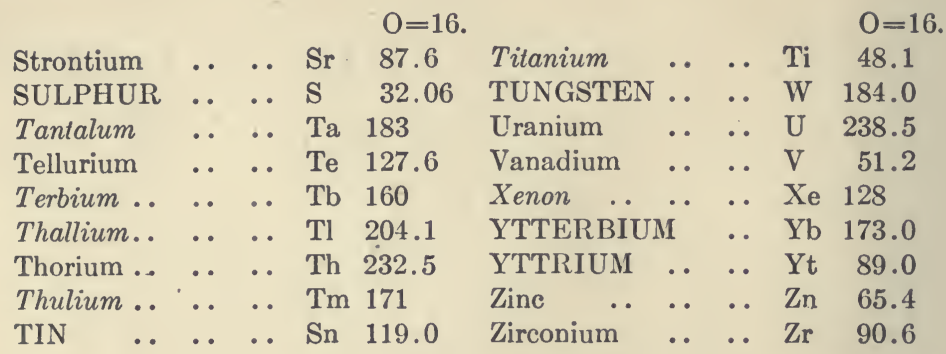

These are the bricks of the universe, out of the permutations and combinations of which all that exists is. Among them you will find many long-known friends, such as copper, iron, sulphur, silver, and, let us hope, gold. But though many of them bulk large in the world's mass, others lie furtively in the hidden places of the earth, and are obtained and isolated only with infinite trouble and cost. Thus, indium is four times, thorium nine times, caesium fifteen times, and very impure radium thousands of times rarer than gold; others are so rare that they cannot be bought at all, and only by one's own painstaking labor can they be brought to the light of day; such are krypton, praesodymium, samarium. Still others are both common and rare. For example, the silver-colored calcium is literally common as dirt; it lies on every street. Seventyone per cent of every barrel of lime is calcium, and yet calcium is worth fourteen dollars a thimble-full. The high cost of the element is due to the difficulty of extraction *

Now, what are these sphinxes? Are these atoms simple, independently created, undecomposable little existences; or will they tell a story of evolution from simpler existences in common with the rest of creation? Whatever story there is, they alone can tell it.

* Since this was written the price of calcium has sunk to about a dollar a pound, owing to a new process of extraction. 
Our present question is: Are they related to one another? Now, if there be any relation among these atoms, it should show in their weights. The first thing, therefore, we shall notice is the number attached to each in the table above. This number stands for the atomic weight; in other words, for the number. of times heavier that particular atom is than the hydrogen atom which is the lightest and the unit. These numbers afford an example of the highest accuracy of hand and brain that science has to show. It is true that if you look at the number attached to hydrogen you will find it placed at 1.008 instead of 1 , as you would suppose, but that is for a certain reason that will soon be made clear.

\section{PROUT'S HYPOTHESIS.}

In the early days when men first began to determine the relative weights of the atoms, it was noticed that the atomic weights of quite a number of the elements, taking hydrogen as unity, were either whole numbers or very nearly whole numbers, and in 1815 Prout suggested that this numerical regularity could be explained on the assumption that the atoms of the different elements were simply condensations of the hydrogen atom; for obviously if, for example, the weight of the oxygen atom were 16 and that of the carbon atom were exactly 12 times as heavy as the hydrogen atom, then these little bodies could be explained by assuming that they were built up of 16 and 12 hydrogen atoms respectively, - and there would be an end of the mystery. This idea was at first very kindly received, but as men became more and more accurate in their work, it was soon discovered that Prout's method of calmly dropping the decimals after the whole numbers as due to experimental errors would not do, nor would anything like it do.

It became evident that though many of the atomic 
weights were curiously approximate to whole numbers, they were with positive certainty not whole numbers. The atomic weight of oxygen, for example, is certainly not 16 , but seems to be established as 15.879 .

The decided approximation, however, referred to above, was certainly curious, and it soon became most conspicuously so; for it turned out that by taking the atomic weight of oxygen as 16 and calculating the weights of the other atoms to that basis, a most remarkably large number of them became actually whole numbers, and another large number very approximately whole numbers. The table of the atoms arranged above is arranged on the basis of oxygen $=16$, which for certain practical considerations is the favorite arrangement among chemists; and this explains why the atomic weight of hydrogen $=1.008$ instead of 1 , as we should expect. WHY?

If you care to look at this table, you will find that no less than 21 (marked in capital letters) out of the number are whole numbers to the second decimal place; that 17 (in italics) are remarkably approximately so; and that the remainder drift along anywhere. Now, that 21 out of the 78 are actually whole numbers, cannot be accounted for as chance on the basis of the law of probability, nor can the wonderful approximation of the other 28 .

Whatever the explanation of this curious approximation to symmetry, there is reason enough at any rate to suspect strongly that there is some hidden relation here. There is enough to whet our curiosity and to lead us on.

\section{TRIADS OF DOBEREINER.}

Another curious and interesting discovery soon came to light. It became apparent that out of the list of elements little groups could be chosen here and there with strongly 
correlated properties. It was just as though, in a company of soldiers raised in the same village, little groups of brothers could be picked out, one here and one there, owning to a strong family likeness. These little groups of correlated atoms are known as the Triads of Dobereiner. Three such groups are given below:

ATOMIC WEIGHT.

Calcium, $\quad 40 \cdot 1$ Chlorine, $\quad 35 \cdot 4$ Sulphur, $32 \cdot 1$ Strontium, $87 \cdot 7$ Bromine, 80.0 Selenium, $79 \cdot 2$ Barium, 134.4 Iodine, 126.8 Tellurium, 127.5

The elements calcium, strontium and barium show chemical similarities to a remarkable degree. They look much alike, act much alike, and in their very variations vary by steps. The same may be said of chlorine, bromine and iodine, or of sulphur, seleniun and tellurium.

Now the curious discovery alluded to above lies in the fact that if you take the mean of the atomic weights of the first and third elements in any of these groups, you will obtain, approximately, but not exactly, the atomic weight of the niddle one. Thus:

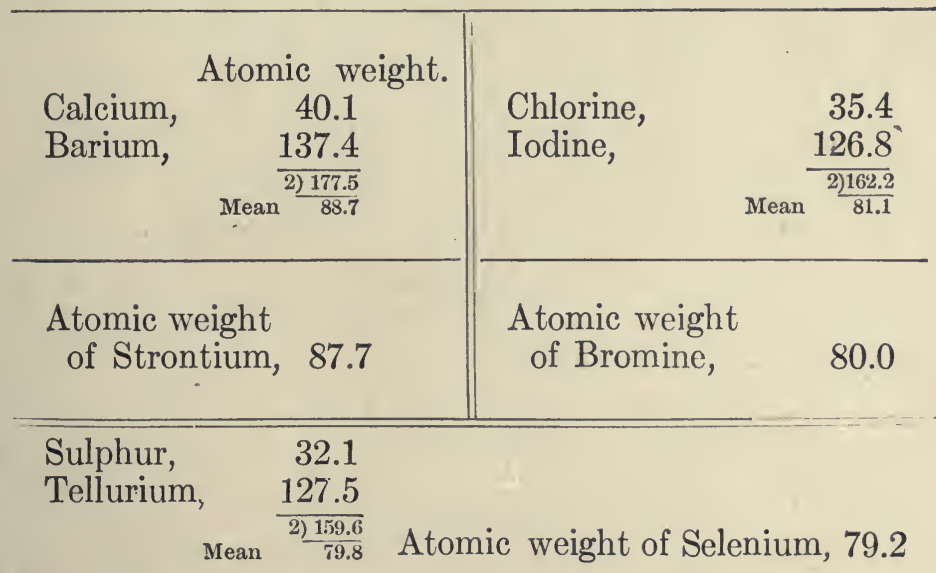


You will notice that the mean of the first and third atomic weights is not exactly the atomic weight of the middle one, but the approximation is so close as to excite remark and to inspire the conviction that there is some hidden reason for it. At any rate our suspicion that the atoms are in some way or other related to one another is confirmed, and it will therefore surprise us less to find ourselves confronted by a new discovery in

THE PERIODIC I.AW.

The Periodic System of the Elements, as we now have it, was discovered independently and almost simultaneously by the Russian, Mendeléeff, and the German, Lothar Meyer; though the germ of the discovery undoubtedly lay in the Octaves of Newlands.

In $1863 \mathrm{Mr}$. John Newlands pointed out in a brief letter to the Chemical News that if the elements be arranged in the order of their atomic weights, beginning with hydrogen $=1$, and ending with uranium $=240$, in a tabular form, they naturally fall into such groups that elements similar to one another in chemical behaviour occur in the same columns; and that, moreover, the number of elements between any one and the next similar one is seven. In other words, members of the same groups stand to one another in the same relation as the extremitics of cne or more octaves in music! This leads us. to think that not only may there be a relation between these little fundamentals of the universe but a veritable harmony.

Briefly and technically, the law states that "the properties of an element are a periodic function of its atomic weight."

This is a very concise statement incleed of an extraordinary fact. The statement means no more nor less than this: 
That if you know the weight of the atom of the element you may know, if you like, its properties, for they are fixed.

Just as the pendulum returns again in its swing, just as the moon returns in its orbit, just as the advancing year ever brings the rose of spring, so do the properties of the elements periodically recur as the weights of the atoms rise. To demonstrate this fact, take some one specific property, for example, the atomic volume, which is the atomic weight divided by the specific gravity of the solid element, and arrange a table on a piece of engineering paper in which the atomic weights read from left to right (the abscissas), while the atomic volumes read from bottom to top (the ordinates). Now construct a curve by pricking out the position of the different elements in accordance with both their atomic volumes and atomic weights, and you will find yourself in possession of a table such as Fig. 2. We see at once from this curve that the atomic volume is a periodic function of the atomic weight. As the atomic weight increases, the atomic volume alternately increases and decreases. The periodicity proclaims itself in the regularly recurring hills and valleys which constitute the curve. Elements which sccupy similar positions on the five hills and valleys have markedly similar properties. Thus, you will notice at the summit of each of the five hills, the symbols of the elements lithium, sodium, potassium, rubidium and caesium, all of these elements possessing amazingly similar properties. Or, again, find the little dot marked S (signifying sulphur) on the slope of the third hill, and you will then notice a little dot marked Se (selenium) and another Te (tellurium) in a correspondingly similar position on the other two hills respectively. These elements have strikingly similar properties. Take now another property altogether, let us say the 


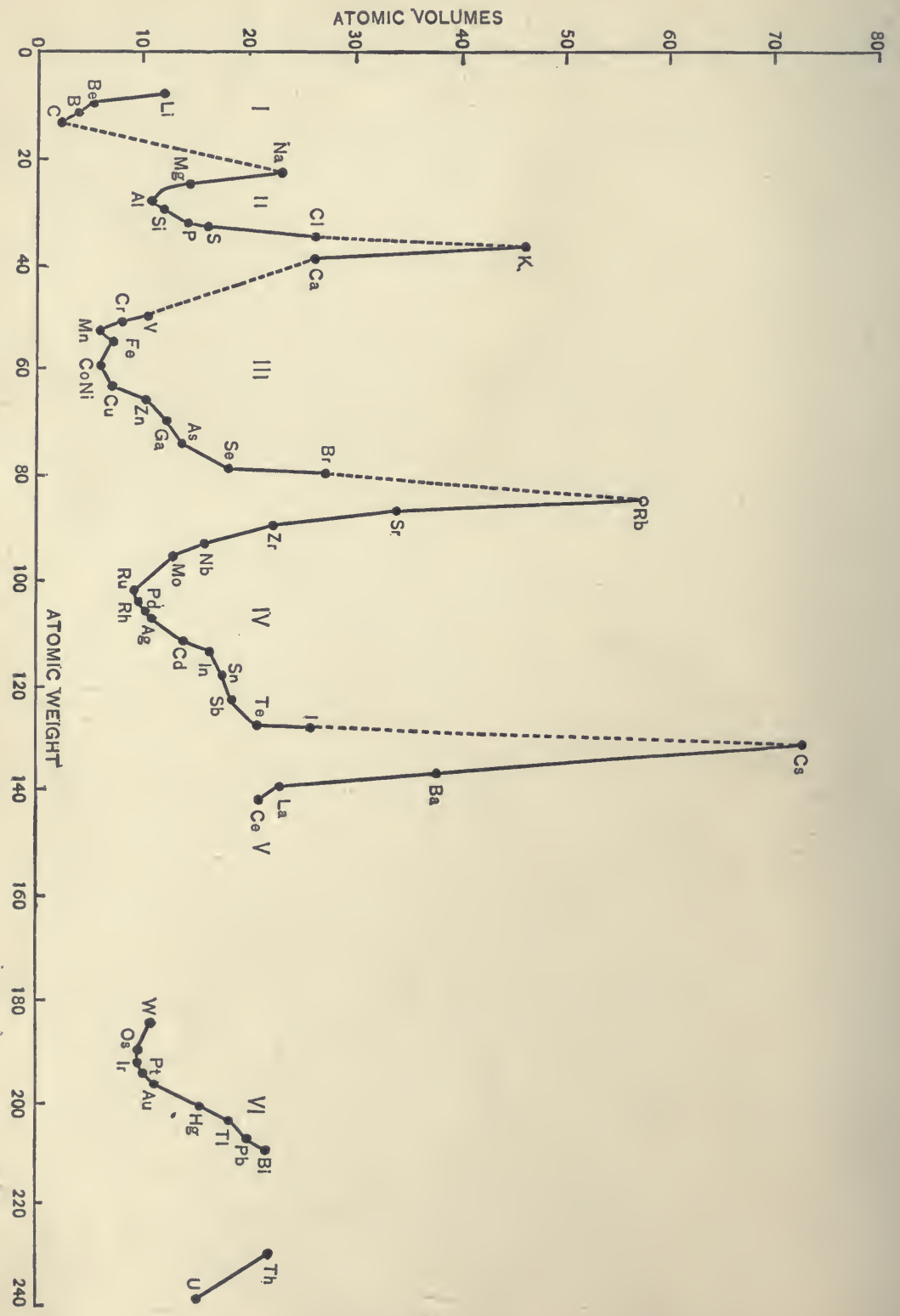


ABSOLUTE TEMPERATUAE

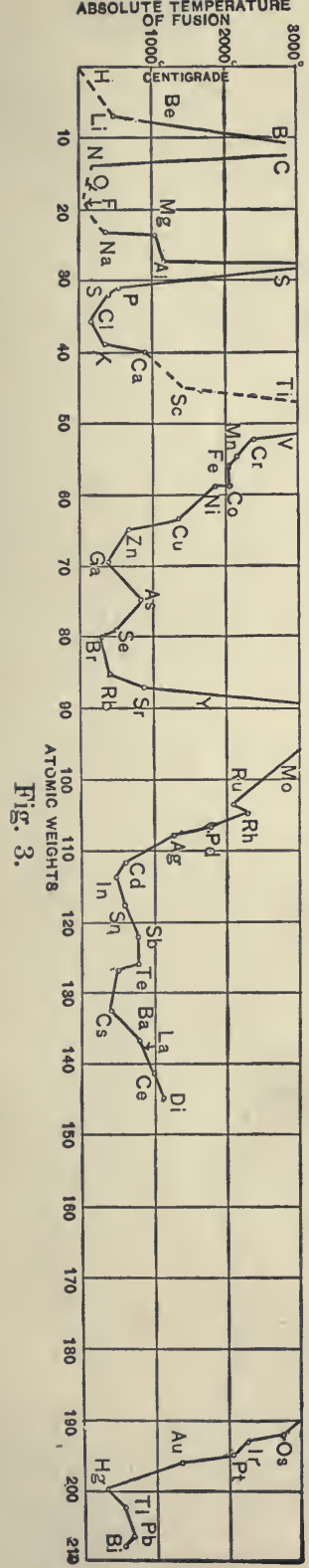

melting-point of the elements, and make a similar diagram (Fig. 3). You get a curve remarkably like the first one, with this exception, that the elements which were at the top of the first curve are now at the bottom. The meltingpoint curve is as strictly periodic as the volume curve and of the same general shape. Notice the regular irregularity of the two curves, and notice also, if you will, that there is not only a periodicity but a double periodicity, as shown in the little hump on the slope of each hill of the curve. Similar curves may be constructed for many other properties. Can we imagine, then, that these atoms, these little invisibilities, in which we all live and move and have our being, are separately created, arbitrarily made, unrelated individuals? Hardly so, for they are obviously created in accordance with some scheme. Would that we might understand this scheme all and in all!

It would be a veritable glimpse behind the veil of existence. But if we cannot read from Alpha to Omega, we may spell out what we can, leaving future letters for future men; perforce content that if in this cryptogram of the universe we know indubitably that there is a cryptogram to be read, we have at least come to the beginnings of knowledge. 


\section{CHAPTER III.}

\section{The Table of the Law.}

This periodicity of the atoms of the elements and the fact that they exist in accordance with a definite scheme is very beautifully shown in the table devised by Mendeléeff, from which additional hints may be obtained. For purposes of study we shall first consider the first part of the Table of the Law as originally formed by Mendeléeff (Fig. 4).

\begin{tabular}{|c|c|c|c|c|c|c|c|c|}
\hline & I & II & III & IV & $\mathrm{V}$ & VI & VII & VIII \\
\hline 1 & H 1 & & & $=$ & & & & \\
\hline 2 & Li 7 & Be 9 & B 11 & C 12 & $\mathrm{~N} 14$ & O 16 & $\mathrm{Fl} 19$ & \\
\hline 3 & $\mathrm{Na} 23$ & $\operatorname{Mg} 24$ & $\mathrm{Al} 27$ & Si 28 & P 31 & S 32 & Cl 35.5 & \\
\hline 4 & K 39 & $\mathrm{Ca} 40$ & 5caft & $\mathrm{Ti} 48$ & V 51 & Cr 52 & Mn 55 & $\begin{array}{c}\text { Fe } 56 \text {, Co } 59 \text {, } \\
\quad \text { Ni } 59\end{array}$ \\
\hline
\end{tabular}

Fig. 4.

Leaving out hydrogen for the present as having no part in the scheme, and beginning with lithium, you will observe that if we arrange the succeeding elements in the order of their atomic weights up to fluorine, that the next or eighth element, sodium (Na), has properties similar to lithium. If, then, we place sodium in the same vertical column with lithium and then arrange the next elements in the order of their atomic weights, we observe that magnesium falls in 
the same column with beryllium, aluminum with boron, silicon with carbon, phosphorus with nitrogen, sulphur with oxygen, and chlorine with fluorine,-all of them very much alike in their properties, in pairs. This is, of course, sufficiently remarkable, but let us begin the third line with the next element-potassium (K). It falls straight into place in the same column with sodium and lithium, which it greatly resembles; calcium with beryllium and magnesium, titanium with carbon and silicon, vanadium with nitrogen and phosphorus, chromium with oxygen and sulphur, and manganese with chlorine and fluorine. Striking analogies again appear between the three members of each group. The members of each group have remarkably similar properties. We now see in this scheme, so far, a verification of the Triads of Dobereiner, for the three elements in each group constitute a triad of the kind discovered by him. We see, also, that it is a verification of the Octaves of Newlands. But Newlands, as we shall see, had but a faintest glimpse of the sweep of this bold generalization, which laid stress not only on the fact that every eighth element resembled the first, but also on the periodicity of the phenomenon. In order to grasp the meaning of this, let us notice that to make this arrangement true and valid, he found it necessary to leave a blank space in Group 3, Series 4, for some element hitherto undiscovered,-and not content with this, he proceeded to predict the properties it should possess when discovered!

Here is the full Periodic System of the elements as it exists to-day: 
THE NEW KNOWLEDGE.

\begin{tabular}{|c|c|c|c|c|c|c|c|c|c|c|c|c|c|}
\hline 1 & & & & 1 & 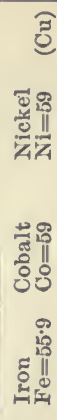 & & 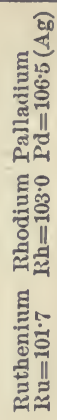 & & I & & 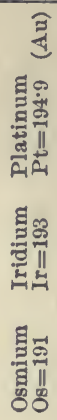 & & \\
\hline 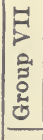 & . & & 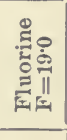 & 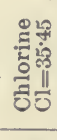 & 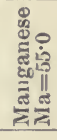 & 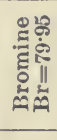 & 1 & 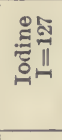 & & 1 & 1 & 1 & ' \\
\hline $\mid$\begin{tabular}{l}
5 \\
5 \\
0 \\
0 \\
0 \\
\multirow{2}{*}{}
\end{tabular} & & . & 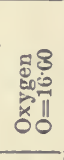 & 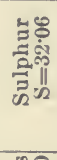 & 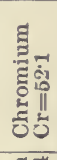 & 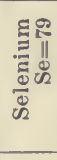 & 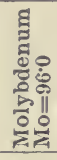 & 胥 & 1 & 1 & 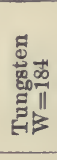 & 1 & 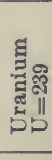 \\
\hline $\begin{array}{l}7 \\
0 \\
0 \\
0 \\
0 \\
0 \\
0\end{array}$ & & & 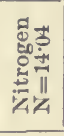 & 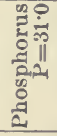 & 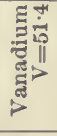 & 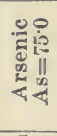 & 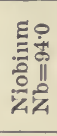 & 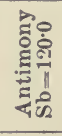 & 1 & 1 & 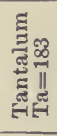 & 물요 & I \\
\hline 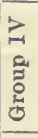 & & & 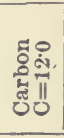 & 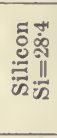 & 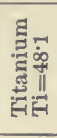 & 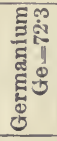 & 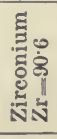 & 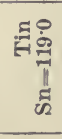 & $\begin{array}{l}\text { 펼워 } \\
\text { 잉 } \\
00\end{array}$ & I & 1 & 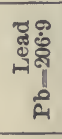 & 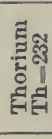 \\
\hline 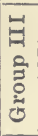 & & & 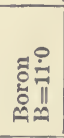 & 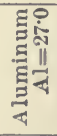 & 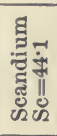 & 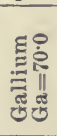 & 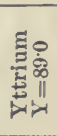 & 胥是 & 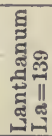 & & 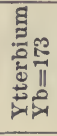 & 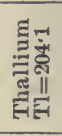 & i \\
\hline 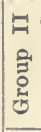 & & & 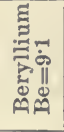 & 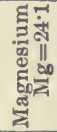 & 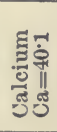 & 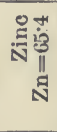 & 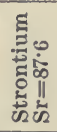 & 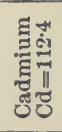 & 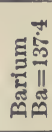 & 1 & 1 & 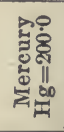 & 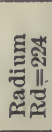 \\
\hline W. & & 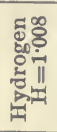 & ह્בٍ & 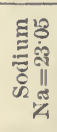 & 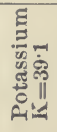 & 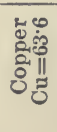 & 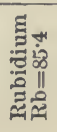 & 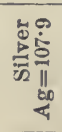 & 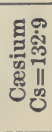 & 1 & 1 & 꿍융 & I \\
\hline 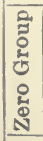 & 8 & $\rightarrow$ & 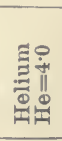 & 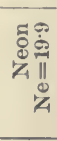 & $\begin{array}{l}\text { 댕 } \\
400 \\
4 \\
4\end{array}$ & & 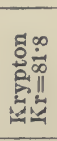 & & 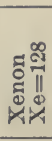 & & 1 & & I \\
\hline 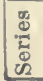 & 0 & - & N & $\infty$ & H & 10 & 0 & $\omega$ & $\infty$ & $\sigma$ & 유 & $\Rightarrow$ & న \\
\hline
\end{tabular}


This periodic law of the atoms is God's alphabet of the universe. By means of it, and by means of it only, can we ever hope to spell out the history and the future of creation. It lies here before us lacking only the master word - the open sesame-to creation; and, who knows, to the Creator, too? If the system were regular, completely symmetrical, we should either understand the mysterythat is, there would be an end of the mystery altogetheror we should forever be beyond the hope of solving it. But the delight of it is, and the hope of it lies in its regular irregularity. Leaving for the moment the whims and caprices of the law that constitute its irregularities, let us turn, first, to

THE REGULARITIES OF THE LAW.

A glance at the table (Fig. 5) will inform the reader that each of the elements of matter has a little compartment of its own in the table. This compartment belongs to it, and the element will refuse to go anywhere else.

To demonstrate this, we may fix our attention upon any one element and consider it in its relation to the other elements which lie either in a horizontal or in a vertical line with it.

The elements which lie horizontally with reference to any given element are called a series; those which lie vertically, a group.

The actual position of any one element in the table is fixed solely by the weight of its atom; and once so fixed, its other properties follow as a matter of necessity from its series and group relations.

The elements in any one series vary by definite steps, but they are sharply differentiated from one another; and in spite of their progressive variations from one side of the table to the other, they are of different types. The elements. of a group vary progressively from top to bottom, but 
they closely resemble one another and are distinctively of the same type; indeed, we may go further, and say that their relationship is so pronounced that we are able to call these groups veritable natural families.

As an example of such group relationship let us consider the elements of Group II. These elements are in the order of their atomic weight: Beryllium, magnesium, calcium, zinc, strontium, cadmium, barium, mercury and radium. Now, in studying these elements, the curious fact crops up that while all the elements of the group resemble each other and are of the same blood, so to speak, they may, nevertheless, be divided into two sub-groups, the members of which are peculiarly like each other. These sub-groups are:

Sub-group $A$.
Calcium
Strontium
Barium
Radium

Sub-group $B$.

Beryllium

Magnesium

Zinc

Cadmium

Mercury

The relations between the two sub-groups may fairly be expressed by saying that calcium, barium, strontium and radium are sister elements and bear only a cousinly relationship to beryllium, magnesium, cadmium and mercury.

The curious nature of this double relationship in a group is accentuated by the fact that every other group is divided in the same way into two sub-groups showing similar relationships. Attention has been drawn already to a double periodicity in the curves of the atomic volumes and meltingpoints, and this double relationship in the group is the logical consequence of it. How clearly related in their properties these sister elements are, may be seen in the subjoined table (Fig. 6). 


\begin{tabular}{|c|c|c|c|}
\hline ELement & CaLCIUM & STRONTIUM & BARIUUS \\
\hline Atomic Mass & 40 & 88 & $\stackrel{137}{\rightarrow}$ \\
\hline Specific Gravity & 1.6 & 2.5 & $\stackrel{3.6}{\longrightarrow}$ \\
\hline $\begin{array}{l}\text { Carbonate Dissociates; } \\
\text { Temperature }\end{array}$ & $600^{\circ} \mathrm{C}$ & $1100^{\circ} \mathrm{C}$. & $\stackrel{1400^{\circ} \mathrm{C} .}{\longrightarrow}$ \\
\hline $\begin{array}{l}\text { Grams of Hydroxide } \\
\text { Soluble in a Liter of } \\
\text { Water at } 15^{\circ} \mathrm{C}\end{array}$ & 1.32 & 18 & $\underset{\rightarrow}{50}$ \\
\hline $\begin{array}{l}\text { Heat of Formation of } \\
\text { Chloride; Units }\end{array}$ & 170 & 185 & $\stackrel{195}{\longrightarrow}$ \\
\hline
\end{tabular}

Fig. 6.

A glance at this table shows their striking similarity of behaviour, even in the most varied properties. This similarity is so great that in general terms, $x$ may be written, standing for either calcium, strontium or barium, in any chemical reaction. The chief purpose of the diagram, however, is to show that even as they vary from one another, they vary progressively and in definite steps. Notice in the diagram that as the atomic weight rises, so does the specific gravity, the temperature at which their carbonates dissociate, the solubility of their hydroxides, and the heat of formation of their chlorides.

Suppose, now, we take another group, say Group VII, known as the family of the Halogens. This group consists, as usual, of two sub-groups:

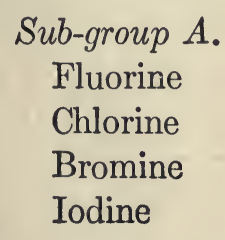

Fluorine

Chlorine

Bromine

Iodine
Sub-group B.

Manganese

Samarium 
Concerning Sub-group A, we find in the table (Fig. 7) the same progressive variation in steps.

\begin{tabular}{|c|c|c|c|c|}
\hline Properties & FLUORINE & CHLORINE & BRoMINE & IODINE \\
\hline Atomic Mass & 19 & 35.5 & 80 & 127 \\
\hline Boiling Temperature & $-187^{\circ} \mathrm{C}$ & $-33^{\circ}$ & $+59^{\circ}$ & $+184^{\circ}$ \\
\hline Specific Gravity & 1.15 (liquid) & 1.5 (liquid) & 3.2 (liquid) & 5 (solid) \\
\hline $\begin{array}{l}\text { Union with Hydro- } \\
\text { gen takes place }\end{array}$ & $\begin{array}{l}\text { In the dark } \\
\text { at ordinary } \\
\text { tempera- } \\
\text { tures }\end{array}$ & In sunlight & At red heat & $\begin{array}{c}\text { At red heat, } \\
\text { but incom- } \\
\text { pletely }\end{array}$ \\
\hline $\begin{array}{l}\text { Heat of formation } \\
\text { of Hydrogen Com- } \\
\text { pound }\end{array}$ & $\begin{array}{c}37.6 \\
\text { heat units }\end{array}$ & 22 & 8 & -6.1 \\
\hline $\begin{array}{l}\text { Stability of Hydro- } \\
\text { gen Compound }\end{array}$ & Most stable & $\begin{array}{c}\text { Decomposed } \\
\text { at } 1500^{\circ} \mathrm{C} . \\
\end{array}$ & $\begin{array}{c}\text { Decomposed } \\
\text { at } 800^{\circ} \mathrm{C} .\end{array}$ & $\begin{array}{c}\text { Decomposed } \\
\text { at } 180^{\circ} \mathrm{C} .\end{array}$ \\
\hline
\end{tabular}

Fig. 7.

Thus, if fluorine will do a certain thing, chlorine will do it more, bromine still more, and iodine most. Or, it may act the other way: If fluorine does a certain thing, chlorine will do it less, bromine still less, and iodine least of all. The important thing is that as the elements vary, they vary progressively in steps as the atomic weight rises. The direction of the arrows in the table shows the direction of the progressive change for each property. Now what holds good for Groups II and VII holds equally good for every other group of the system. As a matter of fact, the elements of matter fall naturally into a series of groups. Each group falls naturally into two sub-groups, which have in certain properties an unmistakable relation to each other, while the constituent members of each sub-group resemble each other 
to an extent so remarkable that in general terms it may be said that what one will do the others will do, and that in their very differences they vary progressively in definite steps. Furthermore, all these relations are true because of the law illustrated in the curves of the atomic volumes and melting-points, that the properties of an element are a periodic function of its atomic weight.

3 


\section{CHAPTER IV.}

\section{The Testing of the Law.}

When once the weight of the atom of an element is known the properties of the element are fixed. There is a fatality about it.

How true this is may be aptly illustrated. Turn to the table of the law (Fig. 5) and note in Group III the third and fourth elements, Sc (Scandium) and Ga (Gallium), and in the fourth group the fourth element Ge (Germanium). When Mendeléeff enunciated his law and made his table originally, he found it necessary, in order to make the table true, to leave these three spaccs vacant for undiscovered elements, and, not content with this, he proceeded in 1871, on the basis of the law, to predict the properties which these elements should possess whon discovered.

Think of the presumption of it, that out of the seventyeight odd substances of which God had made his universe, three were missing! And that these three possessed properties which he proceeded to specify with extreme minuteness. These three hypothetical elements he named ekaboron, eka-aluminum, and eka-silicon, "little imagining," as he says himself, "that he would live to see the verification of his predictions."

But so it was; for out of the night of the unknown, one after another came to mcet him. One from the hills of Scandinavia, another from the Pyrenees of France and a third from the mines of Germany. The three elements were named scandium, gallium and germanium, and they are 
not only very like but they actually are the predicted elements eka-boron, eka-aluminum and eka-silicon respectively. How unquestionable this fact is may be readily seen from, for example, a comparison of Mendeléeff's ekaboron with the scandium afterwards discovered by Nilson.

Eka-boron.

Atomic weight 44.

Oxide $\mathrm{Eb}_{2} \mathrm{O}_{3}$.

Sulphate less soluble than

aluminum sulphate.
Scandium.

Atomic weight 44. Oxide $\mathrm{Sc}_{2} \mathrm{O}_{3}$.

Sulphate less soluble than aluminum sulphate.

Carbonate insoluble in water. 'Carbonate insoluble in water. Salts colorless and form ge- Salts colorless and form gelacinous precipitates with latinous precipitates with potash and ammonia. potash and ammonia.

The predicted properties are identical with the properties found. The hypothetical element discovers itself in scandium.

In like manner the other two elements discovered themselves in gallium and germanium. We see in this successful three-fold prediction the scope and power of the periodic law as an instrument of research. We see convincingly that the law must be the expression of a fact. Suppose that an astrologer informed you that your horoscope led him to believe that you would meet, sometime in your life, three men; and that with the utmost particularity he told you their weights, the color of their hair, the size of their noses, and, in a word, all the habits of mind and body sufficient to differentiate them positively from all other men; and suppose, moreover, that you met these men possessed of qualities identical with the description predicted. You would believe in astrology.

Astrology cannot do these things, but chemistry can 
because of the periodic law. Therefore we believe in the periodic law. We believe that the weight of the atom of the element fixes its properties and its position in a great scheme of relationship. You will find many blank spaces still in the table of the law ready for elements yet in the womb of the future. So thoroughly does the chemist believe in this law that he has not hesitated in several instances to put certain "refractory" elements "in their places." Thus, indium, beryllium and uranium would not fit properly into their proper compartments in the table on the basis of the old determinations of the atomic weights. Renewed investigation, however, showed the errors of these old determinations, and the new atomic weights, accurately adjusted, allowed them to fall straight into the positions to which they naturally belong in the table, and which they hold to-day.

One concluding and conclusive test of the validity of the law was found in the discovery of the rare gases of the atmosphere by Lord Rayleigh and Sir William Ramsay. The history of their discovery is interesting. In 1893 Lord Rayleigh undertook to determine the density of nitrogen with all the accuracy of present-day science. To his astonishment, he discovered that nitrogen from the air and nitrogen from chemical compounds did not weigh the same. The difference was small but exasperatingly constant. Out of this curious anomaly arose the discovery of a new and hitherto unsuspected element of the air which had been weighed as nitrogen and considered as nitrogen by all preceding chemists. This new element was named argon and it constitutes nearly one per cent. of the air we breathe. Subsequently this "argon" was discovered to be itself impure, and from it were isolated four other elements, helium, neon, krypton and xenon. These five new elements are all 
alike in this: that they differ from all other elements in having no combining power whatever. It has been found impossible to make them unite chemically with any other substance in nature. They thus constituted a new and separate family of elements for which there seemed to be no place in the periodic law. Now the law undertakes to find a place for any and every element in nature. The validity of the law was threatened. The case was serious. Let us see how neatly and completely the law was vindicated. One of the most curious facts in connection with the periodic law is the regular increase in the valence of the Groups. By valence is meant the power of an atom to unite chemically with other atoms, in other words " the grabbing-power" of the atom. If we consider these valences, for the present, as so many little arms to hold on with, we find that the elements of the different groups, from Group I to Group VIII, have 1, 2, 3, 4, 5, 6, 7 and 8 arms respectively. This variation in the "grabbing-power" is well exemplified in the way in which the atoms in (let us say) Series 3 unite with fluorine to form fluorides:

\begin{tabular}{|c|c|c|c|c|c|c|c|c|c|c|c|c|c|}
\hline 1 & “ & magnesium & " & 2 & “ & “ & "6 & “" & 1 & “ & “ & “6 & “ \\
\hline 1 & “ & aluminum & 6 & 3 & 6 & " & “ & “ & 1 & " & "6 & "6 & “ \\
\hline 1 & “ & silicon & “ & 4 & " & “ & " & " & 1 & " & “ & " & “ \\
\hline & “ & phosphorus & " & $\mathbf{5}$ & “ & " & “ & " & 1 & " & “ & " & “ \\
\hline & “ & sulphur & “ & 6 & “ & "6 & " & “ & 1 & "6 & " & "6 & $"$ \\
\hline
\end{tabular}

-while the element chlorine does not unite with fluorine at all, owing apparently to the fact that they both belong to the same family, are alike in their nature, and are, so to speak, sister elements.

Now these five new elements, helium, neon, argon, krypton and xenon, have no combining power whatever, no arms at all, so to speak; hence they should constitute a separate group coming before Group I, the members of which 
have one. But will they fit into such a position? Indeed they will; their atomic weights thrust them naturally and inevitably into that very place, thus:

\begin{tabular}{|l|l|l|}
\hline Series & Zero Group & Group I \\
\hline 2 & Helium 4.0 & Lithium 7.03 \\
\hline 3 & Neon 19.9 & Sodium 23.05 \\
\hline 4 & Argon 38 & Potassium 39.1 \\
\hline 5 & & Copper 63.6 \\
\hline 6 & Krypton 81.8 & Rubidium 85.4 \\
\hline 7 & & Silver 107.9 \\
\hline 8 & Xenon 128 & Cæsium 132.9 \\
\hline 9 & & \\
\hline 10 & & \\
\hline
\end{tabular}

The law, therefore, which seemed at first assailed, was amply capable of taking care of itself, and the new and interesting family in the commonwealth of the elements finds a fitting home in the Zero Group of Mcndeléeff's latest table (Fig. 5).

As an extra-conclusive and final test of the law, look at the space in Group 2, Series 12, in this same figure (Fig. 5). Wonderful as that element is, and much as we shall have to speak of it in succeeding pages, its atomic weight leads it inevitably into its proper place in this system of the elements, directly under barium, of which in its chemical properties it is a sister. 


\section{CHAPTER V.}

\section{The Significance of the Law.}

In the foregoing pages we have been confronted with a series of extraordinary facts concerning the atoms of the elements of matter and it now behooves us to seek earnestly for the cause of it all.

The remarkable approximation to regularity in the atomic weights, as observed in Prout's Law, the Triads of Dobəreinər, the Octaves of Newlands, and, finally, the summation of the mystery in the Periodic Law makes a most inpressive demonstration of a scheme of arrangement among the atoms. No such scheme could be the result of mere chance on the basis of the theory of probability. This scheme of arrangement must mean something, and this something must be fundamentally important.

The main characteristic of the whole scheme is relationship. The elements are unquestionably not fragmentary, unrelated facts in nature. They are related to one another in a very real sense; and it is an expression of this relationship that we must seek in the meaning of the law. We may begin either by assuming that the atoms are simple, undecomposable, separately created, ultimate things, or that they are not. There is no tertium quid. If the atoms are in fact ultimates, then you will seek in vain for any explanation of the foregoing mystery. There positively is no conceivable explanation.

If, on the contrary, you assume that they are made up of 
parts, then the fact of relationship may be explained in a simple, rational manner.

For if the atoms are not simple, but on the contrary are made up of component parts, then these parts would, of course, unite together in certain numbers and in certain ways to constitute the composite bodies we call atoms; just as the atoms unite in various numbers and in various ways to constitute the molecules of compounds, and it is reasonable to assume that they actually would do so. Thus, among the compounds of carbon, we are acquainted with series of compounds, which in variations of molecular weight and gradation of properties bear a striking resemblance to the elements when arranged after the fashion of the Groups in the periodic law. For example, we have the series:

\section{Molecular weight.}

$\begin{array}{lll}\mathrm{CH}_{4} & \text { Methane } & 16 \\ \mathrm{C}_{2} \mathrm{H}_{6} & \text { Ethane } & 30 \\ \mathrm{C}_{3} \mathrm{H}_{8} & \text { Propane } & 44 \\ \mathrm{C}_{4} \mathrm{H}_{10} & \text { Butane } & 58 \\ \mathrm{C}_{5} \mathrm{H}_{12} & \text { Pentane } & 72\end{array}$

and a list of others up to a compound of the formula $\mathrm{C}_{30} \mathrm{H}_{62}$ in which, with a regular increase of 14 in the molecular weight, there is a regular variation in their properties in such a way as to constitute them a definite group. Therefore, if groups of atoms may unite together to form bodies with correlated properties and group relationships, why should not groups of sub-atoms unite together to form the atoms with similar group relationships? Again, in chemistry, we occasionally find little groups of atoms actually playing the rôle of elements. Thus, the little 
group $\mathrm{NH}_{4}$, known as the ammonium group, will pass from compound to compound maintaining its integrity and behaving marvellously like the element potassium or sodium. We see, therefore, that groups of atoms may simulate the elements of matter, and we see, moreover, that the scheme of relationship and periodicity of properties, unquestionably evident in the elements, finds a reasonable and natural explanation in the assumption that the atoms of the elements are made up of sub-atoms, which act in the atom just as the atoms act in the molecule. It is all natural, reasonable and, indeed, inevitable. One thing is needed, the existence of a body smaller than ar atom, and it will be one important business of our book to seek and find this thing. But the bare fact of sub-atomicity is not the only secret of the periodic law. We have spoken not only of gradation of properties, but of similarity and relationship. We have spoken of the elements as sisters and cousins; in other words, of a real relationship, not an analogous one. If we may speak of sisters and cousins, why not of fathers and mothers, and even grandfathers ? Throughout all biological science family relationship is taken indubitably to mean common origin. Evolution is based on this assumption. Whenever the biologist finds a series of organisms, vegetable or animal, betraying in their structure manifold likeness of form, he says at once: "These organisms have had a common ancestry; they have been evolved, all of them, from some one simpler form." Now it is this very form of argument that takes us inevitably to the conclusion that the atomic families, themselves, since they show family relationships as sharply defined as any to be found in biology, are of common origin and descent, and that the atoms, as we know them, are the product of an evolution-an inorganic evolution. ' It will be another important part of the 
business of our book to seek and find the sufficient evidence of the evolution of the atoms.

So far as we have gone, our conclusions do not rest on positive or absolutely demonstrative evidence. It is presumptive evidence, the simple fact being that, with these two foregoing conclusions taken as assumptions, things are explained; not taken as assumptions, nothing is or can be explained. 


\section{PART III. GASEOUS IONS.}





\section{PART III.}

\section{GASEOUS IONS.}

\section{CHAPTER I.}

Gases From the Standpoint of Physics: How They Conduct Electricity.

In the foregoing pages an attempt has been made to show above everything else the necessity of finding some one thing to explain our explanations. We have learned that there is a strange law that binds together the diverse elements of matter; and this law has led us to the very reasonable conclusion that the atoms of matter are composite particles, built up of particles smaller still, and that the atoms, as we know them, have probably undergone some form of evolution from simpler conditions.

But we have no positive proof of this. It is simply a reasonable hypothesis, based upon observed facts; and, moreover, even if we actually had this proof we should not be able to explain the meaning of the periodic law and the mystery of matter. The One Thing is missing; and while the chemist may tell us of a certain search he has, he cannot give us the actual touchstone of truth that we demand. We must, therefore, abandon the chemist to his retorts and crucibles, his burettes and condensers, and betake ourselves elsewhere. Preferably, we should go to the laboratory of the physicist. 
Here, we are in another world. Instruments of infinite precision surround us, optical, electrical and magnetic, and the whole atmosphere of the place tingles with accuracy. Things are the subject of investigation, to be sure, as they are in the chemical laboratory, but they are looked at in a different way. The subject of the atom is as interesting to the physicist as it is to the chemist; but the method of attack is different.

As a good example of this difference of method, consider the subject of gases, with which we must now occupy ourselves in order to discover the first clue to the One Thing which is the object of our search. The chemist, of course, considers mainly the chemical properties of gases, their action on other bodies and the products of the action. The physicist, on the contrary, considers primarily the physical properties of gases; to him the particular gas involved is more or less a matter of indifference, for in their physical properties all gases are wonderfully alike: which is very readily shown in the very similar manner in which they expand and contract under the influence of pressure and heat.

The physical property with which we are most concerned in our search is the electrical conductivity of a gas. All gases in the normal state conduct electricity to a slight, but only to a very slight, degree. If the air, for example, were to any marked degree a conductor, it is obvious that telegraph wires would be impossible, for the electricity would leak away. The air, however, does possess a very slight conductivity; and this may easily be demonstrated by a little instrument known as the electroscope.

The electroscope may be made by attaching a thin strip of gold leaf to a vertical, insulated brass plate. If the gold leaf and brass plate be electrified, the repulsive force between the portions of the same charge causes the gold leaf 
to stand out at an angle which measures the amount of electrification. Experience always shows that the charge leaks gradually away, Fig. 8, and the gold leaf falls slowly down to the brass plate. So small, however, is this leakage that physicists have from time to time refused to believe that the air or surrounding gas had conducted it away of itself, and have ascribed the leakage either to defective insulation or to the presence of dust particles in the gas concerned. Nowadays we know positively that such leakage does really occur through air or any normal gas, and that, consequently, we must call a gas, to that extent, at least, a conductor.

In many ways this slight electrical conductivity of a gas may be increased. Gases become conductible, for instance, (1) when they are

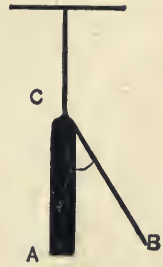

Fig. 8. (An Electro. scope.) AC. Brass Plate.

B. Gold Leaf. $\angle \mathrm{BCA}$. Angle of Electrification. heated up to a certain point, or when they are drawn from the neighbourhood of flames or an electric arc; (2) when they have recently been in contact with glowing metals or carbon; and (3) when they have diffused through a space through which an electric discharge is passing or has passed. Again (4), a gas becomes conductible when X-rays pass through it, or (5) cathode rays. Further (6), the mere presence of certain substances is sufficient to cause this conductivity-substances such as the compounds of uranium, thorium, radium, polonium and actinium. And, finally (7), gases become conductors under the influence of ultra-violet light, or (8) when they are passed over molten phosphorus or bubbled through water.

Having, now, learned so much of the electrical conductivity of gases, we must proceed, in another chapter, to discover where this knowledge leads us in our search. 


\section{CHAPTER II.}

\section{Discovery of Ions: A New Kind of Particles.}

The fact that gases ordinarily possess but a slight electrical conductivity may not seem particularly impressive, or even the additional fact that this conductivity may be vastly increased, until, indeed, they become very good conductors. Yet this simple-secming fact is destined above all others to inform man of some cf nature's most carefully guarded knowledge. Some facts, it may be observed, are pregnant with the meaning of a universe; and this is one of them.

Starting, then, with this apparently unimportant fact, we may best begin our study with a candle flame. Bring the candle up to the little charged electroscope. Observe that the leaves collapse, verifying the fact previously stated, that the gas in the neighbourhood of a flame is a conductor of electricity. Knowing this, it is important to find out why. And we discover the why in the properties of the conducting gas.

In the first place, the gases which come from the flame retain their conductivity, even after they have got some distance away and have been cooled by the surrounding air. It has been proved that such a gas will retain some conductivity six or seven minutes after it has left the flame. Fig. 9. You may prove it for yourself by drawing the gas from the flame over the leaves of the electroscope situated at some distance, under which conditions the leaves collapse, thus showing that the gas retains its (48) 
conductivity for the time taken by it to travel from the flame all the way to the electroscope.

We may now suppose ourselves seeking help from the chemist. "Why," he will say, "the gas from the flame contains nothing but carbonic acid and water. There is nothing remarkable in such things."

"Very true," we say; "but it contains conductivity."

"Conductivity is a condition," he will reply, "not a thing."

But are we sure of that? Let us filter the gas from the flame through a wad of glass wool before it arrives at the

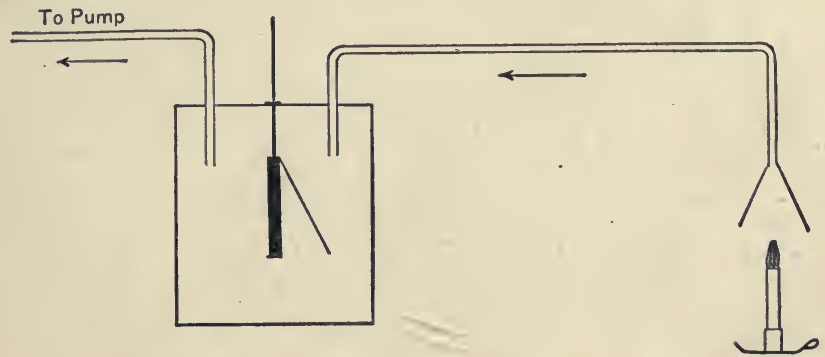

Fig. 9. Apparatus for showing that the air retains its conductivity.

electroscope, or let us bubble it through water, instead. If this be done very carefully, the astonishing result becomes evident that every trace of conductivity is removed! And pursuing our experimentation, we discover that the conductivity may be removed, as well, by making the gas traverse a space through which a current of electricity is passing.

The explanation, then, is clear. The conductivity cannot be a mere condition. If we can blow the conducting air about from one place to another, and if, moreover, we can filter it free from conductivity by passing it through wool or bubbling it through water, it is obvious enough 
that this conductivity must be due to an actual something mixed with the gas, this something being removed by filtration.

It is also obvious that this something-since the gas is perfectly transparent-must be in the nature of particles, and that these particles, which, it must be remembered, are conducting particles, must be different from the particles, or molecules, of the gas in the normal state. The further fact that these particles may be removed by making the conducting gas traverse a space through which a current of electricity is passing shows that the particles must be electrified; and since, moreover, the conducting gas as a whole shows no charge that these particles must be both positive and negative. This latter fact is also shown in Fig. 10, which illustrates the division of a flame

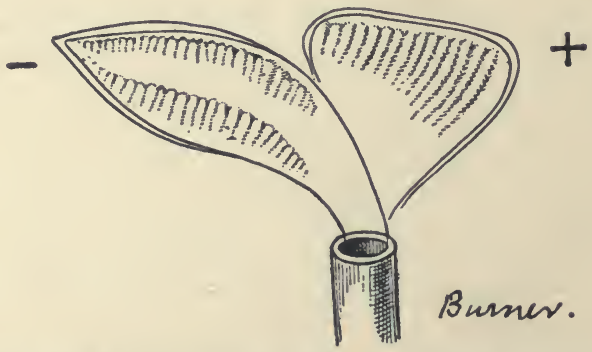

Fig. 10. Showing the division of a flame into two parts by placing it between oppositely charged plates.

into two parts, one part positively and the other negatively electrified, simply by placing the flame between two oppositely charged plates.

We have been led, then, to the discovery of certain electrified particles in the conducting gas. These particles are called ions, and the process by which the gas is made into a conductor, the ionisation of the gas. 


\section{CHAPTER III.}

\section{Discovery of Corpuscles.}

With the discovery of gaseous ions, we have evidently lighted upon a new kind of particles about which nothing is said in the chemistries; and, of course, the questions immediately arise: What are these ions? Do they exist only in gases? Are they molecules, or atoms, or, what is most important to us, are they less than atoms? What is the meaning of their electrical qualities? We may best answer these questions by considering, now, the ionisation produced by glowing metals or by carbon.

The effect of this agency may readily be shown by means of the apparatus shown in Fig. 11. It is a glass vessel con-

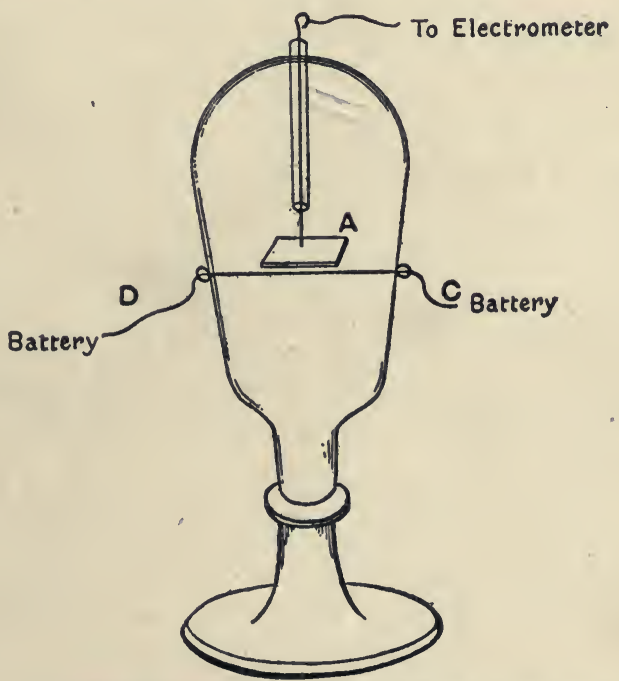

Fig. 11. Apparatus for studying the ions from a hot wire. 
taining an insulated metal plate, $A$, which is in connection with an electrometer; underneath this plate there is a fine metallic wire, which can easily be raised to incandescence by an electric current passing through it from $C$ to $D$. Taking, first, the case in which the air within the vessel is at the ordinary pressure of the atmosphere, it will be observed that, as the wire grows hotter and hotter, until it just begins to glow, the metal plate receives a charge of electricity, and, furthermore, that this charge is positive. It will next be observed that this charge steadily grows, until the wire is at a yellow heat, when it is at a maximum; and that, after passing this stage, it diminishes rapidly with the increasing temperature of the wire, until, when the wire reaches a bright white heat, the charge received by the plate is very small.

So far, we learn that not only may a hot wire as well as a candle flame constitute an electric battery, but that these gaseous ions, which pass from the wire to the plate, need not necessarily convey both kinds of electricity, but may convey one kind only, that kind being positive. At this stage of the experiment, then, and while the wire is still hot, pump out the air within the vessel, which, it must be remembered, has so far been at the pressure of the atmosphere. At first, little change will be noticed in the positive charge upon the metal plate; but as the exhaustion proceeds, at a certain point, depending upon the temperature of the wire, the sign of the electricity upon the plate changes. It is now negative, not positive; and when almost all the air-but not quite all-has been pumped out of the vessel, this negative charge may reach a high value.

We learn by this that the gaseous ions comprise particles of two kinds, one carrying positive electricity and the other negative; and we are now in a position to understand why 
the positive charge on the plate decreased as the temperature rose above a certain point. It was obviously because at a certain temperature negative particles began to be evolved as well as positive, and that, flying side by side with the positive particles from the wire to the plate, they tended to neutralize their effect. Thus, a low temperature and a high pressure are favorable to the production of positive ions; and, conversely, a high temperature and a low pressure are favorable to the production of negative ions.

These negative particles, or ions, owing to the importance they have developed, are given a special name. They are called corpuscles. 1 


\section{CHAPTER IV.}

Factors of a Corpuscle: An Experiment.

Concerning corpuscles, we have so far found that they are little bodies, laden with negative electricity, dancing off from glowing metals, incandescent carbon or gas flames; and we have now a very reasonable curiosity to know (1) how fast they travel, (2) what electric charge they carry, and (3) what they weigh. If we but knew these three elements, we may be sure we should know the corpuscles fairly well, so far as their extrinsic qualities go. And, if our search is to continue, it is to the discovery of these elements that we must now proceed.

These values are readily determinable for corpuscles as they fly off from hot metals, but it may be more convenient to derive them, here, for corpuscles emitted by metals under the impact of ultra-violet light. We are already acquainted with the fact that glowing metals give off negatively electrified particles, or corpuscles; but it is an entirely new statement to say that metals, without the application of any heat whatever, will give out these same corpuscles on mere exposure to light. But the fact is without difficulty demonstrated by charging a newly cleaned surface of zinc with electricity, and exposing it to the light from an arc lamp; for the zinc plate rapidly loses its electrification, and, reasoning anologous to that previously applied, leads irresistibly to the conclusion that the loss is occasioned by corpuscles flying away with it.

It turns out, however, that the active constituent of the (54) 
light that causes this corpuscular migration is the ultraviolet waves-that is, waves that are too short to cause the sensation of sight to the eye, and which, on dispersing the light through a prism, lie beyond the violet end of the spectrum. These ultra-violet light waves, though they do not affect the eye, are nevertheless for the most part the active agents in affecting the sensitive plate of a camera, or in tanning the skin. Sunlight is not rich in them, for the atmosphere absorbs them; but a copious supply is found in the light obtained from an arc lamp, or by burning magnesium wire, or by sparking with an induction coil between zinc or cadmium terminals.

Our task is to weigh and to determine the motion of and the charge on the corpuscles as they fly off from a metal plate under the incidence of ultra-violet light. This is done by means of an apparatus shown in Fig. 12. $A$ is a charged aluminum plate on which the ultra-violet light shines; this light comes from a spark between zinc terminals connected with an induction coil, and enters the tube through the quartz window, $B$, which is peculiarly transparent to ultra-violet waves. $E$ is another metal electrode, perforated in the middle. It shields the right-hand part of the apparatus from the electrified plate, $A$, and provides a window through which the corpuscles may fly into the right-hand chamber. $D$ and $C$ are little metallic plates that can be connected with an electrometer.

All this apparatus is enclosed in a sealed glass vessel from which the air has been almost altogether exhausted by pumping. On sending the ultra-violet light through the quartz window, $B$, so that it falls on the charged aluminum plate, $A$, corpuscles fly off from $A$ at right angles to it, and, passing in a beam through the window of the screen, $E$, they strike the metal plate, $D$, give up their electricity to it and 
signify their presence in the electrometer in connection with it.

So far, so good. But how does this help us to the weight and velocity of the corpuscles? Let us see. The first thing we notice is that while the electrometer, or measurer of electrification, connected with the plate, $D$, is charged on the im-'

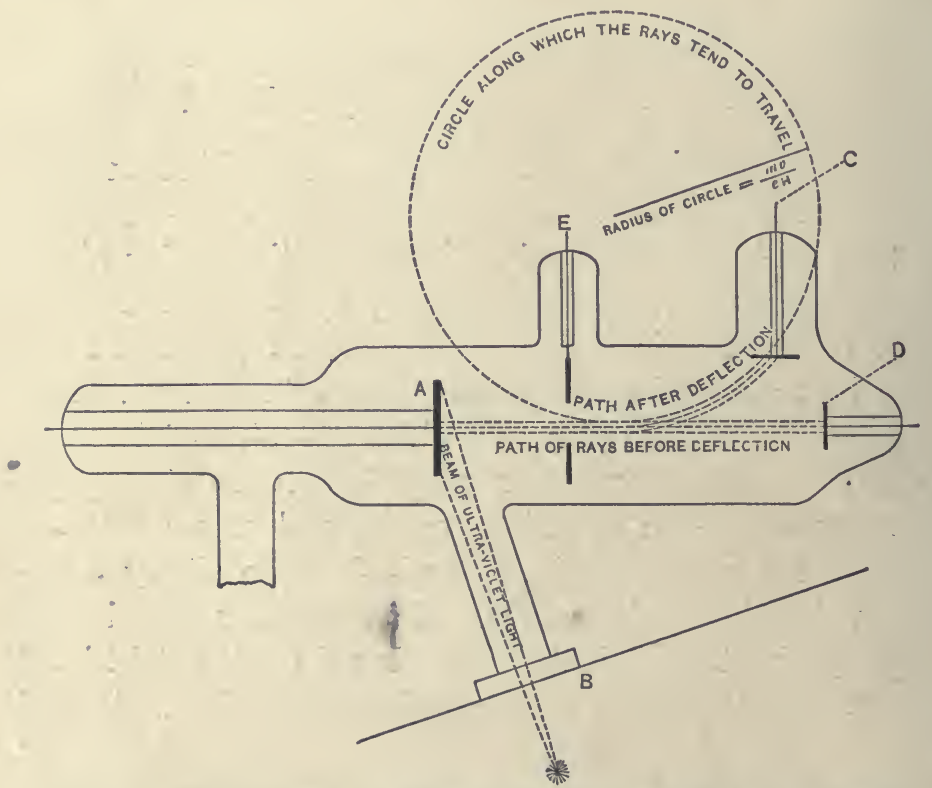

Fig. 12. Experiment for determining the velocity of a corpuscle.

pact of the corpuscles, the electrometer connected with $C$ is quite unaffected. This shows us that the corpuscles tend to travel in straight lines. The next thing to be noticed is that on the approach of a magnet the corpuscles may be deflected so that they fall on $C$, and its electrometer will show a corresponding deflection, Fig. 13. A photographic representation of a beam of corpuscles shows plainly the deflection 
they undergo. The path of the corpuscles is made visible by a special method to be afterward considered.

This fact, namely, that a magnetic force will bend a beam of corpuscles, solves our problem. It may be shown beyond all question that when a magnet is presented at a stream of corpuscles, each corpuscle tends to describe a circle at right angles to the magnetic force, and, furthermore, that the

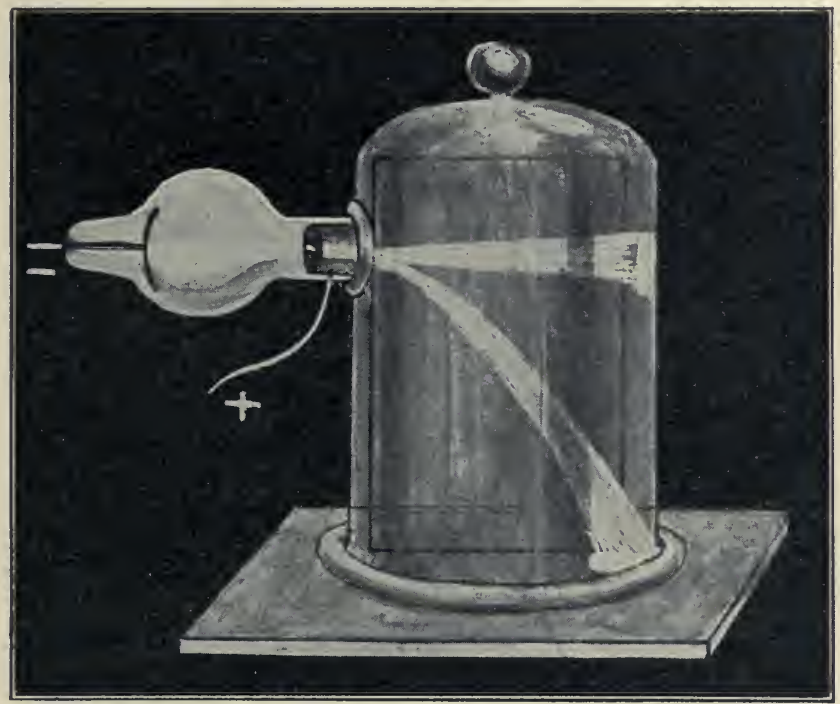

Fig. 13. Showing rays deflected by horseshoe magnet.

radius of this circle equals $\frac{m v}{e H}$ where $m$ is the mass of the corpussle, $v$ its velocity, $e$ its electrical charge, and $H$ the amount of the magnetic force. Returning to the diagram of the apparatus, you will find that it is possible to measure the radius of this circle of corpuscular motion; for when the magnetic force is just sufficient to deflect the corpuscles wholly to the electrode; $C$, they travel from $E$ to $C$ along 
the arc of this very circle. The size of the circle is indicated in the diagram, and the length of its radius is fixed by the relative positions of $E$ and $C$.

Now, the magnetic force that is just sufficient to cause the deflection of the particles to $C$ is easily measured; and hence, we have the following equation:

Radius of circle (which we know) $=\frac{\mathrm{mv}}{\mathrm{e} \times \mathrm{H} \text { (which we know) }}$, which with a shifting of one quantity to the other side of the equation, is:

Radius of circle $($ known $) \times$ magnetic force $($ known $)=\frac{\mathrm{mv}}{\mathrm{e}}$

And we are thus, to some extent forwarder, at least; for we have a definite value for,

$$
\frac{\text { the mass of the corpuscle } X \text { its velocity }}{\text { its electrical charge }}
$$

Is there any hope of our going further? There is. We must now determine the velocity of the corpuscles. 


\section{CHAPTER V.}

The Speed of a Corpuscle and How it is Estimated.

In order to determine how fast corpuscles move, we should consider that during the flight of a corpuscle from the aluminum plate, $A$, until it passes through the window of the screen, $E$, energy is being acquired by it from the electric field which exists between the two plates, $A$ and $E$, both charged electrodes. This energy may be represented by $V e$, where $V$ is the difference in electric potential between the two plates and $e$ the electrical charge on the corpuscle. Now, the kinetic energy of a body may be represented also by the familiar formula, $\frac{\mathrm{m} \mathrm{v}^{2}}{2}$. Hence we have, $\frac{\mathrm{m} \mathrm{v}^{2}}{2}=V e$, in which $m$ is the mass of the corpuscle, $\mathrm{v}$ its velocity, $e$ its electrical charge, and $V$ the difference of electrical potential between the plate and the screen. Placing $V$ over to the other side of the equation, we find that $e=\frac{\mathrm{m} \mathrm{v}^{2}}{2 \mathrm{~V}}$. From our equation concerning the magnetic deflection, $R=\frac{\mathrm{mv}}{\mathrm{eH}}$, it is evident that $e$ must also equal $\frac{\mathrm{mv}}{\mathrm{RH}}$. And hence, $\frac{m v^{2}}{2 \mathrm{~V}}=\frac{m v}{R H}$. Simplify this equation and you will find that $\mathrm{V}=\frac{2 \mathrm{~V}}{\mathrm{RH}}$. That is to say:

Velocity of corpuscle $=\frac{\text { Twice difference of potential }}{\text { Radius of circle } \times \text { magnetic force }}$.

The value of the three terms on the right-hand side of the equation are known; and the problem is solved.

So determined, the velocity of the corpuscles is simply 
prodigious. The speed of the swiftest rifle bullet is insignificant in comparison. Their velocity is not at all constant, for it depends on the electric force with which they are charged, and upon the amount of air left in the vessel; but the corpuscle that does not travel with a speed a thousand times that of the swiftest cannon ball, which is two thousand miles an hour, is slow indeed. The only velocity with which the speed of corpuscles can be compared is that of light-186,000 miles a second-and corpuscles have been observed with about half this velocity. In fact, the velocity of a corpuscle, depending on the conditions, may be taken as anywhere frcm 10,000 to $\$ 0,000$ miles a second.

We see, then, that a candle flame, or a glowing wire, or a metal exposed to light, is not by any means the restful object it appears. Every object in the neighborhood of such bodies must be continuously bombarded by bullets flying with an enormous velocity; and small, indeed, must these bullets be to leave us all, so long, utterly unsuspicious of their existence. But small as they are, we must weigh them; and to do this we must first of all derive the value of $\frac{\mathrm{e}}{\mathrm{m}}$. 


\section{CHAPTER VI.}

The Relation of the Charge in a Corpuscle to its Mass: How Important it is.

The value, $\frac{\mathrm{e}}{\mathrm{m}}$, is a most important one in the elucidation of the nature of corpuscles. By it is meant simply the ratio of the electrical charge on the corpuscle, $e$, to its mass, $m$; and it is evident that, having obtained this value, we need only determine the electrical charge to know the mass of the corpuscle; that is to say, the amount of matter of which it is composed.

It is easy to obtain the value of $\frac{\mathrm{e}}{\mathrm{m}}$ from our equations, (1) $\mathrm{RHI}=\frac{\mathrm{mv}}{\mathrm{e}}$, and (2) $\mathrm{v}=\frac{2 \mathrm{~V}}{\mathrm{RH}} . \quad$ For, substituting $\mathrm{v}$ in the first equation for the value of $\mathrm{v}$ in the second equation, we have,

$$
\mathrm{RH}=\frac{\mathrm{m} \times \frac{2 \mathrm{~V}}{\mathrm{RH}}}{\mathrm{e}}
$$

Hence,

$$
\frac{\mathrm{e}}{\mathrm{m}}=\frac{2 \mathrm{~V}}{(\mathrm{RH})^{2}}
$$

And since $V, R$ and $H$ are known, there is no more difficulty-the problem is solved. On the basis of the experiment, $\frac{\mathrm{e}}{\mathrm{m}}=10,000,000$. Hence, $\mathrm{m}=\frac{\mathrm{e}}{10,000,000^{\circ}}$. So that all we have now to do is to determine the charge on the corpuscle and divide it by $10,000,000$ to obtain the mass of the corpuscle. 
Before proceeding to this, however, there are certain interesting facts about $\frac{\mathrm{e}}{\mathrm{m}}=10,000,000$ that deserve our attentive consideration. The first fact is, that no matter from what source these corpuscles come, whether glowing metals, gases or what not-no matter by what method they are evolved, whether light, electricity or heat-and no matter by which one of the many experimental methods the value of $\frac{\mathrm{e}}{\mathrm{m}}$ is deduced-the result, within the limits of experimental error, is a constant quantity, about $10,000,000$. This shows us that the corpuscles, whatever their nature, are independent of the kind of matter from which they are evolved. The second interesting fact is that the value of $\frac{\mathrm{e}}{\mathrm{m}}$ for the lightest chemical atom known, that of hydrogen, is only about 10,000 , which is one thousand times less than the value of $\frac{\mathrm{e}}{\mathrm{m}}$ for the corpuscle.

The question now arises: Is this thousand times difference between the ion and the corpuscle due to a difference in the masses of the ions, or to a difference in the electrical charge, or to both? Let us have at $e$, then, to settle the matter. 


\section{CHAPTER VII.}

How the Electrical Charge in a Corpuscle is Estimated: A New Use for Clouds.

In order to find the electrical charge on the corpuscle, it is best to consider, now, the influence of ions on the formation of clouds. This cloud formation is a very striking effect produced on moist air by the presence of ions, whether positive or negative, whenever the air is expanded a quarter of its original volume. The fact seems to be that each corpuscle acts as a nucleus about which the moisture of the air collects, so that it becomes the centre of a visible drop of water, and, where before there existed a moist, invisible gas, there now suddenly appears a beautiful cloud.

Though corpuscles due to any of the ionizing agencies mentioned in Chapter I cause this cloud-condensation, one of the best for the purpose is the $\mathrm{X}$-rays, which are peculiarly efficient in forming clouds in any gas through which they pass. The mechanism of the experiment, in its simplicity, is a mass of moist gas enclosed in a glass vessel, through which are passing weak X-rays and in which the moist air may suddenly be expanded with the formation of a cloud of water drops. But the determination of the many factors which it is necessary to know in order to arrive at the electrical charge on a corpuscle by this means, is most formidable.

The procedure is somewhat as follows: The velocity with which each drop of water falls is measured; from this, the radius of the drop may be calculated; knowing the radius 
of the drop, it is next possible to determine, by calculation and experiment, the mass of water deposited from the cloud; and knowing these two factors, the number immediately follows from the equation, $\mathrm{n}=\frac{q}{\frac{4}{3} \pi} \mathrm{a}^{3}$, where $n$ is the number of drops (and, hence, the number of corpuscles), $\frac{q}{4}$ the volume of water deposited in the form of drops, and $a$ the radius of the drop. Having the number of corpuscles in the gas, the electrical charge on each individual corpuscle follows by experimentally determining the total electrification and dividing by the number.

The value of $e$ turns out to be 0.00000000034 in electrostatic units. And, now, finally, we are in a position to know the mass, or amount of matter, in a corpuscle. 


\section{CHAPTER VIII.}

How the Mass of a Corpuscle is Determined: DiscovERY OF The ONe Thing.

It will be remembered that $\frac{\mathrm{e}}{\mathrm{m}}=10,000,000$. Therefore; $\mathrm{m}=\frac{\mathrm{e}}{10,000,000}$. Or, since $e$, as we have determined, has the value of $0.00000000034, \mathrm{~m}=\frac{0.00000000034}{10,000,000}$. And this is the weight of a corpuscle. Well, we need not translate this value into a fraction telling us just what portion of a gram the weight of a corpuscle is. It would constitute a decimal stretching from one side of the page to the other. What we want particularly to know is the relation between the weight of a corpuscle and the weight of an atom.

This falls neatly into our hands; for it turns out that the electrical charge on a hytrogen atom is exactly the same, within the limits of experimental error, as the electrical charge on a corpuscle. Now, it will be remembered that the total value of $\frac{\mathrm{e}}{\mathrm{m}}$ for a hydrogen atom is 1,000 times less than the total value of $\frac{\mathrm{e}}{\mathrm{m}}$ for a corpuscle. If, therefore, the mass of a corpuscle equals 0.00000000034 divided by ten million, and the mass of an atom equals 0.00000000034 divided by ten thousand, it follows that the mass of the hydrogen atom is one thousand times greater than the mass of a corpuscle!

So, starting with a candle flame and a gold-leaf electroscope, we have been carried irresistibly to the conclusion 
that there are bodies a thousand times smaller than thesmallest atom. Next we have seen that, no matter what their source, these little particles are all alike in nature and size. And, finally, we know that they constitute an actual part of the forms of matter from which they fly. The far-reaching influence of these conclusions on the inner structure of the universe explains the painful efforts we have made to show how they are obtained, and why-since the how is not so important in this world as the why-we are so sure in our conclusions.

That we have in a corpuscle the veritable key to many a mystery, it will be the function of the latter part of our book to disclose. Our present duty is to elucidate still farther the nature of these strange little bodies. And, for this purpose, there is no place in which they are better developed, or in which they have greater freedom from extraneous influences, than in the cathode rays. 


\section{CHAPTER IX.}

Properties of Corpuscles: Cathode Rays.

In the absence of any of the ionizing agencies we have so far considered, the very high resistance of the air can be overcome only by the application of intense electrical forces. Instead of an invisible leakage we then obtain a sudden spark, as one sees any day in the discharge of an electrical machine or in a lightning flash. But this spark discharge is due to the fact that the air or gas is at the normal pressure of the atmosphere, about $15 \mathrm{lbs}$. to the square inch. Just so soon as we begin to decrease this pressure the phenomenon begins to change; and this change goes on progressively until its character becomes absorbingly interesting.

The less the pressure the easier it is to form these little negatively electrified particles under the influence of electric forces. If an electric machine or induction coil be connected with metallic terminals fused into a glass bulb, so arranged in connection with an air pump that the air can be gradually withdrawn, one of the most beautiful experiments in physical science makes evident the maximum properties of corpuscles. When the air has been withdrawn until it has a pressure of about one ten-thousandth of an atmosphere, the first effect noticeable in the 
bulb is illustrated in Fig. 14. Near the positive pole, $a$, is situated a cloud of light which, when the pressure of the

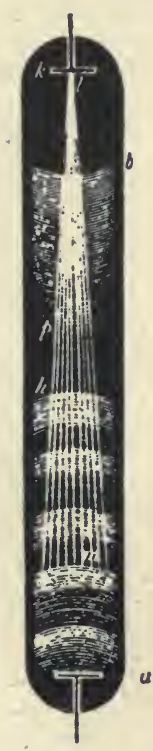

Fig. 14. air and the current of electricity lie within certain definite limits, shows beautiful fluctuating striations.

The negative pole, or cathode, $k$, is surrounded by a faint glow, and beyond the glow lies a dark space, $k$ to $b$. If the exhaustion of the bulb be now increased, the dark space extends farther and farther through the bulb, until, finally, it strikes the other side of the bulb and impinges on the glass. When it strikes the glass a brilliant phosphorescent light appears, green if the glass contain soda, blue if it contain lead, and the glass itself, or the metal within the bulb, becomes a source of $\mathrm{X}$-rays. Fig. 16 is a photographic representation of such a bulb in action. The positive and negative terminals (the anode and cathode) are marked + and - respcctively. Looking only at the wire Showing general phenomena in vacby which the current leaves the bulb (this wire is called the cathode; it is the one marked uum tube. in the figure), you will see a velvety glow about the terminal of the wire within the bulb. In front of this is the space called the dark space; in front of this, again, the bulb is luminous for some distance, this luminous portion being called the negative glow; and, finally, the brilliant phosphorescence of the pear-shaped end of the tube will be noticed as a mass of white.

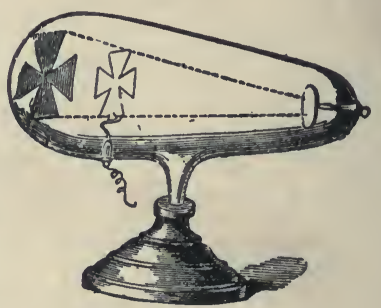

Fig. 15.

Showing that the phosphorescence arises from the cathode. 
It was soon discovered that the phosphorescence in the end of the bulb was caused by something coming from the neighborhood of the cathode, for a solid placed between the cathode and the end of the bulb casts a shadow on the bulb. An example of this effect is shown in Fig. 15, where the shadow is caused by a maltese cross of mica, placed between the cathode and the end of the bulb. The shape of the shadow shows that the cause of the phosphorescence travels in straight lines, and that, moreover, it comes straight from the cathode. It is to the agent producing this phosphorescence in the bulb that the name, cathode rays, has been given.

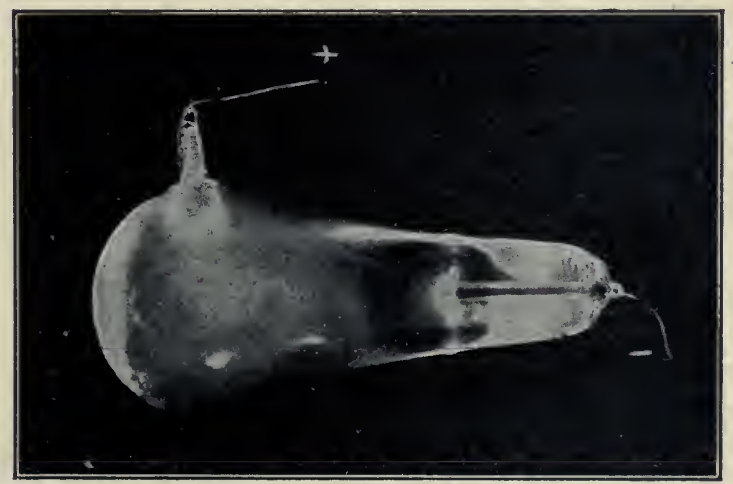

Fig. 16. Photographic representation of a vacuum tube in action.

Now, cathode rays constitute simply a beam of corpuscles; that is, they consist of negatively electrified particles having a velocity equal to that of corpuscles obtained in other ways, and their mass is a thousand times less than the mass of a hydrogen atom.

\section{PHOSPHORESCENCE.}

A very large number of bodies give out a phosphorescent 
light when exposed to a bombardment of the corpuscles in cathode rays. This phosphorescence is very beautiful, its color depending on the nature of the substance struck. The spectrum given out by these bodies is generally a continuous one, but certain rare earths, such as yttrium, yield, on corpuscular bombardment, a bright-line spectrum; and this fact has been of great importance in the study of the rare earths.

The power of glass to phosphoresce under these rays has already been referred to. It ought to be stated, however, that the glass will in time "grow tired." This may be seen with the apparatus shown in Fig. 15, where, if the cross, which is on hinges, be thrown down, the phosphorescence of that part of the glass which has hitherto been in the shadow of the cross, is now much brighter than that of the surrounding glass.

The substances barium platino-cyanide and calcium tungstate are exceedingly sensitive to the impact of corpuscles. Their phosphorescence is, in fact, used to detect the presence of corpuscles.

\section{CHEMICAL EFFECT.}

Corpuscles cause chemical changes in certain bodies on which they fall. Thus, rock salt takes a beautiful violet color, which, unless exposed to moisture, it will retain for years. Lithium chloride is remarkably sensitive to the inpact of corpuscles. If a beam of corpuscles be slowly moved over the salt by a magnet, the path of the beam traces out a colored band on the surface of the salt.

\section{HEATING EFFECT.}

Corpuscles heat a body on which they fall. They may be concentrated by a bowl-shaped cathode, such as shown 
in Fig. 17; and a piece of platinum, if placed in the focus, may be raised to a white heat; and glass may be melted, and a diamond charred.

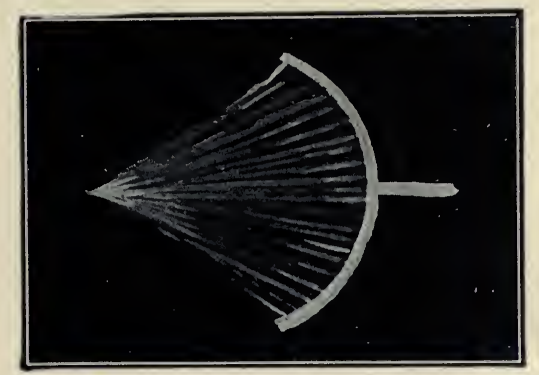

Fig. 17. Cathode rays of corpuscles brought to a focus.

MECHANICAL EFFECT.

Corpuscles, when they strike against an object, tend to push it away. This is very prettily shown in the apparatus in Fig. 18, where the impact of the corpuscles in the cathode rays makes the little carriage move from one end of the rails to the other.

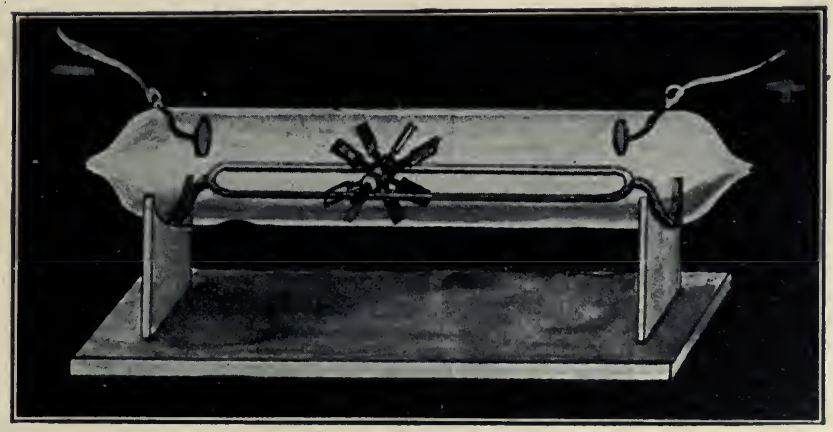

Fig. 18. Showing that corpuscles will move a body which they strike. 
POWER TO PENETRATE MATTER.

It was at first supposed that solid bodies were absolutely impenetrable to these corpuscies. Nowadays, however, we know that this is not.so. Lenard has made a tube which has in it a small window of aluminum foil, and on shooting the corpuscles against this window, he found that they passed straight through it, and so got outside the tube, where they could be more easily investigated. Cathode rays which have passed through the glass bulb into the outer air are consequently called Lenard rays.

\section{LENARD RAYS.}

It will be understood that these rays consist simply of corpuscles which have passed through an aluminum window, and are in no way different from corpuscles in general or from the cathode rays within the tube. They have turned out to be very useful, however, in determining the Law of Absorption. The absorption of ordinary light by different substances bears no relation to the density, or weight, of the absorbing medium. Heavy materials, like iron or glass, light bodies, such as cork or water, may be transparent or opaque to ordinary light, as the case may be. On the other hand, in the absorption of corpuscles in the Lenard rays very-different phenomena appear.

A given thickness of material, whether gas, liquid or solid, absorbs these rays simply in proportion to its density, and entirely independently of any other property. Thus, (X) though the density of the lightest substance is only one sixty-millionth of the heaviest, throughout this enormous range all substances, including air, carbonic acid gas, paper, copper, glass and gold, absorb these rays in direct proportion to the relative weight of the substances involved. 


\section{CORPUSCLES AND X-RAYS.}

When the air pressure in the bulb producing cathode rays is so low that the glass of the bulb becomes brilliantly phosphorescent, an entirely different set of rays proceeds from the tube, having properties that differentiate them altogether from the cathode rays, or corpuscles, that produce them by their impact on the glass or on a metal plate within the bulb. These rays illuminate a phosphorescent screen, affect a photographic plate, and have an astonishing power of penetrating substances opaque to ordinary light. They are called X-rays because at the time of their discovery their nature was an unknown quantity. And so it is, to a certain extent, even now. They are not corpuscles; though it is not one of the least interesting properties of corpuscles that they produce X-rays. Their probable nature, and their relation to corpuscles, will be considered when we wish to make use of them in the elucidation of another problem.

\section{CORPUSCULAR CONDENSATIONS.}

Except in the phenomena of radio-activity, which constitutes the subject-matter of the next part of our work, these ultra-atomic particles, or corpuscles, are found only in gases or metals at high temperatures or in the low pressure which exists in a good vacuum. The reason for this is that no sooner is a corpuscle let loose than it tends to unite itself with anything else available, whether this be another corpuscle, an atom or a molecule; so that it is only in the long, open spaces of a good vacuum, where they have a path free from much chance of collision, that we can study them as they are. At the ordinary pressure of the atmosphere, or at ordinary temperatures, they are no sooner set 
free than they become nuclei, about which atoms and molecules collect, until they form masses many times larger than the original molecules of the gas. This is quite consistent with what we have learned concerning the formation of clouds in the presence of corpuscles.

Résumé of what we have learned about corpuscles.

Corpuscles are generated from:

(1) Burning gases.

(2) Glowing metals and carbon.

(3) Electrical discharges in gases at low pressures.

(4) X-rays.

(5) Metals on the impact of ultra-violet light.

Nature and properties:

(1) They are negatively electrified particles.

(2) They have a velocity of from 10,000 to 90,000 miles a second.

(3) They have the same electrical charge as a hydrogen atom.

(4) They have a mass equal to one one-thousandth of a hydrogen atom.

(5) They discharge electrified bodies.

(6) They are deflected by a magnet so that they tend to go in a circle.

(7) They are deflected by an electrostatic force.

(8) They cause phosphorescence in bodies which they strike.

(9) They give rise to heat in bodies which they strike.

(10) They communicate mechanical motion to bodies which they strike. 
(11) They give rise to X-rays in bodies which they strike.

(12) They are absorbed by all bodies in direct proportion to the density of those bodies.

(12) They act as nuclei about which atoms and molecules collect. 


\section{CHAPTER X.}

Positive Ions: The Other Kind of Particles.

Has the reader forgotten that the gaseous ions of the candle flame and the glowing wire consist of particles of two kinds, the one carrying negative electricity, the other positive? Since the negative particles, or corpuscles, have turned out to possess properties so unprecedented and unlooked for, it is high time to renew our inquiries concerning the positive particles.

These positive particles afford a surprise. Though they may be developed by any of the forgoing methods, in their properties they are almost diametrically opposed to corpuscles.

(1) They carry positive electricity, not negative.

(2) Their velocities are less than those of corpuscles.

(3) Their electrical charge is of the same order as that of an ordinary atom.

(4) The value of $\frac{\mathrm{e}}{\mathrm{m}}$ is one thirty-thousandth of $\frac{\mathrm{e}}{\mathrm{m}}$ for a corpuscle.

(5) Their mass is a thousand times as great as the mass of a corpuscle, and is about equal to that of an atom of ordinary matter.

(6) They can be deflected by a magnet only to a slight extent, and require for this deflection a magnetic field immensely strong.

It is evident, then, from a comparison of the two kinds (76) 
of particles, that "Codlin is our friend, not Short"-the corpuscle, not the positive ion. For, though we shall refer to the positive ion again and again, if we wish to know something of the birth of matter, the decay of matter, the nature of matter, of the nature of electricity and the relation of electricity to matter, of the nature of the sun and the sun's rays, of the possible cause of gravitation, the cause of clouds and rain, and the reasonable solution of many another mystery -if we wish to know something of all this, the corpuscle is our most informing friend.

In earnest of this, we may say that so far as we have gone in this part of our work there is barely a paragraph that will not be utilized in the study of the foregoing problems. Surely, then, we have in the corpuscle the fulcrum for the lever of thought, the philosopher's desire, the one thing to explain our explanations, for which alchemy so earnestly sought in the dim, vague light of the middle ages and called it the philosopher's stone, and for which, chemistry, the daughter of alchemy, has so sorely felt the need to make herself consistent in the periodic law.

It is an interesting thought that, throughout the ages, in this search for the one thing, the medieval scholar, laboriously poring over his great book in the light of his little candle, and the modern savant in his laboratory, radiant with electric illumination, have alike been literally bathed in the light of the truth-bombarded, hands and face and eyes, by the one thing, with only that short space lacking, between the retina and the innermost centre of the brain where the power of deduction lies, to know.

Verily,

"Truth is within ourselves; it takes no rise From outward things, whate'er you may believe. 
Rather consists in opening out a way.

Whence the imprisoned splendour may escape,

Than effecting entry for a light

Supposed to be without." 


\section{PART IV.}

NATURAL RADIO-ACTIVITY: A NEW PROPERTY OF MATTER. 



\section{PART IV.}

\section{NATURAL RADIO-ACTIVITY: A NEW PROPERTY OF MATTER.}

\section{CHAPTER I.}

\section{Antecedent Discovery.}

The theme of this present part of our book is of a new thing done-the discovery of a new natural property of matter, and an explanation of this property in terms of what we already know.

If one questioned the discoverer-the beginner of the work - about himself, he would probably say that his work, possibly, was something - he himself was nothing; and in a measure he is right; for in a few years he will pass, while his work will endure forever. Still, we wish to know him for his work's sake, and surely it will not be amiss to say something at least about him.

Henri Becquerel, Membre de l'Institut, is the discoverer of Becquerel rays, the basis of the phenomena of radioactivity. He comes very honestly by his powers. His grandfather, Antoine César (1788-1878), through sixty years of indefatigable labor, contributed more than five hundred memoirs, works of note on mineralogy and electricity. His father, Alexandre Edmond (1820-1891), was the author of so 
many memoirs that they constitute practically a history of the relations of optics to electricity through the past fifty years. Henri Becquerel, the son, was subjected to the training and influence of these honoured men, and it is little wonder, then, that, through heredity and environment, he should bear the face of one who sends his soul into the invisiblefor that, in good solid truth, is what every true experimenter literally does.

In due time he succeeded to the Professorship of Physics, the chair of his father, and began his work in their laboratory in the quaint old home of Cuvier in the Jardin des Plantes, - "a laboratory to which I had gone," he says, "from the time I was able to walk." There he wrought nobly for the credit of his name, until Röntgen's discovery of the X-rays initiated an investigation which culminated in the discovery of the Becquerel rays and radio-activity.

Now, Becquerel did not discover his rays and their radioactivity out of nothing. Every scientific discovery has a genealogy of its own, going back to the primal ancestor of all thoughts; no discovery comes into the world parentless of previous conceptions. Here is a table showing a few steps in the genealogy of the Becquerel rays:

GENEALOGY OF THE RAYS.

Cathode Rays.

Lenard Rays 1 X-Rays

(?) N-Rays

Niewenglowski's Rays. Becquerel Rays.

$\mathrm{X}$-rays are in some way entangled with the phosphorescence in a Crookes' tube. Consequently, the discovery of 
Professor Röntgen set men wondering as to whether the power of emitting penetrating rays might not be a property of phosphcrescent bodies in general. In this instance there was Niewenglowski, who made the interesting discovery that some such rays were actually emitted; that much at least. His experiment, as afterward repeated by Becquerel, is perfectly demonstrative. A certain compound of sulphur and calcium, calcium sulphide, which is the basis of luminous paint, shines in the dark after exposure to sunlight-that is, it is phosphorescent. Niewenglowski placed a photographic plate in a plate-holder, and instead of a cover-slide, he inserted a thin sheet of aluminum. The plate was thus completely sheltered from the action of light. Upon the sheet of aluminum he placed squares of thin glass, and upon these, in turn, pieces of a certain calcium sulphide previously exposed to light, which were protected from external influences by dome-shaped clock-glasses. The arrangement of the experiment is seen in Figure 19, the cover-slide of aluminum, the

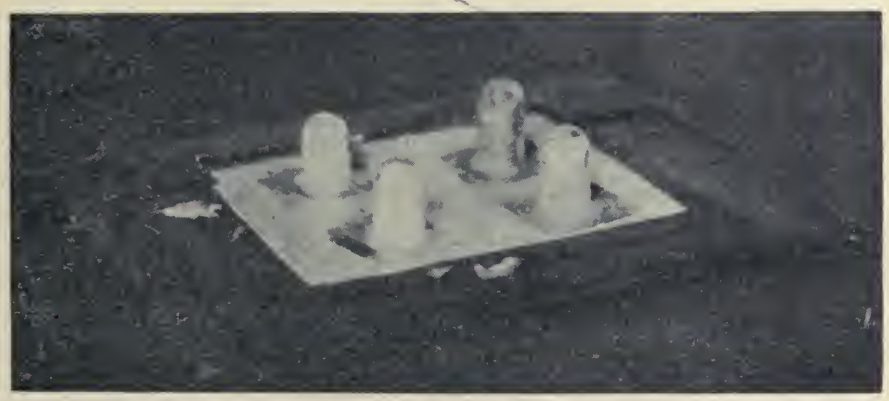

Fig. 19. Niewenglowski's Experiment.

glass, the sulphide above it, and the clock-glasses covering all. The apparatus was left in the dark for twenty-three hours. The plate was then developed. A print from the 
actual plate, which is here produced (Fig. 20) leaves no muddy obscurity for the reader. Upon the plate are imprinted the

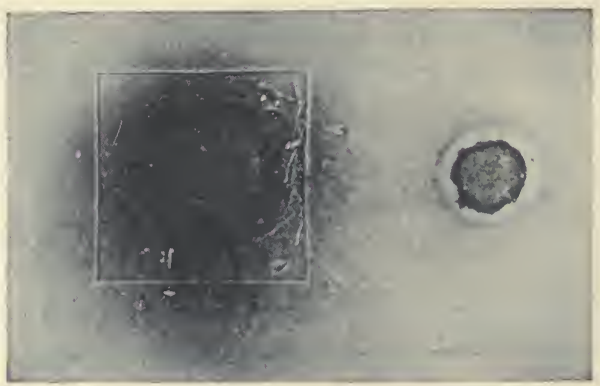

Fig. 20. The result of Niewenglowski's Experiment.

square of glass and the round section of the clock-glass cover. The rays had, necessarily, to pass straight through the aluminum cover-slide to print them there. It was thus, then, that the question was asked of Nature, "Does this substance, this calcium sulphide, emit rays which will penetrate glass and metal and affect a photographic plate?" And Nature answered in her legible signature, "This substance will." Are these rays light? The answer is upon the same plate. It is affirmative. If you examine the imprint of the square of glass upon this plate, you will notice that it is bordered by a perfectly white line which has been . left untouched by the rays. This can only be accounted for by supposing that they were bent, or refracted, on passing through the edges of the glass into the air. Now rays that are made up of particles, or corpuscles such as we have studied in Part III, cannot be refracted in the slightest degree. Light rays always are, and must be, from their very nature, as wave motions. Niewenglowski, therefore, discovered penetrating rays of light capable of passing through a sheet of metal, a substance which anybody would consider 
opaque-not X-rays, nor corpuscles, but light rays of a most remarkable kind. It should be remembered, however, that these penetrating light rays were not given off by the sulphide in its natural condition. It had previously to be exposed to sunlight, whence it derived its energy. 


\section{CHAPTER II.}

\section{The Discovery of Radio-Activity.}

But Becquerel, abreast of the same wave of investigation, thought as Niewenglowski. He says, "For my part, from the day on which I first had knowledge of the discovery of Professor Röntgen, there came to me, too, the idea of seeing whether the property of emitting very penetrating rays was not intimately bound up with phosphorescence." His thought was soon represented concretely; for, taking fragments of various phosphorescent substances, he placed them one after another on a photographic plate enveloped in black paper, and thus gave them an opportunity of telling their secrets by penetrating the paper and affecting the plate beneath. In this, his work resembled that of Niewenglowski; but the importance of it is and the luck of it was, that he experimented with different substances. Out of all the different substances tried, there was one, uranium, that had waited long for this one precious day. For one day of twenty-four hours this substance lay upon a photographic plate enveloped in black paper, and thus, after ages upon ages of waiting, found utterance. This plate was affected. A glance at Fig. 21 will make it evident; and a close examination will reveal the shadow of the copper cross through which the rays had to pass. The plate is obscure, as would be the picture of the approach of dawn; and it is equally significant. It reveals nothing but the presence of penetrating rays. "Here I am," said Nature, "now, tell me, am I Niewenglowski's rays?" "I thought, then," says Bec- 
querel, "that it was necessary previously to expose the substance to light in order to provoke this very penetrating emission, but a short time after I recognised that the emission of the rays was produced spontaneously, even when the substance had been kept completely sheltered from any previous exposure to light." This settles the question. Niewenglowski's rays were directly due to the action of the sun upon the substance which emitted them; Becquerel rays arise from a

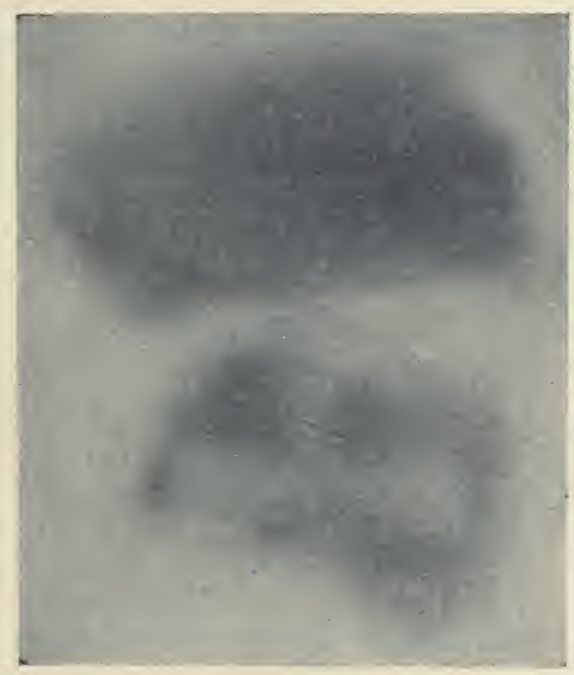

Fig. 21. Becquerel's first experiment.

substance whose natural property it is, not only to emit them, but, apparently, to manufacture them. It may be stated here that since this discovery, the rays emitted by this particular fragment of uranium compound have shown no signs whatever of diminution. They are, apparently, a permanent property of this form of matter. Furthermore, it was soon seen to be a matter of indifference what uranium 
substance was employed. Any substance containing uranium gave off the rays. Metallic uranium itself, obtained in Moissan's electric furnace, gave out more rays than any of its compounds. More than that, the emission of the rays turned out to be altogether independent even of phosphorescence. Uranium bodies, whether phosphorescent or not, emitted rays. Here, then, was no stored up, transformed sunlight, such as Niewenglowski's rays, but pene-

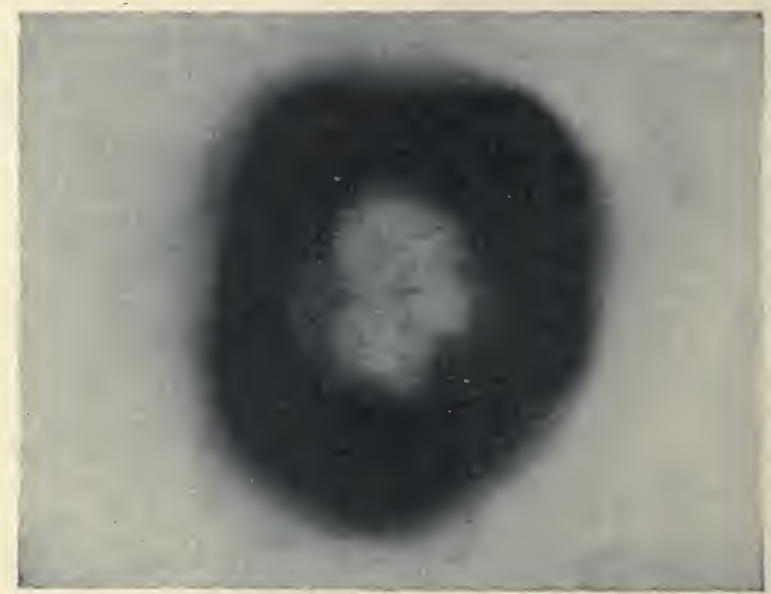

Fig. 22. Uranium radiograph.

trating, continuous emissions from a substance having no relation to light. The emission of rays capable of passing straight through copper from a chemical substance in its normal condition constituted to us a new property of matter -a new thing in nature.

So, as Becquerel stood in his laboratory that night, with this thought in his mind and the plate in his hand, he appears sharply silhouetted against the background of the ages; he is comparable with that Theophrastus who, two thousand 
years ago, rubbed a piece of amber on his coat-sleeve and noticed that it attracted bits of paper, unknowing that this bit of amber was equal to the lamp of Aladdin, or to that Paleolithic savage, who, the first of all men, noticed the attractive powers of lodestone. New properties of matter are not so common that their significance can be exaggerated. This new property of matter was called radio-activity, and as such it takes its place beside magnetism, electricity, light and heat. 


\section{CHAPTER III.}

Discovery of Radio-active Elements.

Radio-activity, a new property of matter, had been discovered, but whence its source? "The metal uranium itself," you say, "since it gives off the rays." Yes; but still a doubt-a little, tiny doubt-remained. Was it not possible that the power of emitting rays, the radio-activity, was due to some small impurity present in the uranium? That doubt was the key which unlocked the door to a roomful of other discoveries.

It arose in the minds of two investigators who had been interested observers of Becquerel's work, M. Pierre Curie, Professor of Physics in the School of Physics and Industrial Chemistry at Paris, and Madame Sklodowski Curie, his wife. They resolved to investigate the ray-emitting power of pitchblende, the parent substance from which all uranium is extracted. To their gratification they discovered that selected specimens of pitchblende possessed a radio-activity four times greater than metallic uranium itself (Figs. 23 and 34). Nature never insul ts us by caprice, and, consequently, we find the Curies saying: "It becomes then very probable that if pitchblende has so strong an activity it is because the mineral contains, in small quantities, a substance wonderfully radio-active, different from uranium or any of the simple bodies actually known.

"We proposed to ourselves to extract this substance from pitchblende and we have, in fact, been able to prove that it (90) 


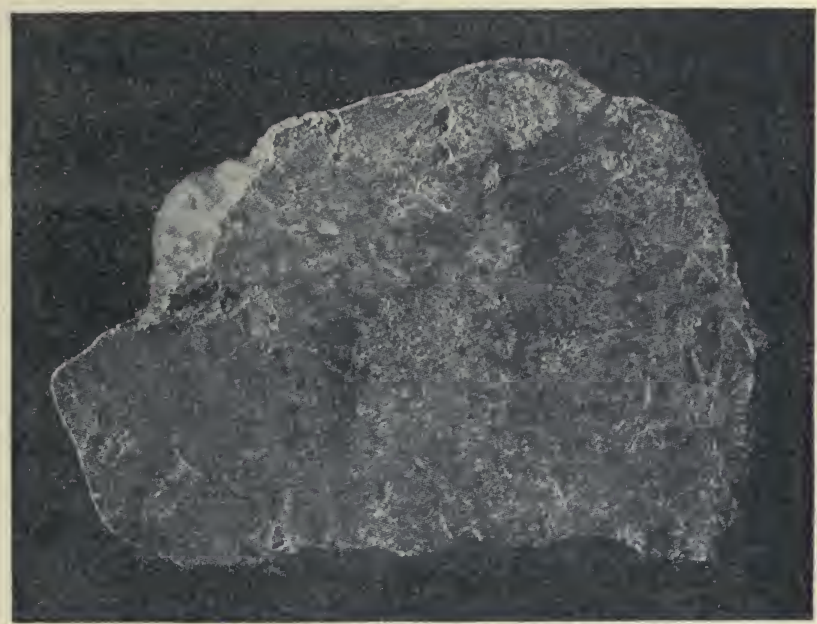

Fig. 23. Photograph by ordinary daylight of a section of pitchblende, by Sir William Crookes.

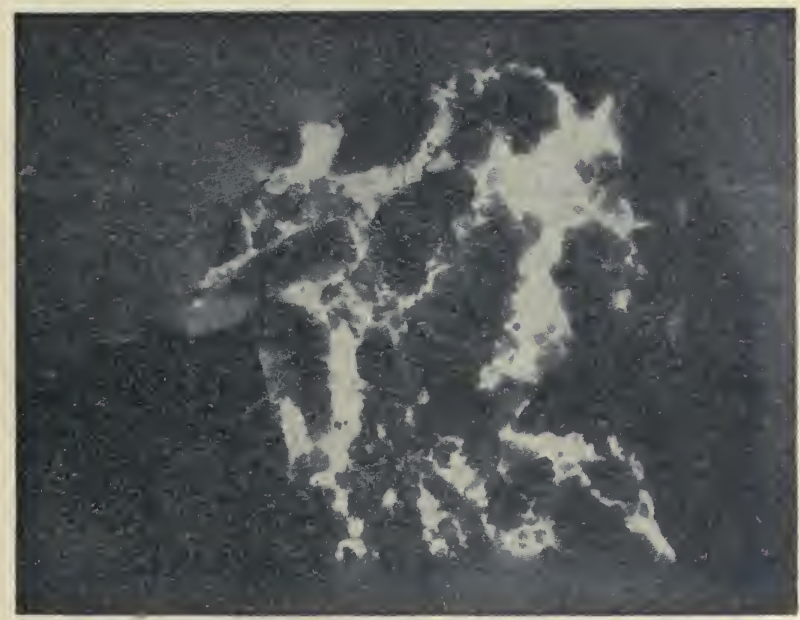

Fig. 24. Photographic imprint of the same section of pitchblende as it imprinted itself in the dark when laid on a plate enveloped in black paper. The white portions of the print are due to the rays. 
is possible, by the methods of ordinary chemical analysis, to extract from pitchblende substances, of which the radioactivity is in the neighborhood of 100,000 times greater than that of metallic uranium."

In this simple manner did the Curies announce their discovery of three new elements with transcendent ray-emitting powers-radium, polonium, and actinium which they discovered with Debierne. Since that time others have been discovered. Of these strangers in the world of matter, we shall select radium as our first object of study, as it is the most easily obtained. Its discovery, with its ray-emitting power 100,000 times greater than uranium, placed in the hands of investigators a mighty engine of research for determining the properties of Becquerel rays. 


\section{CHAPTER IV.}

\section{RADIUM.}

Radium has never been isolated. As a free element it has never been seen, never been touched, never been handled, as gold and iron may be, but it is manifest in the properties of its compounds. It has been studied only in combination with other elements, chiefly in the form of the chloride or bromide. We know that it exists as an element different from any other body in nature, solely and completely through the fact that every element has had its own sign manual, or spectrum, by means of which it signifies its existence, whether it is found in the sun, the stars or the laboratory. Fig. 25 is the spectrum of radium as obtained by M. Demarcay from a small quantity of chemically pure radium chloride provided by Professor Curie. The lines numbered at the top
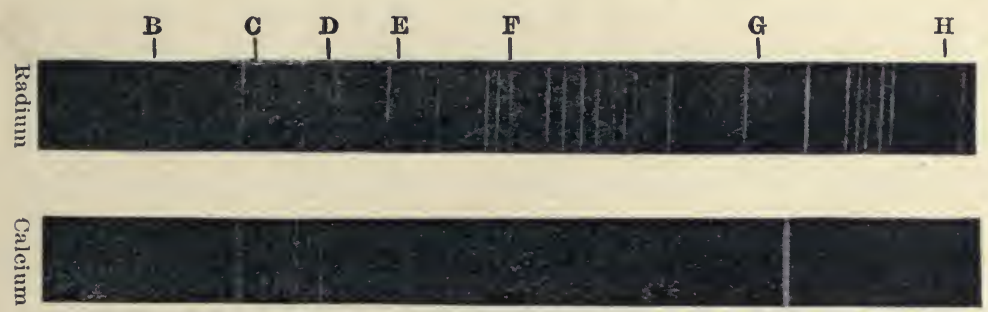

Fig. 25. Comparative spectra of radium and calcium.

of the picture are caused by no known element on the earth or in the heavens. Therefore radium is a new element. 
But if radium is an element, it should find a place in the family grouping of the periodic law. And so it does. An examination of the chemical behaviour of radium shows that it is allied in all its properties to barium. It is, in fact, so like barium that it is almost impossible to separate one from the other. The family resemblance is unmistakable. Barium is a sister to radium. Now, if you will examine the table of the periodic law, page 28, Part II, you will notice that Barium $(\mathrm{Ba}=137)$ occurs in Group II and that there are several vacant spaces in the groups marked with black lines for elements hitherto undiscovered. Into one of these blank

Group II spaces radium ought to fit if the periodic law is - the expression of a fact. The determining factor Mo. is, of course, the weight of the atom. That setBe 9 tles its place in the table. Now, the atomic $\mathrm{Mg} 24$

Ca 40 Zn 65 Sr 87.6

Cd 112 $\mathrm{Ba} \ 137$ weight of radium has been determined with extreme accuracy by Madame Curie, and her results lead to the value 225 . This is the atomic weight of an element which should fill the blank space below mercury (Hg 200) in Group II; and so it is no wonder that, chemically, radium should resemble barium for they belong to the same family.

$\mathrm{Hg} 200$

The amount of radium in pitchblende is less than one ten-millionth per cent., rarer than gold in sea water; and the quantities of the much rarer polonium and actinium are literally infinitesimal. The difficulties of extraction are immense. The residue of the mineral pitchblende, out of which the radium has been extracted gat Jochimsthal, Bohemia, is sent to Professor Curie's works at Ivry, France, where it is precipitated and reprecipitated and crystallized and recrystallized an amazing number of times in order to separate it from the multitude of other things contained in the pitchblende. Finally, a few grains 
of the ton or so of material reaches Professor Curie himself as very impure radium chloride or bromide. It still contains many times its weight of its sister barium and now under Professor Curie's own hands it undergoes the final laborious process of fractional crystallization by means of which the barium is slowly fined away. A slight difference in solubility is practically the only means by which the separation may be accomplished, and its progress is tested by the increased ray-emitting power of the substance which, beginning with 2,000 , rises to $10,000,100,000$ and, finally, as pure "radium," to 1,300,000 times the activity of the uranium in which Becquerel first proved the existence of the new property-radio-activity. But, alas! out of the ton of material but barely the hundredth of a gram remains. It is like attempting to collect the pollen of a single flower scattered over an acre of ground.

Considering only the cost of the pitchblende from which it is extracted, the value of radium would be at least $\$ 10,000$ a gram. As a matter of fact, not much more than a gram exists. Of course the amount is slowly increasing and it is now possible to buy a few milligrams of varying degrees of purity in the chemical markets of the world. 


\section{CHAPTER V.}

\section{The Becquerel Raỵs from Radium.}

This small amount of radium distributed among the scientific workers in the field has been sufficient for the elucidation of the properties of the Becquerel rays.

\section{LAW OF ABSORPTION.}

Their surpassing power of penetrating matter generally considered opaque led to their discovery, as we have seen, and it was therefore one of the first properties to be investigated. It soon became evident that the power was quite independent of the kind of matter through which they passed.

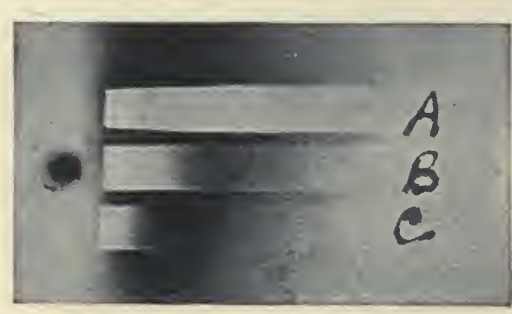

Fig. 26. Radiograph showing how the - power of the rays to penetrate matter depends on the density. The strips $A, B$ and $C$ are platinum, aluminum and paper respectively. It is easy to see that the platinum is penetrated least.

It was influenced only by the density of the substance interposed. Aluminum, for example, bcing light in weight, is to the Becquerel rays what glass is to lightcomparatively transparent. Lead, on the contrary, being heavy, is comparatively opaque. As a matter of fact, they obey the law of absorption, page 72 (Part III), and in this they resemble the corpuscles of the cathode rays (Fig. 26). 
PHOTOGRAPHIC POWER.

In their power to take radiographs, Becquerel rays from radium resemble $\mathrm{X}$-rays (Fig. 27). A radiograph of a purse

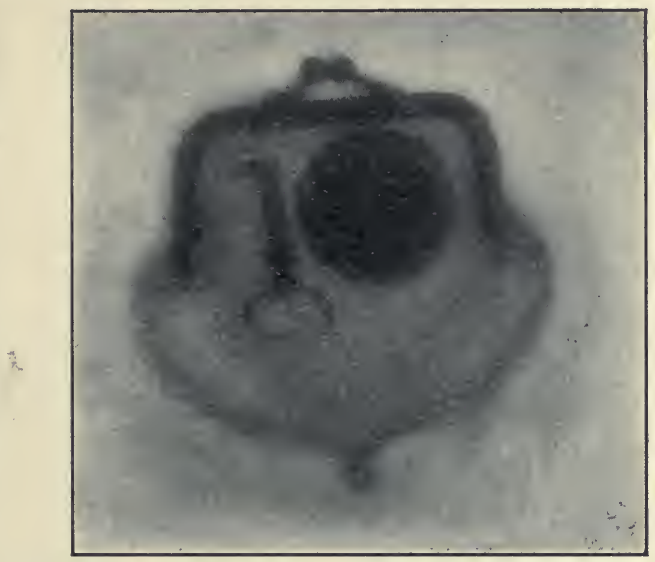

Fig. 27. Radiograph by the Curies. A pinch of radium was used at a distance of a foot. Time, 1 hour.

was taken in the dark by exposing the plate with the purse upon it to the invisible Becquerel rays for one hour. It has all the characteristics of an X-ray picture.

\section{PHOSPHORESCENCE.}

Many substances when they are exposed to Becquerel rays shine in the dark-that is they phosphoresce. The diamond and the ruby shine out vividly on being held up in the invisible rays emitted by a pinch of chloride of radium. So do fluorspar, calcium sulphide, barium platino-cyanide, and many others. So powerful is the phosphorescence caused by Becquerel rays that if a tube of radium bromide be held to the forehead, and the experimenter close his eyes, he will still see light. The retina itself becomes phosphorescent. 
They even strike backward upon the radium substance itself, so that it, too, becomes luminous, and shines vividly with a light which, since the discovery of radium, has shown no shadow of variableness. Becquerel rays by means of this self-phosphorescence will photograph the radium which emits them. Fig. $28(a)$ is a picture of some radium chloride photographed by daylight, and Fig. $28(b)$ shows the same radium chloride photographed in the dark by its own light -a life-size portrait of the first radium chloride in the world executed by itself. They seem strange things, then, these

Fig. $28(a)$. Radium chloride photographed by daylight, by M. Curie.

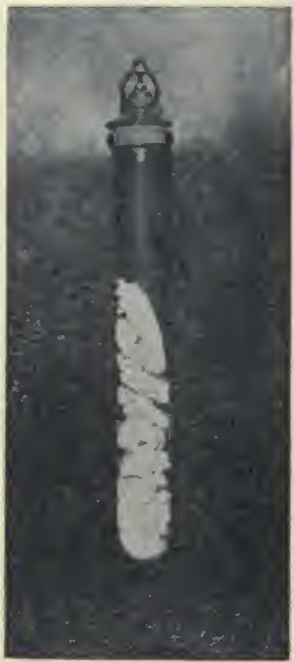

Fig. $28(b)$. Radium chloride photographed in dark by the light of its own phosphorescence.

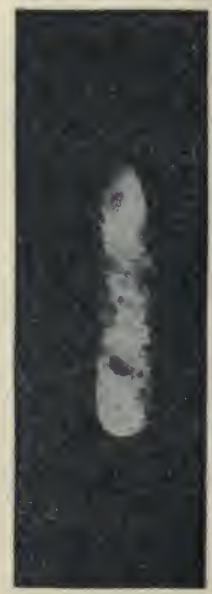

[To obtain the wonderful photographs shown in Fig. 28 ( $a$ and $b$ ), less than $\frac{3}{100}$ of a gram of c..emically pure radium chloride was utilized by $M$. Curie. The value of a gram of radium would be $\$ 10,000$ or more. Less than a gram exists.]

Becquerel rays from radium and yet strange as they are, in this power of causing phosphorescence in bodies which they strike, they exactly resemble the corpuscles of cathode rays, page 69 , Part III. 


\section{PHYSIOLOGICAL EFFECT.}

The physiological effect of Becquerel rays from radium is most intense-almost incredible. A pinch of radium salt, contained in a sealed glass tube was placed in a cardboard box, which was then tied to the sleeve of Professor Curie for an hour and a half. An intense inflammation resulted, followed by a suppurating sore which took more than three months to heal. Professor Becquerel, as he went about his work one day, chanced to carry a sealed glass tube of radium salt in his pocket, placed there for convenience. He was sorry, for the sore was painful and most tedious in healing. Becquerel rays from radium will cause paralysis in mice and caterpillars subjected to their action, and diluted to a sufficient degree bid fair to exercise a decidedly curative effect upon human ills. In their physiological action they resemble markedly the X-rays of Röntgen.

\section{ELECTRICAL EFFECTS.}

Photographic plates and electrified bodies are widely different. Yet Becquerel discovered at about the same time that they were both affected by his rays. A photographic plate was blackened; an electrifiel body was discharged; either was a detector of radio-activity. With the discovery of radium, the discharging effect became, of course, exceedingly apparent. Fig. $29(a)$ is an electroscope with its little gold leaves spread apart by electrification. On the approach of a glass tube con-

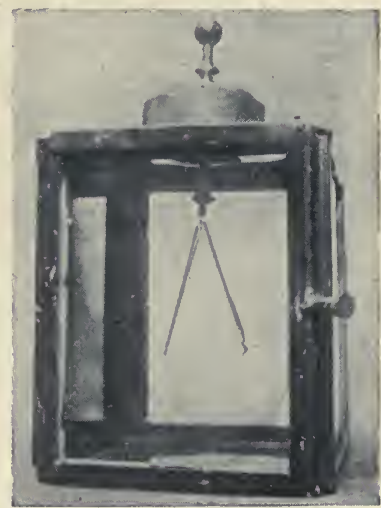

Fig. $29(a)$. 
taining a tiny amount of radium chloride, the leaves at once collapse through the discharge of their electrification, Fig. $29(b)$. The approach of radium and the discharge

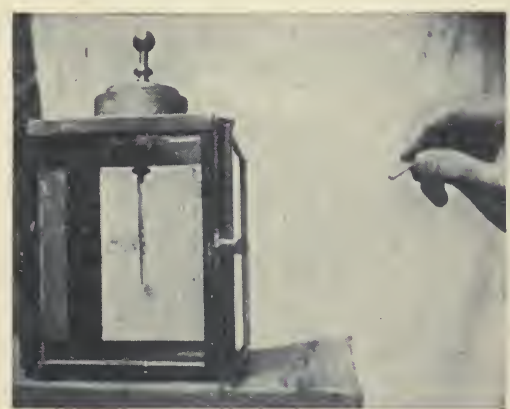

Fig. $29(b)$. of the leaves are simultaneous. Investigation showed that the effect was due to the fact that the rays emitted by the radium spontaneously rendered the air a conductor of electricity, and naturally the electrification of the leaves flew away with as much ease as if they had been touched by a copper wire. As a matter of fact, an electrified body is a more sensitive detector of radio-activity than a photographic plate. In this property of discharging electrified bodies the Becquerel rays are identical with positive ions, corpuscles and X-rays.

\section{CHEMICAL EFFECT.}

Becquerel rays cause chemical action. Emitted from radium they will discolour paper, cause glass to take a violet tint, turn oxygen into ozone, yellow phosphorus into red 7 phosphorus, mercury perchloride into calomel and will decompose iodoform. In the power of causing chemical action, they resemble both the corpuscles in cathode rays and X-rays.

\section{THE SECRET OF THE BECQUEREL RAYS.}

We have learned how Becquerel discovered his rays, we have studied some of their properties, and we are now face to face with the problem, most important of all. What are they? 
In their study so far, we have discovered no property not shared by the positive ions, corpuscles or X-rays emitted by candle flames, hot wires or Crooks' tubes as elucidated in Part III. Can it be that Becquerel rays are identical with these bodies? And if so, which? Fortunately they have one more strange property which Becquerel discovered them to possess, and which, as it turns out, affords a master key to their nature.

\section{BECQUEREL RAYS ARE BENT BY A MAGNET.}

Becquerel proved this by one of his characteristic fecund, - simple experiments. Taking a narrow photographic plate enveloped in black paper, he placed it horizontally between the poles of a powerful electromagnet (Fig. 30). On the black envelope of the plate he then placed a little lead trough containing a small amount of the radium compound. The rays could thus

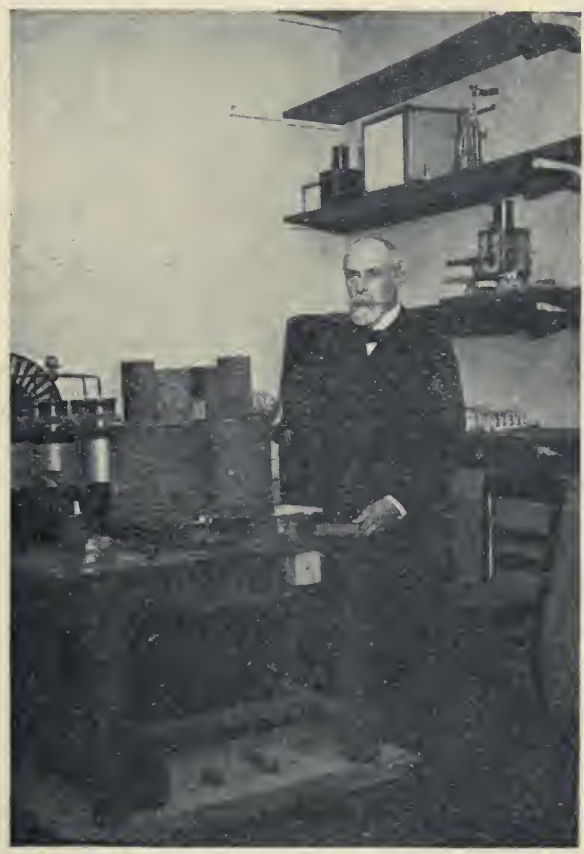

Fig. 30. M. Becquerel and the experiment with the magnet.

affect the plate only by bending over, for the lead is opaque. He energized the magnet; then after a certain time, he re- 
versed the polarity, thinking that, if the rays bent at all, they would bend in the opposite direction. Fig. 31 is the

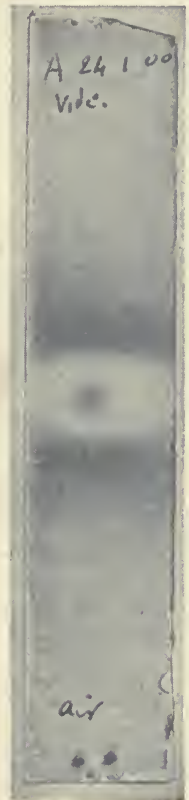

Fig. 31 .

The magnetic deviation of B e c querel Rays. answer-clear as sunlight. The plate shows two broad bands, proving that the rays must have been curved down to meet it; that there are two bands instead of one proves that reversing the polarity causes the rays to bend in the opposite direction. Becquerel rays are deviable by a magnet. But are they all equally deviable? Are they homogeneous? Upon another plate of the same kind he placed strips of platinum, aluminum and paper, and at the end of the plate, as before, the little lead trough containing the radium compound. If they were all equally deviable, they would form a line when they bent to meet the plate; if not, they would form a band. After energizing the magnet and developing the plate, he obtained the result shown in Fig. 32. The rays are not equally deviable ; they form a broad band, a veritable spectrum, of an infinity of rays unequally deviable. The same plate shows as well that the rays penetrate the screens in this order: the platinum least, the

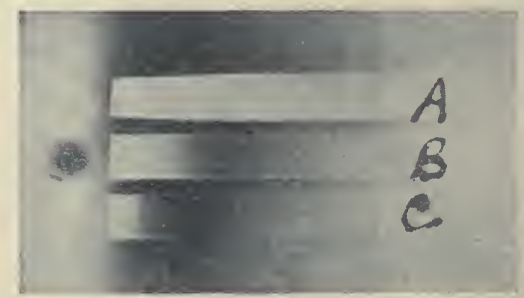

Fig. 32. Radiograph showing how the power of the rays to penetrate matter depends on the density. The strips $A, B$ and $C$ are platinum, aluminum and paper respectively. It is easy to see that the platinum is penetrated least. aluminum next, and the paper most of all. Are they all 
deviable? Is it not possible that some of them are totally unaffected by the magnet, and do not bend at all? To find out, why not place the narrow photographic plate vertically, instead of horizontally, between the poles of the magnet. The idea was carried out, and the result is plain beyond all question. The Becquerel rays consist of at least two kinds of radiation. One kind, $A$ (Fig. 33 ), is bent by the magnet;

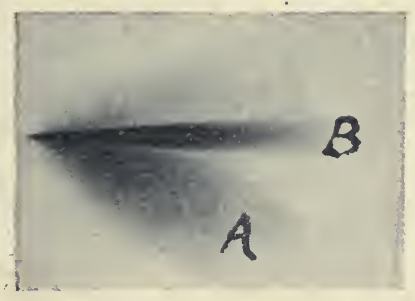

Fig. 33.

the other, $B$, is apparently unaffected by it, and passes undeviatingly on. The print (Fig. 34) taken under the mag-

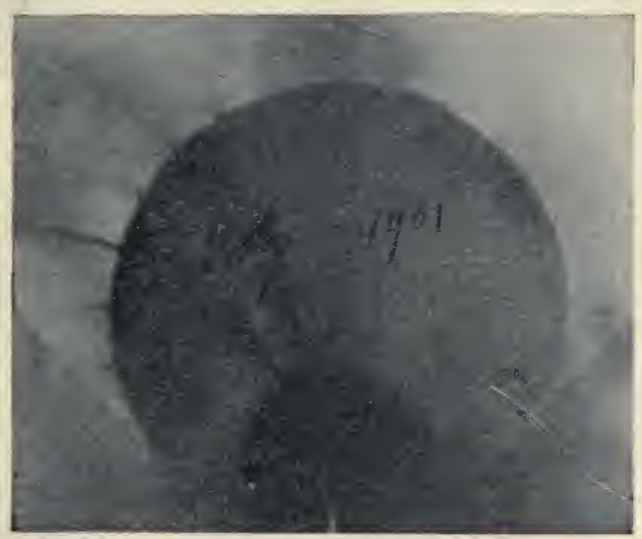

Fig. 34 .

net, shows still more clearly the existence of two distinct kinds of radiation. With these two kinds of radiation 
science for a time remained content, and, indeed, in error; for, as it turned out, Professor Rutherford was finally able to show that, by the application of magnetic forces transcendently strong, part of the so-called undeviable beam could, as a matter of fact, be to a slight extent deviated but in the opposite direction from the deviable portion already known, while the other part remained still absolutely undeviable. Furthermore, it turned out that this truly undeviable portion of the beam of rays possessed a penetrative power to an extent simply extraordinary, producing an appreciable effect . on a photographic plate through a foot thickness of solid iron! By means of the magnetic effect we have thus been able to analyze the Becquerel rays from radium into three distinct types or kinds of radiation:

(1) Rays that have very little penetrative power and are only slightly bent by the strongest magnetic forces obtainable. These are known as the alpha-rays.

(2) Rays that are very penetrating in character and are easily bent by weak magnetic forces in a direction opposite to that of the alpha-rays. Those rays are known as the beta-rays.

(3) Rays that are absolutely undeviable by the strongest magnetic force obtainable and have an unexampled power of penetrating matter generally considered opaque. These are the gamma-rays.

All these three types of rays, it must be remembered are continuously given off by radium compounds in their natural condition without any diminution whatever so far as has yet been detected. We have now all the data necessary for answering with a reasonable degree of confidence the question: What are the alpha-, the beta- and the gamma-rays from radium? 


\section{CHAPTER VI.}

\section{The Alpha-, Beta- and Gamma-rays.}

\section{THE ALPHA-RAYS.}

The secret of the alpha-rays drops into our hands as soon as we compare them in their properties with the positive ions of Part III. The positive ions, as we learned, were tiny bodies laden with positive electrification flying off, under certain conditions, from gas flames, red-hot metals and other bodies. We learned that their velocities were anywhere from ten to twenty thousand miles a second, that their mass was about twice that of a hydrogen atom and that on the application of intense magnetic force they could be slightly bent or deviated. Now the alpha-rays from radium have properties identical with those stated above. They are the positive ions, but instead of requiring high temperatures or other exceptional conditions for their existence they fly off from the substance radium in its natural normal state. On the basis of all the evidence necessary to convince a reasonable man, the alpha-rays from radium are streams of little bodies with a mass about twice the mass of the hydrogen atom flying off from radium and laden with positive electricity. Their velocity is about 20,000 miles a second! Compare this velocity with that of the swiftest projectile that man can fire from a gun. A rifle bullet travels with a velocity of about half a mile a second, and we consider this speed of transit extreme, but these projected atoms have a velocity 40,000 times greater. Now the energy of any moving body increases as the square of 
its velocity (Energy $\frac{\mathrm{m} \mathrm{v}^{2}}{2}$ ); and hence the energy carried off from radium by these little flying bullets is almost incredibly large compared with their mass. As Professor Rutherford says: "If it were possible to give an equal velocity to an iron cannon ball, the heat generated by the impact on a target would be many thousand times more than sufficient to melt the cannon ball and dissipate it into vapour." This is the conclusion of mathematical reasoning, but no amount of reasoning is half so demonstrative to the average mind as the sight of a fragment of radium at work. We have stated that the mere presence of radium will cause certain substances in the neighbourhood to phosphoresce or to light up with a glow. Now among the substances affectable by radium there is one, zinc sulphide, which answers

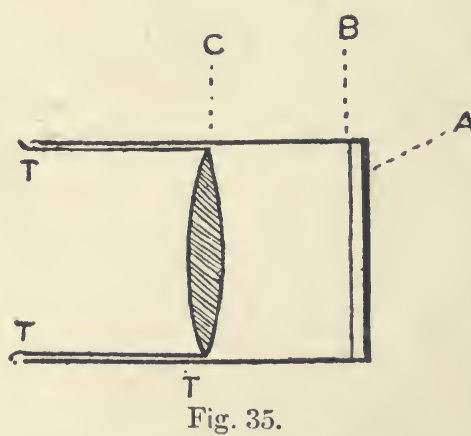

Section of Crookes' Spinthariscope. $\mathrm{T}$ - The outer containing tube.

$\mathrm{T}, \mathrm{T}$ - The sliding tube, for focussing. A-The screen, coated inside with blende.

B-The wire supporting the speck a tube containing a magniof radium salt.

C-The magnifying lens.

to the bombardment of the alpha-rays alone. This property has been utilized by Sir William Crookes in the construction of a little instrument which he has called a sphinthariscope, which shows beautifully the bombardment of the alpharays. This instrument consists of a small fragment of radium placed behind a zinc sulphide screen, which is viewed in the dark through fying eyepiece (Fig. 35). At once one sees a thousand tiny flashes of light, for the spark of each atomic projectile as 
it strikes the zinc sulphide target is at once made visible to the eye. The appearance is that of a swamp full of fireflies, or the scintillating stars on a clear night. And when one remembers that these flashes of light are caused by a rain of projectiles, each impact being marked by a flash of light, just as sparks fly off from iron when it is struck by a hammer, and, moreover, that this rain of projectiles is incessant, day in and day out, year in and year out, the wonder becomes most impressive that the radium should not soon dissipate itself by this continuous projection of matter. The number of atoms, however, in the small mass of radium is so enormous that the process will probably continue several hundred years before an appreciable part of the radium has disappeared. Becquerel has recently brought forward evidence to show that the light-flashes observed are due to cleavages produced in the zinc sulphide crystals by the impact of the alpha particles.

\section{THE BETA-RAYS.}

These have been the most widely studied of the rays from radium, owing to their great penetrating power and their action in exciting phosphorescence in bodies which they strike. It is hardly necessary to tell the reader, formally, what they are. Suppose we construct a table of comparison between the beta-rays from radium and the corpuscles from candle flames and hot metals. Let us make X equal the possession of any one specific property possessed by both in equal decree. 
Comparison between Beta-rays and Corpuscles.

Property.
They are negatively electrified particles.
Velocity.
The same electrical charge as a hydrogen
atom.
They have a mass equal to one one-thou-
sandth of a hydrogen atom.

They discharge electrified bodies.

They are deflected by a magnet in the opposite direction from the alpha-rays and positive ions.

They are deflected by an electrostatic force.

They cause phosphorescence in bodies which they strike.

They give rise to heat in bodies which they strike.

They communicate mechanical motion to bodies which they strike.

They give rise to $\mathrm{X}$-rays in bodies which they strike.

They are absorbed by all bodies in direct proportion to their density.

They act as nuclei about which atoms and molecules collect.

\begin{tabular}{|c|c}
\hline Beta-rays. & Corpuscles. \\
\hline $\mathrm{X}$ & $\mathrm{X}$ \\
\hline $\begin{array}{c}150,000 \text { miles } \\
\text { per second }\end{array}$ & \begin{tabular}{c}
$\frac{90,000 \text { to }}{\text { per second. }}$ \\
\hline $\mathrm{X}$
\end{tabular} \\
\hline $\mathrm{X}$ & $\mathrm{X}$ \\
\hline $\mathrm{X}$ & $\mathrm{X}$ \\
\hline $\mathrm{X}$ & $\mathrm{X}$ \\
\hline $\mathrm{X}$ & $\mathrm{X}$ \\
\hline $\mathrm{X}$ & $\mathrm{X}$ \\
\hline $\mathrm{X}$ & $\mathrm{X}$ \\
\hline $\mathrm{X}$ & $\mathrm{X}$ \\
\hline $\mathrm{X}$
\end{tabular}

We see from the table above that the one and only difference between the corpuscles of candle flames and Crooke's 
tubes, and the beta-rays from radium is one of velocity. The beta-rays fly faster, for they reach the enormous average velocity of more than one hundred thousand miles a second. We have here, not an analogy nor a similarity, but an identity. The beta-rays from radium are corpuscles, for they possess the same properties and in the same degree within the limits of experimental error. What a wonder, then, have we here; an innocent looking little pinch of white salt not so different in its general properties from ordinary table salt and yet possessed of special properties utterly beyond even the fanciful imaginings of men of past time; for nowhere do we find in the records of thought even the hint of the possibility of things which we now regard as established fact. This pinch of salt projects from its surface bodies possessing the inconceivable velocity of over 100,000 miles a second, a velocity sufficient to carry them, if unimpeded, five times around the earth in a second, and possessing with this velocity masses a thousand times smaller than the smallest atom known to science. Furthermore, they are charged with negative electricity; they pass straight through bodies considered opaque with a sublime indifference to the properties of the body, with the exception of its mere density; they cause bodies which they strike to shine out in the dark; they affect a phototgraphic plate; they render the air a conductor of electricity; they cause clouds in moist air; they cause chemical action and have a peculiar physiological action. Who, to-day, shall predict the ultimate service to humanity of the beta-rays from radium!

\section{THE GAMMA-RAYS.}

The gamma-rays from radium are still to a certain extent a mystery. Unlike the alpha- and the beta-rays they cannot be bent by a magnet, and their most remarkable prop- 
erty consists apparently in their power of penetrating matter generally considered opaqua. They will pass through a foot of solid iron or through several inches of metallic lead. They seem to be neutral electrically, and they are seemingly the agent chiefly concerned in the physiological action of radium. They also affect a photographic plate. They appear to be X-rays, or at least some type of X-rays. In our study of the properties of corpuscles (Part III) we learned that whenever corpuscles of a Crookes' tube struck against a metal plate or the walls of the glass containing vessel, $\mathrm{X}$-rays were developed; and that, in fact, an ordinary X-ray bulb was nothing but a tube in which corpuscles were generated. If the beta-rays from radium are in solid truth the corpuscles of Part III, it is natural to expect that they should generate X-rays in their back-stroke as they left the radium, and consequently it should be no matter of surprise to find in the gammarays nothing but $\mathrm{X}$-rays as a natural accompaniment to the corpuscles. While the gamma-rays are, therefore, in their nature probably nothing but $\mathrm{X}$-rays it is at this time not positively certain. Of course, the identity of the gammarays with $\mathrm{X}$-rays does not tell us what the gamma-rays are in themselves unless we know the nature of the $\mathrm{X}$-rays, and in the $\mathrm{X}$-rays we have still, more or less, a mystery. $\mathrm{X}$ is an unknown quantity. It is probable that they are not a form of matter, that is, that they are not particles at all, but more in the nature of pulses or waves in the surrounding ether set up by the impact of the corpuscles or beta-rays. It is natural and, indeed, inevitable that the vibrations of corpuscles should disturb the surrounding ether into waves just as shaking a stick in water must set up water waves, or as the grosser atoms of matter set up the etherial waves of heat and light And it is also natu- 
ral enough that these waves set up by corpuscular vibrations should be very different in properties from those arising from the vibration of grosser atoms. It is probable that the $\mathrm{X}$-rays are due to ethereal vibration, not material particles, and that the gamma-rays from radium are $\mathrm{X}$-rays.

We have thus found in the alpha-, beta- and gamma-rays from radium the positive ions, corpuscles and X-rays of Part III, their natural progenitors in the history of discovery. "What an anti-climax," says the reader. "We started out to study a new property of matter, and here we end up with an old one." Not a bit of it. We called the new property of matter radio-activity-not Becquerel rays. "What is the difference?" All the difference between a natural intrinsic property and a property of condition. The light of an arc-lamp is a property of condition; suppose you found, deep in the earth, some natural substance blazing forever with a light as great, that would be a natural intrinsic property - and a very curious one-radioactivity. So with the positive ions, the corpuscles and the X-rays of Part III. They arise from candle flames, red-hot metals, or electrified vacuum tubes, all of them substances or mechanisms under very special conditions. The Becquerel rays from radium, on the contrary, arise from a substance dug out of the ground which will emit them, apparently, for centuries in the future as it has emitted them apparently through the countless centuries of the past, without any extrinsic influence. It is their natural intrinsic property-a new property of matterradio-activity.

Part III taught us the existence, under special conditions, of bodies a thousand times smaller than the smallest atom. Part IV, so far, has taught us the natural emission of such particles from a substance in its normal state. 


\section{CHAPTER VII.}

\section{Emanations.}

Having thus analyzed the rays from radium into three different kinds apparently identical with the positive ions, corpuscles and $\mathrm{X}$-rays, it may seem to the reader that we have now explained the whole mystery of radium in terms of what we already know. But this is far from being the case. The mystery of radium is still a mystery as beautiful and fascinating as ever. Let us now consider one more remarkable property of radium which opens up a new world of wonders. Professor and Madame Curie have discovered that any substance placed near radium becomes itself a false radium. "We have found," say the Curies, "that any substance placed in the neighbourhood of radium acquires a radio-activity which persists for many hours, and even days, after the removal of the radium. This induced radio-activity increases with the time during which it is exposed to the action of the radium up to a certain Jimit. After the radium is removed, it decreases rapidly, and tends to disappear. The kind of substance exposed to the action of the radium is almost a matter of indifference. They all acquire a radio-activity of their own." This fact has been verified over and over again by every experimenter in the field. The zinc, iron and lead fittings, the air of the laboratory, the water, the clothing of the workers, their very persons, in the presence of radium, start into activity and give out rays comparable to radium in affecting a photographic plate and discharging electricity. This becomes (112) 
very vexatious and disconcerting and extreme care is necessary to prevent the radium giving out rays altogether misdirected. For days Professor Curie was unable to approach his electrometers or even to enter his laboratory, owing to his acquired raciio-activity. These secondary radiations, in the case of zinc, were four times as intense as ordinary uranium. Moreover, this acquired radio-activity cannot be removed by washing. It must be remembered, however, that the radio-activity is only temporary. It vanishes sooner or later upon the removal from the neighbourhood of the potent radium. Fig. 36 is a photograph taken in

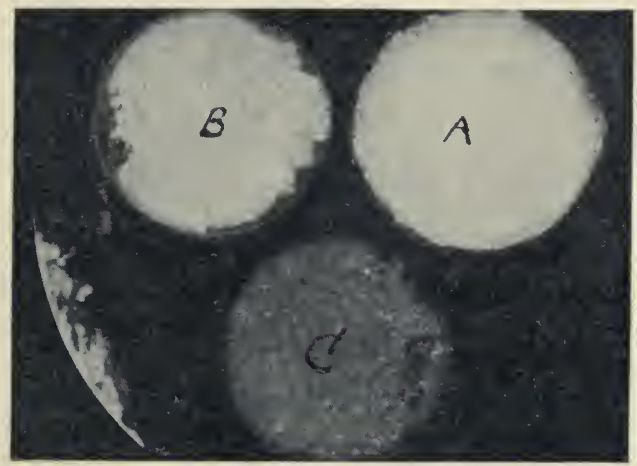

Fig. 36. Phosphorescence induced by induced radio-activity.

Professor Curie's laboratory, of phosphorescent action caused by these induced secondary radiations. It was obtained in the following way: Two samples of zine sulphide, $A$ and $B$, and a sample of a salt of uranium, $C$, were placed in cardboard pill-boxes, and these were laid on a metallic plate, under which was the radium chloride. The metallic plate was quite thick enough to be opaque to the Becquerel rays, but under their influence it gave off secondary radiations which caused the salts within the pill-boxes to phos- 
phoresce. The photographs were taken from above. They were caused by the induced light of induced radio-activity. We have used the word "induced" here as descriptive of this secondary or acquired radio-activity because it was at first Professor Curie's opinion, as it was nearly everybody's else, that bodies in the neighbourhood acquired this temporary and secondary radio-activity because of the mere presence of the radium, in the same way that iron filings become magnetic in the presence of a magnet or as the induced electric currents arise in an induction coil. Some facts, however, soon became apparent, that have altered completely this conception of the nature of the acquired radio-activity. For example, Professor and Madame Curie performed the following experiment: Two small flasks were connected together by a lateral tube fused into their necks (Fig. 37), and having a stop-cock in the

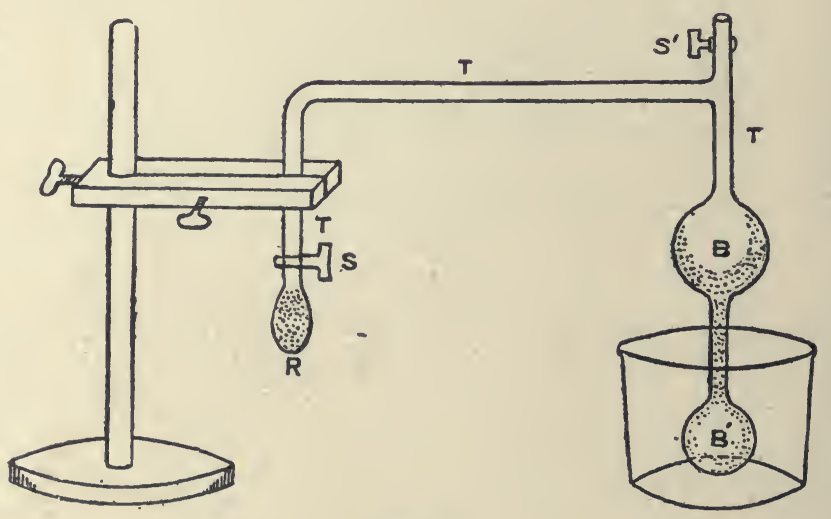

Fig. 37.

tube joining them; the cock being closed, a solution of the radio-active substance was passed into one of the flasks, while a gelatinous white precipitate of sulphide of zinc, 
which it is to be remembered, is phosphorescent to the action of radium rays, was placed in the other flask; then both flasks were closed. So long as the cock between the flasks remains closed, nothing is visible in the dark; but the instant it is opened, the sulphide of zinc becomes brilliantly phosphorescent and continues so as long as the tube connecting the flasks remains open. Now we cannot believe that either the alpha-, the beta- or the gamma-rays from radium have the power to pass around a corner as they would necessarily do in order to pass from flask to flask to cause the zinc sulphide to phosphoresce. In fact we know they do not, and hence we must believe, for there is no other way out of it, that a something more or less in the nature of a gas, and not these rays at all, must pass from flask to flask; and since, moreover, this something causes the zinc sulphide to shine in the dark, we must also believe that it is radio-active. Now this radio-active something which passes out of radium and which is a something distinct and apart from the rays themselves has been called an emanation. It is called an emanation rather than a gas because Rutherford, its original discoverer, was not sure that it was a gas. It is apparently the cause of this induced radio-activity acquired by all bodies in the neighbourhood of radium, for spreading out from the radium it settles on surrounding objects and renders them radio-active. Having settled, then, the fact of a radioactive something spreading out from radium independent of the straight line radiations of the alpha-, beta- and gamma-rays, it is of extreme importance to find out what it is. Here, then, are some experiments, which one after another elucidates, to some extent, the nature of the emanation.

First, let us remember that whether it is a gas or not, it 
acts like one in continuously diffusing into the surrounding air and that, moreover, by passing a current of air over the radium it may be carried away like an ordinary gas, and that the air so permeated by it continues to give off rays long after its passage over the radium. Next it became obvious that the amount of emanation given off by it in the solid cold state was insignificant compared to the veritable rush emitted on heating the radium salt or on dissolving it in water. This also is quite in accord with the supposition that it is a gas of some kind occluded or hidden away in the radium. This latter method, that of solution, is the best method of obtaining the emanation for purposes of study. A small quantity of radium chloride is dissolved in water and the rush of emanation is collected by bubbling air through the solution and carrying off the air so permeated with the emanation into an ordinary gas-holder, where it will light up a screen of phosphorescent zinc sulphide for days and will show some radio-activity even after the lapse of a month. On passing this ray-emitting air containing the emanation from the gas-holder over platinum, palladium, zinc, magnesium and lead chromate, all at an intense red heat, it was found impossible to alter the ray-emitting power to any sensible degree. The ray-emitting power of the emanated air is absolutely conserved. No ordinary gas could withstand the action of the powerful reagents specified above and hence we are obliged to assume that if it is a gas, and it seems to be, the emanation must belong to that interesting family of inert gases discovered by Raylaigh and Ramsay in the atmosphere, which are known as helium, neon, argon, krypton and xenon and which the reader will find tabulated in the zero group of the periodic law and discussed in Part II. The probability that the emanation is an actual gas is greatly emphasized by the fact that it 
may be condensed from the air with which it is mixed by the action of extreme cold. The radium emanation condenses on the glass walls of the vessels into a brilliant patch of phosphorescent light at 150 degrees below zero, Centigrade. If, therefore, it behaves in all these respects like an ordinary gas the reader may wonder why it should not be definitely called a gas, but the difficulty of it is that the emanation exists in so minute a quantity that it has not yet been brought within the range of the spectroscope or the balance. The emanation has been -detected, and investigated by the electroscope [Figs. $38(a)$ and $38(b)$ ], which

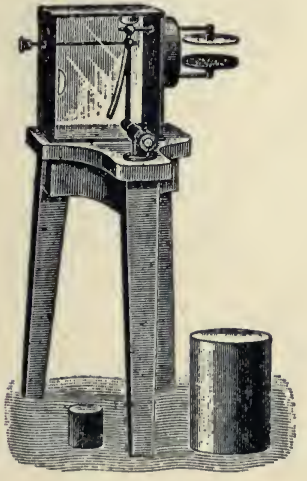

Fig. $38(a)$.

Curie's Electroscope for the study of radio-activity.

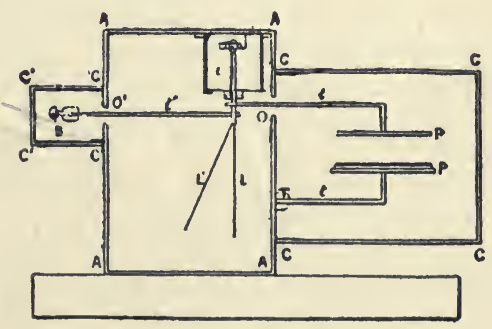

Fig. $38(b)$.

Diagrammatic representation of

Fig. $38(a)$.

An electroscope will detect one one-millionth of a millionth of a milligram.

measures the radium rays by the power to discharge its electrified gold leaves. The electroscope is about a mil- For son lion times more sensitive than the most sensitive spectroscope and yet the spectroscope is capable of detecting easily the millionth part of a milligram of matter. So it is that history repeats itself. The spectroscope, when placed new 
in the hands of science, revealed the existence of several elements occurring in quantities too small to be detected by any other means. In a similar way additional elements have now been detected and isolated by this more powerful instrument, the electroscope, which for years has been the toy of every high school laboratory. There is every probability that when greater quantities of radium are at the disposal of the investigator the radium emanation will be collected in quantity sufficient to demonstrate clearly its spectrum as an element and its vapour pressure as a gas. The amount of energy radiated by the emanation is almost incredibly large compared with the small amount of matter involved. We have said that the emanation from a grain or two of radium chloride when liberated by solution is capable of illuminating brightly a screen of phosphorescent zinc sulphide for days at a time, and yet this rapid emission of energy arises from a quantity of gaseous matter hundreds of thousands of times beyond the power of the most delicate balance to detect. Professor Rutherford has calculated that if a thimbleful of this active gas could be collected the bombardment of its powerful rays would heat to a red heat, if it would not melt down, the walls of the glass tube containing it! This remarkable fact leads naturally to two very important questions:

(1) What is the nature of the rays emitted by the emanation? Are they alpha-, beta- or gamma-rays; or, to use the terminology of Part III, are they positive ions as big as atoms, corpuscles a thousand times smaller than atoms, or $\mathrm{X}$-rays?

(2) What becomes of the radium from which the emanation has been removed, the de-emanated radium? Has it lost any of its radio-activity, what kind of rays does it still emit? 
For the first question the answer is ready. The emanation emits only alpha-rays, bodies positively electrified as big as atoms.

For the second question, the answer is also ready. The radium from which the emanation has been extracted has lost about seventy-five per cent. of its activity, and the rays which it does still emit after the lapse of an hour or so are, again, only alpha-rays. Leaving for the present the question as to what becomes of the beta- and gamma-rays, we are now face to face with possibly the most remarkable, the most interesting and the most illuminating fact in connection with all this strange eventful history of the nature of radium. We have said that the emanation abstracted from the radium retained its ray-emitting power for some time. The obvious inference is that it eventually loses its power completely. It does. We have also said that the radium from which the emanation has been abstracted, after the lapse of an hour or so, loses seventy-five-per cent. of its activity. This also is true. But wait a month, and the most remarkable fact crops out that the radium, during the interval, has restored all its lost emanation and has fully regained its activity. The interesting phase of the fact lies in the further discovery that the emanation abstracted from the radium loses its radio-activity at the same rate and according to the same laws as the de-emanated radium regains it. A perfectly clear demonstration of this is given in the diagram (Fig. 39), in which the curve A represents the actual rate of recovery of the radium activity and curve $B$ the rate of decay of the radium emanation. The illuminating phase of the fact lies in its inferences. If, as is apparently the case, the radium is constantly generating and storing the emanation and the emanation as constantly decaying, the activity of the radium at any one time is due to a balance between the decaying 
and restoring processes; and since, moreover, these processes are wholly outside the sphere of known controllable forces, and cannot be created, altered or destroyed - since the process is independent of the chemical form of the radium, whether bromide, chloride, sulphate, etc.,-we are absolutely shut up to the conviction that it is a function of its atom. We are in the presence of a veritable decay of the atom. The atom of radium breaks down into atoms of emanation and

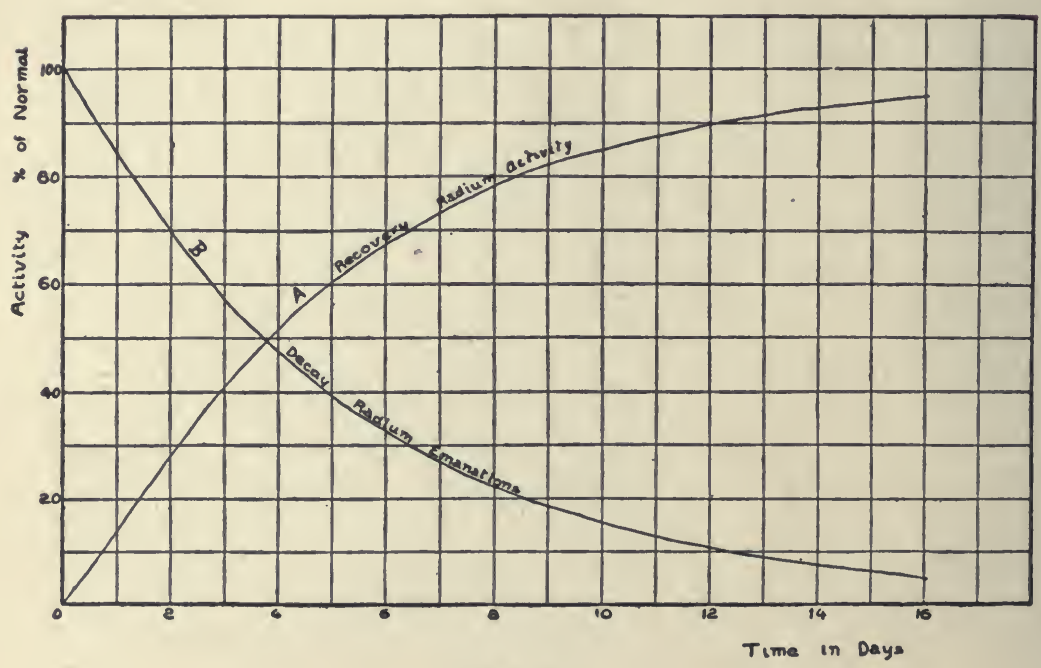

Fig. 39 .

the atoms of emanation in their turn break down into something else. The activity of the emanation decays in accordance with the curve given in Fig. 39, and falls to half value in about 3.7 days. This has rendered it possible to calculate that there should be 463,000 times as much emanation stored in the solid as is formed per second. Now, on dissolving the radium in water all this emanation should be spontaneously emitted in a rush, and this rush of emanation 
can be measured by an electroscope and the figures stated above put to the test. This was done, and it was discovered as a matter of fact that the amount of emanation stored in the solid was 477,000 times greater than the amount afterwards developed per second. The agreement between theory and experiment is remarkable and the experiment shows just how accurately it is possible to predict the results of experiments in radio-activity. 


\section{CHAPTER VIII.}

Emanation $\mathrm{X}$ and the Birth of Helium.

In addition to the power of giving off the alpha-rays or positive ions possessed by the emanation, it has the additional very remarkable property of exciting activity in any substance with which it comes in contact. This is the induced radio-activity discovered by Curie. This activity of surrounding objects not otherwise radio-active is due to the fact that the emanation in decaying breaks down into a third invisible and unweighable radio-active body which deposits itself upon neighbouring bodies and which, apparently, is in the nature of a solid. Surrounding objects thus become radio-active. This "excited" activity, since it is evolved from and results in the decay of the emanation has been called emanation $\mathrm{X}$. The emanation $\mathrm{X}$ has definite chemical properties for it can be dissolved in some acids and not in others. If the acid in which the emanation $\mathrm{X}$ is dissolved be evaporated it is left behind on the dish and its radio-activity is unimpaired. It has recently been discovered that this emanation $\mathrm{X}$ may be volatilized at a white heat and re-deposited on cold bodies in the neighbourhood, making them radio-active. It is not the emanation for the rate of decay of its activity is markedly different from the rate of decay of the emanation. It is a second form of active matter generated from radium via the emanation. It is this form of matter that gives rise to the betaand gamma-rays which are emitted from the solid radium compound and which we failed to find either in the emana- 
tion or in the radium from which the emanation had been removed. The emanation $\mathrm{X}$ emits alpha-rays as well, and it is therefore probable that it, in its turn, breaks down into two other forms giving rise to the beta- and gamma-rays respectively, but we have now reached the last link in the chain of consequences which result from the decay of radium. The instruments of the physicist, refined though they are, refuse to take him farther. The radio-activity of radium may be explained to this extent. The solid radium compound is continuously giving off energy, in the form of alpha-, beta- and gamma-rays. Of this energy 25 per cent. belongs to the radium itself, consists of alpharays, and may not be removed. Of the remaining 75 per cent. 18 per cent. belongs to the emanation proper and consists also of alpha-rays; while the residue of the energy, 57 per cent., belongs to the emanation $\mathrm{X}$, and the final products and consists of all three types of rays. To the emanation $\mathrm{X}$ the solid active body produced by the emanation and capable of settling on other bodies the major part of the energy from radium must thus be ascribed. In a solid radium compound, therefore, all three bodies, the regenerating radium, the decaying emanation gas and the solid emanation $\mathrm{X}$ exist together; and the total activity of the radium is due at any one instant to a balance between the qualities and activities of the three bodies therein contained. A question must now suggest itself to the reader. What is the end of this chain of consequences? What is the final product formed in the decay of radium? Surely some evidence of it must exist. Now, some twenty-five years ago, Sir Norman Lockyer discovered that there exists in enormous quantities in the atmosphere of the sun a certain element which, because it was not then known on earth, was named after its habitat-helium, or the sun element. Twenty 
years after its discovery on the sun it was identified by Sir William Ramsay as a constituent of certain minerals in the earth's surface. Its discovery both in the sun and in the earth depends upon the fact that the element has a peculiar characteristic spectrum (Fig. 40). It turned out to belong to the Argon series of elements, those elements which the reader will find tabulated in the zero group of the periodic law (page 28), and which are all alike in the fact that they are gases incapable of entering into chemical combination and in this respect are different from all other elements. It is a very remarkable fact that this gas, helium, as found on earth is always associated with radio-active minerals; and it soon occurred to many minds that possibly it was a product of the atomic disintegration of the radium. A few months ago this was the merest speculation but now, thanks to the rapid progress of science, it looks as though it were a veritable.fact. The discovery arose in the following way: Sir William Ramsay and Mr. Soddy in the summer of 1903, were examining. with the spectroscope the air which had been bubbled through a solution of radium bromide in order to find whether or not it was possible to discover any traces of a spectrum of the emanation, which, the reader will remember, is obtained in that way. They did discover some bright lines which they ascribed to the emanation, but after standing for some time the spectrum of helium made its appearance and increased in brightness for several days. This indicates that the helium is produced from the emanation; that is to say that helium is a disintegration product of the radium emanation. It is possible that the helium consists of the alpha-rays or positively electrified particles given out by the emanation. The fact that the mass of the alpha particle is about twice that of the hydrogen atom bears out that idea, for the helium atom is next 
7. to hydrogen to lightness. However that may be, if, as seems to be the case, helium is produced from the radium decomposition, the world, in this experiment, has witnessed the greatest triumph of modern science-no more nor less than the transmutation of matier. The dream of the alNOT chemists is, true. Whether helium is the final product of the radium disintegration, or a by-product from the emanation, is to-day unknown.

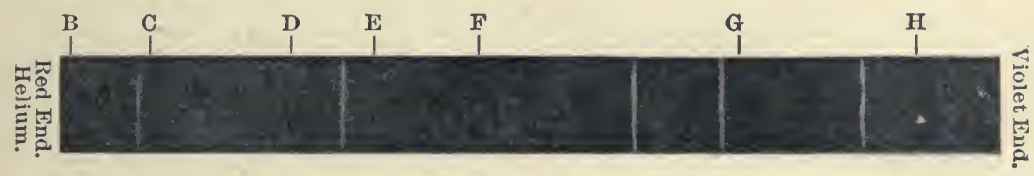

Fig. 40. The five characteristic bright lines of the spectrum of helium.

We may now sum up the series of radio-active changes in radium by the following tabulation, remembering that between the emanation $\mathrm{X}$ and the final product there probably exists several intermediate forms, and that somewhere in the chain helium appears.

Radium containing 25 per cent. of non-separable activity in the form of alpha-rays.

Radium emanation containing 18 per cent. of the activity in the form of alpha-rays.

Radium emanation $\mathrm{X}$ containing 57 per cent. of the total activity as alpha-, beta- and gamma-rays.

Final productinactive. is $\angle E A D(P b)$ 


\section{CHAPTER IX.}

\section{Thorium, Uranium, Polonium and Actinium.}

While radium seems, to-day, to be the radio-active element par excellence, radio-activity is not confined to radium. Among the other radio-active elements, thorium is important. Thorium is a comparatively rare element, and is the fundamental constituent of nearly all the Welsbach gas mantles used for lighting. Its radio-activity is exceedingly small compared with that of radium, but small as it is, it is in some respects more interesting even than that of radium. All thorium compounds are radio-active. All thorium compounds give off alpha-, beta- and gammarays-but, after this is said, the resemblance between radium and thorium ceases. The radio-activity of radium remains constant no matter how drastic the treatment to which it is subjected. The radio-activity of thorium is not constant. In fact it has been found possible by chemical processes to separate out nearly all its activity and to concentrate it afterwards into a minute quantity of intensely active matter.

If ammonia is added to a solution of thorium, the thorium is precipitated in the form of a solid and so separated from the water in which it was dissolved. But the water now retains the activity of the thorium and the precipitated thorium has lost it. On evaporating this water solution down to dryness and igniting it, a small residue of intensely active matter remains which turns out, weight for weight, to be over a thousand times more 
active than the thorium from which it was extracted. This small quantity of very active matter has been called by the discover, Rutherford, thorium $\mathrm{X}$. On examining the thorium $\mathrm{X}$ and the precipitated thorium a month later, the astonishing result became evident that the thorium $\mathrm{X}$ had completely lost its activity while the thorium had wholly regained it; furthermore it was discovered that the rate of decay of the thorium $\mathrm{X}$ was exactly equal to the rate of recovery of the thorium. This fact is demonstrated in the diagram (Fig. 41) in which the actual curves

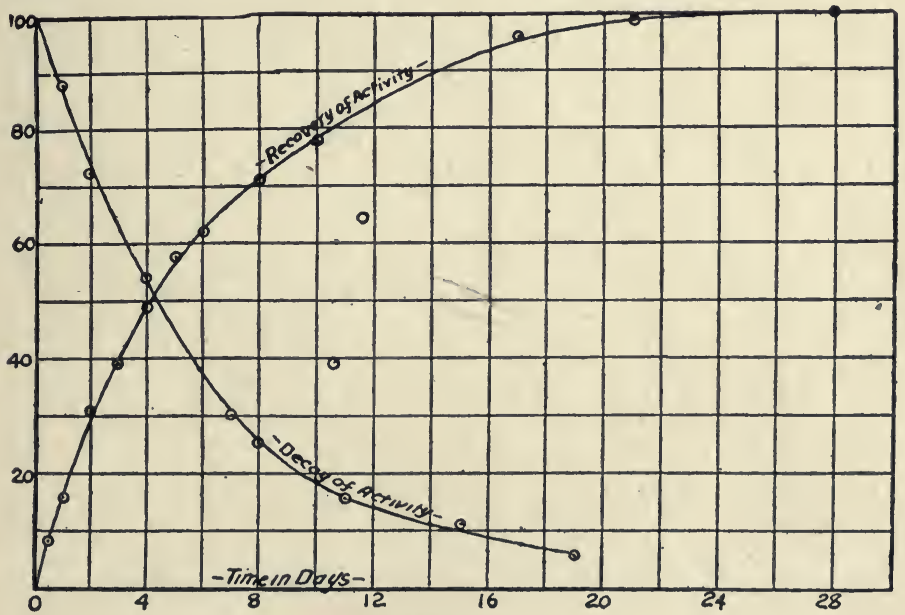

Fig. 41.

of decay and recovery are given. The only conceivable explanation of this fact lies in the somewhat extraordinary proposition that the element thorium is constantly generating from itself another solid element, which decays at the same rate at which it is generated. The radio-activity of thorium is due to a balance between two opposing forces which are: (1) the radio-activity resulting from the manu- 
facture of thorium $X$, and (2) the decay of the activity of the thorium $\mathrm{X}$, so produced. Here again is a transmutation of matter! We are not however at the end of this process of change, for it turns out that this thorium $\mathrm{X}$ in decaying, decays into an emanation similar in character to the emanation from radium but not identical with it. Both the radium and thorium emanation give rise to alpha-rays only, but while the radium emanation condenses on the walls of the glass vessel at 150 degrees below zero Centigrade, the thorium emanation condenses at 120 degrces below; furthermore the activity of the radium emanation decays to half value in 3.7 days, while the thorium emananation from thorium $\mathrm{X}$ decays to half value in one minute. The two emanations are therefore not identical, though they are both unaffected by the most drastic methods of chemistry and seem to belong to the same chemical family. The thorium emanation gives rise to an emanation $\mathrm{X}$ just as in the case of radium. This emanation settles on the walls of the containing vessel apparently with the form of a solid and emits all three radiations, alpha-, beta- and gamma-rays. As with radium emanation, it is soluble in some acids and not in others, but it is no more identical with radium emanation $\mathrm{X}$ than thorium is identical with radium-just as with the two emanations the time rates of decay of activity in the two emanations $\mathrm{X}$ are different.

Finally, as with radium, the thorium emanation $\mathrm{X}$ decays into some end product which does not possess ray-emitting powers and which the instruments of to-day are unable to determine. The main difference between the radio-activity of radium and thorium seems to lie chiefly in a difference in intensity and in the fact that thorium breaks down into a radio-active solid intermediate between the thorium and the. 
thorium emanation. No similiar radium $\mathrm{X}$ has yet been discovered. The radio-activity of a solid thorium salt is then due to the radio-activity of the thorium, the thorium $\mathrm{X}$, the emanation, and the emanation $\mathrm{X}$, all condensed within it.

THE RADIO-ACTIVITY OF URANIUM.

Uranium was the first element discovered to possess radio-activity, the power of continuously emitting penetrating rays. Since radium was extracted from uranium minerals, it was at first imagined that the activity of uranium was due to radium impurity. This was a mistake. The radio-active power of uranium, however, is very small; $1,500,000$ times less than pure radium. It possesses, however, a special interest in the fact of its simplicity. Like thorium, and unlike radium, it continuously gives rise to a solid disintegration product, uranium $\mathrm{X}$, though this differs from thorium $\mathrm{X}$ in emitting beta- instead of alpha-rays. The uranium from which the uranium $\mathrm{X}$ has been extracted emits only alpha-rays. Just as in all radio-active processes, the decay of the activity of the uranium $\mathrm{X}$ and the revival of the activity of the pure uranium take place at the same rate, so 'isut the activity of a uranium compound at any one instant is due to a balance betwecn the opposing forces of decay and restoration. Half of this process of decay and restoration takes place in twenty-two days. Unlike both radium and thorium the uranium $\mathrm{X}$ gives rise to no emanation and consequently to no emanation $\mathrm{X}$. As a result of this fact bodies in the neighbourhood do not become radioactive. The active uranium $\mathrm{X}$ decays, apparently, directly into some inactive product. Uranium has been used to test the constancy of radio-active processes. For over five years the activity of a sample of uranium has been tested at 
intervals of 48 hours and during this interval no perceptible weakening of the radiation has been observed. A variation of one one-hundredth thousandth of its activity would have been apparent-a singular example of the constancy of radio-activity and the powers of radio-active methods.

\section{POLONIUM.}

Polonium was first extracted from the mineral pitchblende by Mde. Curie and named in honour of her native country, Poland. It is chemically a sister to bismuth, from which it has never been satisfactorily separated. A most minute quantity, only, has been obtained for experimentation. Polonium is intensely active but differs from other radio-active elements in giving rise to alpha-rays only. Furthermore, its activity seems to decrease with time, a result quite out of concord with the activity of the other elements.

Prof. Markwald has recently succeeded in extracting what seems to be the same substance by another method. The "polonium" obtained by him is intensely active. A minute trace on the end of a rod will cause a diamond to phosphoresce brightly and, indeed, may be used to distinguish the diamond from imitations. The activity of polonium is so great that an electric bell will ring at its mere approach for it renders the air in its neighbourhood a strong conductor of electricity.. Owing to the minute traces as yet isolated, knowledge of polonium is in a chaotic condition; but since its activity seems greater even than radium it bids fair to be an important factor in future research.

ACTINIUM.

Another radio-active element discovered/in Prof. Curie's laboratory has been called actinium. Chemically it resembles thorium but its activity is many thousands of times 
greater. Like radium and thorium, it gives rise to an intensely active emanation which, however, loses its activity in a few seconds. A minute quantity only has been extracted, but it has been sufficient, nevertheless, to demonstrate its powerful radiations. A piece of paper placed in the same vessel with a trace of actinium becomes in a short time radiantly active and is capable of lighting up a screen of zinc sulphide by its mere presence.

These then are the radio-active elements : radium, thorium, uranium, polonium, and actinium. Each one has properties which differentiate it from all the others.

We append a tabular statement of the main radio-active changes which uranium, thorium, and radium undergo, together with some of the properties of the changing bodies. 


\begin{tabular}{|c|c|c|c|c|}
\hline ctiv & $\begin{array}{l}\text { rties of } \\
\text { matter } \\
\text { going } \\
\text { d. per } \\
\text { d. }\end{array}$ & $\begin{array}{l}\text { Time taken } \\
\text { for half of } \\
\text { body } \\
\text { und e rg o } \\
\text { change. }\end{array}$ & $\begin{array}{c}\text { Kind of } \\
\text { Rays. }\end{array}$ & $\begin{array}{l}\text { Chemical and } \\
\text { physical prop- } \\
\text { erties. }\end{array}$ \\
\hline $\begin{array}{c}\text { Uranium } \\
\downarrow \\
\text { Uranium X } \\
\downarrow \\
\text { Final product }\end{array}$ & $\frac{36}{100,000,000}$ & $\begin{array}{c}22 \text { days } \\
\ldots\end{array}$ & $\begin{array}{c}\text { beta } \\
\text { (and } \\
\text { gamma?) }\end{array}$ & $\begin{array}{l}\text { Soluble in ex- } \\
\text { cess of ammo- } \\
\text { nium carbonate. } \\
\text { Insoluble in ex- } \\
\text { cess of ammo- } \\
\text { nium carbonate. }\end{array}$ \\
\hline $\begin{array}{c}\text { Thorium } \\
\downarrow \\
\text { Thorium X } \\
\downarrow \\
\text { Thorium emanation } \\
\downarrow \\
\text { Emanation X } \\
\text { (first change) } \\
\downarrow \\
\text { Second change } \\
\downarrow \\
\text { Final product } \\
\end{array}$ & $\begin{array}{c}2 \\
1,000,000 \\
115 \\
10,000 \\
22 \\
100,000 \\
174 \\
10,000,000\end{array}$ & 55 minutes & $\begin{array}{c}\text { no rays } \\
\text { alpha, } \\
\text { beta and } \\
\text { gamma }\end{array}$ & $\begin{array}{l}\text { Soluble in am- } \\
\text { monia. } \\
\text { Soluble in am- } \\
\text { monia. } \\
\text { Behaves like a } \\
\text { chemically inert } \\
\text { gas of heavy } \\
\text { m o l e c u l a r } \\
\text { weight, con- } \\
\text { denses at }-120 \\
\text { C. A } \\
\text { Attaches itself } \\
\text { to the surface } \\
\text { of bodies. } \\
\text { Soluble. in some } \\
\text { acids and not in } \\
\text { others. }\end{array}$ \\
\hline $\begin{array}{c}\text { Radium } \\
\downarrow \\
\text { Radium emanation } \\
\downarrow \\
\text { Emanation X } \\
\text { (first change) } \\
\downarrow \\
\text { Second change } \\
\downarrow \\
\text { Third change } \\
\downarrow \\
\text { Fourth change } \\
\downarrow \\
\text { Final product } \\
\end{array}$ & $\begin{array}{c}\frac{211}{100,000,000} \\
4 \\
1,000 \\
318 \\
1,000,000 \\
\frac{41}{100,000}\end{array}$ & $\begin{array}{c}3 \cdot 7 \text { to } 4 \text { days } \\
\text { about } 3 \\
\text { minutes }\end{array}$ & $\begin{array}{l}\text { no rays } \\
\text { alpha, } \\
\text { beta and } \\
\text { gamma } \\
\text { alpha } \\
\text { and beta }\end{array}$ & $\begin{array}{l}\text { Behaves like a } \\
\text { chemically inert } \\
\text { gas. Condenses } \\
\text { at }-150 \mathrm{C} \text {. } \\
\text { Attaches itself } \\
\text { to the surface } \\
\text { bodies. } \\
\text { Soluble in some } \\
\text { acids and not in } \\
\text { others. }\end{array}$ \\
\hline
\end{tabular}




\section{CHAPTER X.}

\section{RAdio-ACTIVITY Everywhere.}

Radio-activity is not confined to the radio-active elements. It exists everywhere though in minute degree. The air of cellars and caves is markedly radio-active. So is the air sucked up from the soil, and particularly clay. The air of the free atmosphere, normal air, is slightly radio-active.

A wire strongly electrified and suspended in the air for a few hours acquires a strong ray-emitting power which may be rubbed off and transferred to leather moistened with ammonia.

Freshly fallen rain and snow are radio-active. Air bubbled through the Cambridge tap-water emits rays; so does the surface water of New Haven, Connecticut, and air boiled off from the mineral springs at Bath. Natural carbonic acid arising from great depths of old volcanic soil has been tested and found active, and so has the fine mud from the mineral springs of Northern Italy and the air of the Baltic coast. Everywhere over the earth there seems to arise an emission of penetrating rays. For the most part these rays seem to be due to the presence of small quantities of radium contained in the earth and permeating the atmosphere with its emanation. But is it all due to this? Are we sure that all matter is not to some slight extent radio-active? Many ordinary substances certainly do show radio-activity. Thus, tin-foil, glass, silver, zinc, lead, copper, platinum and aluminum, all of them are slightly radioactive. Shall we account for this on the ground that they 
all contain small quantities of the strong radio-active elements as an impurity, or that it is the natural intrinsic property of all matter to emit rays ?

That important question is for the future to decide. Of one thing we may be certain: If all forms of matter possess the power of emitting rays they do so to an exceedingly minute degree. Radio-activity, as we are accustomed to consider it, seems to be par excellence the property of the heavy atom of matter. And if in the future new heavy atoms are discovered we may safely predict for them, as an intrinsic property, the possession of radio-activity. 


\section{PART V.}

\section{THE RESOLUTION OF THE ATOM.}





\section{PART V.}

\section{THE RESOLUTION OF THE ATOM.}

\section{CHAPTER I.}

Modern Alchemy: The Transmutation of Matter.

Amid the shifting scenes wherein they live, men have always believed in the existence of an underlying reality or unity of which the ordinary changing forms of matter are but a superficial manifestation.

"There abides in nature a certain form of matter which being discovered and brought by art to perfection, converts to itself all imperfect bodies that it touches." This is a saying of the ancient alchemy, and it constitutes a proposition from the rooted belief in which have sprung many centuries of sweaty, toilsome, futile effort.

"In chemistry we recognize how changes take place in combinations of the unchanging." This is the statement of chemistry, the daughter of alchemy.

The two forms of statement are alike in this, that they postulate an underlying essence of simplicity and perfectness.

With the alchemist this simplicity lay in a certain substance. Commonly, it was called the philosopher's stone and, later, the elixir of life. By means of it, if one could but come at it, it was possible, at a touch to transmute all baser metals into gold and, by drinking it, to gain eternal life on earth. 
The possibility of transmuting one metal into another seemed entirely reasonable to medieval men, and, taking their point of view, it was reasonable. They were imbued with the idea of growth and change. They saw that plants and animals grew from one form into another and, if so, why not metals?

Here is something of the argument between Subtle and Surly in old Ben. Johnson's "Alchemist," in which Subtle is endeavoring to persuade Surly of the transmutability of the metals and, incidentally, to cozen him out of his money.

Subtle: No egg. but differs from a chicken more Than metals in themselves.

Surly: That cannot be.

The egg's ordained by nature to that end,

And is a chicken in potentia.

Subtle: The same we say of lead and other metals,

Which would be gold if they had time.

. . . . . . . for 'twere absurd

To think that nature in the earth bred gold, Perfect in the instant; something went before.

There must be remote matter."

This remote matter was of course the philosopher's stone which Subtle was about to prepare at Surly's expense. The lines in which Subtle concludes his argument are interesting:

"Besides, who doth not see in daily practice Art can beget bees, hornets, beetles, wasps, Out of the carcasses and dung of creatures; Yea, Scorpions of an herb, being rightly placed ? And these are living creatures, far more perfect And excellent than metals." 
If "art can beget bees. . . . out of the carcasses and dung of creatures," why, the production of gold out of lead ought to be, in comparison, a simple task, for, certainly, a bee is a more complicated structure than a metal. But Surly is proof against the subtleties of Subtle, and says:

"That alchemy is a pretty kind of game Somewhat like tricks o' the cards, to cheat a man With charming;" and so, in truth it was;

that wonderful transmuting stone still evaded the mind and hand of man to find.

The ycars rolled on; alchemy glided into chemistry, and the search for the one simple perfect thing capable of transmuting by its touch one element into another became itself transmuted into the study of "how changes take place in the combinations of the unchanging,"-the unchanging things being what the chemists called the elements of matter, gold, iron, copper and the like. The alchemists, fanatics, knaves, or knavish-fanatics, gave place little by little to investigating men of another type, keen-minded, accurate, and conservative in their judgments; pre-eminently, men who did not believe in fairy-tales. Robert Boyle in 1681 in the title of his book "The Skyptical Chymist" defines, in general, the character of all succeeding chemists, for "skyptical" they have always been, beyond, even, the followers of any. other science. Beginning with Boyle, these men gradually displaced the alchemical "simple, perfect essence" by a thorough-going belief in the existence of from seventy to eighty elements which they found it impossible to break down into simpler bodies, and out of which in their various combinations the world of matter is made. These elements were undecomposable, unchanging, simple things. It is true 
that chemists were always careful to guard their definition by the statement that the elements were undecomposable so far as they could do, and simple so far as they could see, but the underlying assumption of two hundred years of chemists was that the elements were simple, unchanging bodies. Gold was gold and iron was iron, and any attempt to make them other than themselves was the proper function of the men of a thousand years hence. Of course, there were men who divined rather than reasoned that this simplicity and unchangingness were apparent rather than real. Thus, in 1811 we find Davy saying "It is the duty of the chemist to be bold in pursuit. . . . He must recollect how contrary knowledge sometimes is to what appears to be experience. .. . To inquire whether the metals be capable of being decomposed and composed is a grand object of true philosophy." Again, in 1815, Faraday uses similar terms when he says: "To decompose the metals, to reform them, and to realize the once absurd notion of transmutation, are the problems now given to the chemist for solution." But these were voices crying in the wilderness and the possibility of the transmutation of one element into another was, on the part of everybody, deemed as absurd as the existence of the philosopher's stone which, to the alchemists, was to accomplish the work.

We have now to present to the reader some remarkable facts: Let us leave, for the nonce, all talk of atoms, ions and corpuscles, and the mysterious rays of radium, to consider in a simple way some straightforward matters of fact connected with radio-activity. We are dependent for these "facts" on the men who enunciate them; but if these men are men of light and leading, if they command the respect of all their confréres, and if they occupy positions of the highest honour and responsibility in the world of science we 
must have faith in their "facts." Such are the men upon whose ipse dixit the facts of the science of radio-activity mainly rest. They are distinctly men of credibility. Having confidence, then, in their statements of fact let us examine into them.

We discover that there exists in nature a certain wellknown " element," uranium. This element is radio-active; that is, it has the power of continuously emitting rays. These rays are of two kinds: one, the positively electrified and slightly penetrating alpha-rays, and the other the highly penetrating and negatively electrified beta-rays.

By methods of chemical fractionation somewhat similar to that by which radium is isolated from pitchblende, it has been found possible to separate from this uranium another substance altogether; and, furthermore, it turns out that this separated substance is entirely responsible for the beta-rays of the original uranium, the substance from which it was extracted giving rise only to the alpha-rays. The extracted substance is known as uranium $\mathrm{X}$. This fact is followed by another. The extracted uranium $\mathrm{X}$ gradually but completely loses its power of emitting the beta-rays, and at such a rate that half of it has disappeared in about 22 days; while, on the contrary, the uranium from which it has been extracted regains this power at the very same rate, and eventually becomes as potent as ever. After it has been restored you may, if you like, extract a second quantity of uranium $\mathrm{X}$, and a third, and a fourth, and so on, so far as is known, ad infinitum. This is a matter of fact into which no theory enters. On the basis of this fact, then, we seem compelled to conclude that the uranium is continuously manufacturing from itself another substance, uranium $\mathrm{X}$, which has only a transitory existence; and that the power of emitting these penetrating rays, which an 
ounce of any uranium compound at any time possesses, is due simply to this uranium $\mathrm{X}$ existing therein, the quantity of which depends on a balance between the rate at which it decays and the rate at which the uranium manufactures it.

We may attempt to illustrate this mechanism by con . structing a crude analogy.

Let us suppose that we have a full-grown sweet-pea vilte and that the vine is the uranium.

The tendrils of the vine are the alpha-rays from uranium. The flowers are uranium $X$.

The scent of the flowers are the beta-rays from uranium $\mathrm{X}$.

Let us suppose, moreover, that we leave the vine strictly alone. We can easily see that there will come a time in our garden when the flowers of the vine will decay as fast as the vine produces them, and that the total number of flowers on the plant will depend upon a balance between their rate of growth and decay. Similarly, there comes a time with the uranium, when the amount of uranium $\mathrm{X}$ produced decays as fast as the uranium produces it, and the total amount of uranium $\mathrm{X}$ in the uranium depends upon a balance between its rate of growth and decay. If we were working with our flowers in the dark as we are, metaphorically speaking, with our uranium, we might estimate their number by picking them out by their scent; we do estimate the amount of uranium $\mathrm{X}$ formed by the amount of its beta-rays. Now, let us suppose that some dewy morning we snipped off every flower; in other words suppose we extract the uranium $\mathrm{X}$ from the uranium. We now have the flowers with their scent in one hand, and the uranium $\mathrm{X}$ with its beta-rays in the other. There remains the destitute vine with its tendrils and the destitute 
uranium with its alpha-rays. The flowers with their scent decay in our hand; so does the uranium $\mathrm{X}$ with its betarays. But the vine begins at once to restore its flowers with their scent and soon has as many as before; so does the uranium soon restore its uranium $\mathrm{X}$ with its beta-rays. We must not be misled by our analogy: The plant produces its flowers by growth, the uranium its uranium $\mathrm{X}$ apparently by decomposition.

"But" you say, " do you mean us to infer that the element uranium (the element, mind you) is transformed into a totally different body?" We may as well face the issue squarely. Yes. We do. Furthermore, we believe that it is changing at a definite rate every second of the day, day in and day out forever, or at any rate so long as any of it remains. We believe that we have here a veritable transmutation of matter just as wonderful as would be the transmutation of lead into gold, no more no less. We believe that the alchemists were right, that matter is not only. transmutable but transmuting, and that without the aid of any philosopher's stone, diabolic influences, or even the modern appliances of a scientific laboratory. Nay, in spite of them; for, apparently, no human effort can either aid or hinder this process. It seems to be the very symbol of inevitability.

We may now imagine ourselves confronted by an opponent in the form of a chemist of the old school, one whose mind has lost some of its plasticity so that he does not readily assimilate new ideas, but who, nevertheless is true to the traditions of his class in being thoroughly "skyptical." We can imagine this gentleman saying: "Pooh. How do you know that this uranium $\mathrm{X}$ is different from uranium?" We can answer this question fairly and squarely by the statement that it has different chemical 
qualities. Uranium is soluble in excess of ammonium carbonate while the uranium $\mathrm{X}$ is not. In a mixture of ether and water, the uranium dissolves in the ether while the uranium $\mathrm{X}$ dissolves in the water. There is no better criterion for a difference in nature than a difference in chemical property. "But how do you know," says he, "that the element uranium has anything to do with the matter? You use the uranium in the form of a compound. It is a property of the compound, not of the element." No, it is not. The radio-activity of the compounds of uranium, and hence the amount of uranium $\mathrm{X}$ formed-, depends solely upon the per cent. of uranium which the compounds contain; and it is a matter of indifference whether it is in the form of nitrate, oxide or what not. Not only so, but the free element itself is radio-active and on being dissolved will give rise to uranium $\mathrm{X}$. There is no escape from the fact that the phenomenon is a function of the element uranium itself. "Well," says the old gentleman, testily, "you say that the uranium $\mathrm{X}$ is a transitory element, (save the mark !), and that it decays. Now, what does it decay into? What becomes of the dead uranium $\mathrm{X}$ ?"

This is an awkward question, so far as uranium is concerned. We do not know what becomes of the uranium $\mathrm{X}$ for the reason that it decays into a body which does not emit rays, and its radio-activity is the only means by which we can measure it. The amount of uranium $\mathrm{X}$ formed is so small that it would take geological epochs of waiting to secure enough to weigh, much less examine chemically. But if we cannot follow the process farther in the case of uranium, we certainly can in that of an analogous radio-active body. For just as uranium gives rise to uranium $X$, so does the element thorium give rise to 
a similar body, thorium $\mathrm{X}$. Unlike, however, uranium $\mathrm{X}$, the thorium $\mathrm{X}$, on decaying, gives rise to a third radioactive body which has been called the thorium emanation, -an emanation, because its discoverer Rutherford was unwilling to prejudge the question as to whether it was a gas. On dissolving the thorium compound in water and bubbling air through it, this emanation passes away with the air and floats about with it. Its presence is obvious from its ray-emitting power which is intense. It is certainly not finely disseminated thorium $\mathrm{X}$ because its rate of decay is wholly different. It seems to be a gas. We explain this to our opponent who lifts his bushy eyebrows and quietly asks: "If this emanation is a gas, at what temperature does it liquify?". This is a terrible question, for if it is a gas, or matter at all, there must be a temperature at which it will condense just as steam condenses to water at 100 degrees Centigrade; and our instruments should be able to determine this condensation through its ray-emitting power. We want nothing better, though, than this question. The emanation from thorium condenses sharply at a temperature of 120 degrees below zero on the Centigrade scale to a brilliant patch of phosphorescent light.

We proceed to inform our opponent that not only has the emanation a definite liquifying point but that it obeys Boyle's law in that, in a definite volume of air, its quantity is proportionate to the pressure; and, further, that from its rate of diffusion through air, or through a porous plug, its density has been determined by well-known methods as about 100 times that of hydrogen gas. We heap this up by saying that we can even tell the particular family of the elements to which the emanation belongs; for since it is absolutely indestructible and unchangeable under the most drastic chemical treatment, it is, evidently, a gas belonging 
to the argon family of the elements in the periodic law. This dazes the old gentleman a little, but he returns to the attack. "This so-called emanation is probably nothing but dust in the air which has beccme radio-active through contact with the thorium. You know that the international congress of chemists has decided that a new element, to have any validity, must have a mapped spectrum. I am going to ask you, then, for the spectrum of this emanation which you tell me is a transmuted element from thorium." This request is hardly fair, for the instruments which measure the properties of these interesting bodies, the electroscope and electromcter, are hundreds of thousands of times more refined than the most delicate spectroscope.

Yet we are able to satisfy him; not, it is true, with the emanation from thorium, for its life is too short. Half of it has died in a minute from the time of its birth, and this is too short a time for the adequate observation of the infinitesimally small quantity of matter involved.

But we can easily satisfy him with a perfectly similar emanation from the new element radium; for the life of the radium emanation is longer.

About the first of June, 1904, Sir William Ramsay succeeded in determining with certainty the position of certain lines in the spectrum of this transmuted element, the "emanation" evolved from radium.

The spectral lines characteristic of the emanation are transient because the element itself is transient, but they are definite, and different from the lines belonging to the spectrum of any other known form of matter.

It is interesting to note in this connection that one of the most persistent of the lines observed is identical with one observed in a lightning flash by Pickering. So sure is Ramsay that the emanation from radium has a definite though 
transient existence as a true element, that he proposes to give it a definite name as an element so that it may take its place with others in the Table of the Elements. He has called it exradio, the element evolved out of radium.

"There is just one thing more," -says our sceptical chemist, "that I can fairly ask you to do. These transmuted elements, such as your emanation, are new. Evolve me, now, an element that we know,- and I shall be an alchemist."

We shall do it. In June, 1903, about one year prior to the discovery alluded to above, Sir William Ramsay and Mr. Soddy discovered that this radium emanation decayec into, or became transmuted into, an entirely different element with which the world of science has been acquainted for years,-namely, the element helium. By observing through a spectroscope a spectrum-tube containing the radium emanation, they were able to observe the actual birth of helium. At first, no spectrum lines characteristic of helium were observed; but presently they appeared, faint at first but ever increasing in brightness until they became unmistakable, and the birth of helium was an accomplished fact. Helium has been a well-known element ever since its discovery on the sun by Lockyer twenty-five years ago, and its subsequent discovery on earth by Ramsay in 1895 . We have discovered that it is a transmutation product of the element radium.

"Well," says our chemist, sceptical no longer and with all the humour of his class, "I am like Kipling's elephant when the alligator had him by the nose. "This is too buch for be.'"

And so, in truth, it is.

We have learned, then, without the use of any theoretical conceptions, and as a matter of simple fact, that cer- 
tain elements such as uranium, thorium, radium, with as much right to the title of elements as any other, break down or become transmuted into certain other elements also, with a perfect right to the title. Certain of these transmuted elements have but a brief span of existence, and are but half-way stages to some final products of decomposition. The following table shows us the duration of existence of some of these transmuted elements:

NAME OF TRANSMUTED ELEMENT. TIME TAKEN FOR HALF OF BODY TO UNDERGO CHANGE.

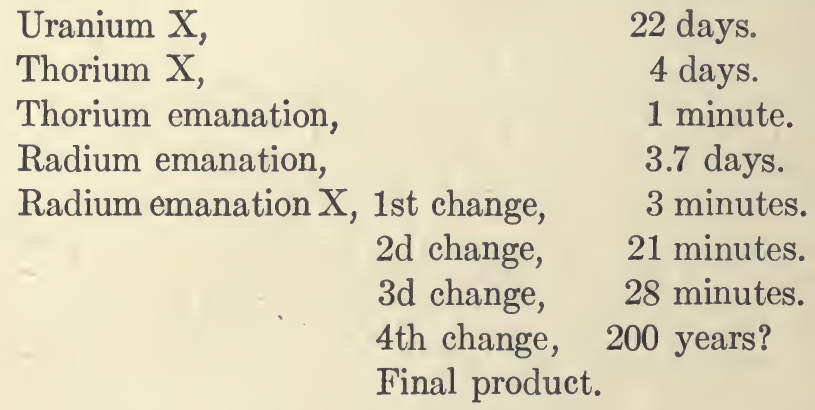

We know this elemental transmutation only as it is revealed by radio-activity, the power these elements possess of emitting penetrating rays. The instruments by which these changes are traced are hundreds of thousands of times more sensitive than any known mechanism, but their results are definite and reliable. The amount of elemental transmutation taking place at any one instant is exceedingly small, but it is actual. It.is, at this day, beyond the power of man to aid or hinder this process. It seems inevitable.

Twentieth Century Science has this work to do. To use the prescient words of Faraday nearly a century old: "To de- 
compose the metals, to reform them, and to realize the once absurd notion of transmutation, are the problems now given to the chemist for solution."

The alchemist became the chemist, and the chemist has become the alchemist. - BOSH- wOROS - wORDS. 


\section{CHAPTER II.}

\section{Atomic Disintegration.}

Let us for a moment come to a pause with knowledge to consider what we have already gained without regard to the heights above.

First, we discovered in Part II, called, "The Mystery of Matter," that the atoms of the elements were so curiously related to one another that any hope of explaining the mystery apparently inherent in them lay in the finding of particles smaller than themselves out of which they could be built up. Next, in Part III, called "Gaseous Ions," we discovered that such particles, a thousand times smaller than the smallest atom, do actually exist in candle-flames and glowing metals, within the arc-lamps of the street, in the neighbourhood of dynamos, in the presence of X-rays, or on bubbling gas through water. Furthermore, in Part IV, on "Radio-activity," we found these same particles flying off with inconceivable velocity from bodies in their ratural normal condition,--bodies such as uranium, thorium and radium; and finally we find that the soil and water of the earth itself emits them and that the air we breathe contains them. These little bodies are invariably associated with matter and arise from matter-from any form of matter under special conditions, and from special forms of matter under any conditions. From whatever source-they arise, these corpuscles are similar in all respects with the exception of mere velocity. 
Since the mass of the corpuscles is a thousand times smaller than the mass of any known atom, we see that the corpuscle must be a constituent of all substances,- - that as a matter of fact, the atoms of all the elements must have corpuscles in common. We are in this way face to face with the idea that the atoms of the chemical elements are actually built up of corpuscles. Evidence in support of this hypothesis is not wanting. For example, on page 72 of Part III of our work will be found the law of absorption for corpuscles, in which it is apparent that the resistance which substances interpose to the passage of corpuscles through them, in other words, their opaqueness, depends solely upon the density of the substance. If one substance is twice as heavy as another it is only half as transparent to corpuscles. The particular kind of matter has nothing to do with it. How different substances act towards light waves may be seen in the case of cork which is just as opaque as iron. It is all easily explicable on the theory we are considering. If each atom of matter is built up of corpuscles and if these corpuscles are extremely minute compared with the atom as a whole, it is evident enough that we must look upon an atom as an open structure in which the vacant spaces are enormous compared with the size of the tiny corpuscles scattered throughout the atomic system. We may, with Lodge, illustrate the relation of a corpuscle to the atom which it inhabits, thus:

If we imagine an ordinary church to be an atom of hydrogen, the corpuscles constituting it will be represented by about 1000 grains of sand each the size of a period so . , dashing in all directions inside or rotating with inconceivable velocity, and filling the whole interior of the church with their tumultuous motion. Such an atom would be penetrable to other corpuscles in inverse proportion to the 
number of corpuscles constituting it, while it would be opaque to other atoms. In other words, the absorbing power of a substance must, therefore, on the basis of our theory, be simply proportional to its density; and as we find it so in fact, it makes our theory just so much the stronger. Reinforced by this independent fact we can therefore go forward with good courage.

In the preceding chapter we found that the element uranium became continuously transmuted into a totally different element, uranium $\mathrm{X}$, and that the same transmutation was true of other elements. Any given mass of the element uranium consists simply of $x$ or $y$ atoms of that element, and, hence, if there is a transmutation into any other element, it must consist, simply, in the transmutation of the atom of the first into the atom of the second. The transmutation is entirely atomic. But this leads us to think that the atom of any given element consists not only of corpuscles but of systems of corpuscles. Take, for example, the case of thorium. The atom of thorium breaks down into the atom of thorium $\mathrm{X}$ with the evolution of material particles that we call the alpha-rays. The atom of thorium $\mathrm{X}$, in its turn, breaks down into the atom of the thorium emanation with the evolution of still more alpha-ray particles. The atom of the thorium emanation follows the example of its predecessors in breaking down into the atom of the thorium emanation $\mathrm{X}$ again with the evolution of alpha particles; and the atom of the thorium emanation $\mathrm{X}$ itself breaks down into some atom of an unknown type with an evolution not only of the material particles of the alpharays but of beta- and gamma-rays as well. The original thorium must, therefore, be an exceedingly complex system of corpuscles,-system within system-for it has within itself the potentiality of at least five different atoms. This 
leads us to think that, as Rowland long ago said, "a broadway grand piano is a very simple mechanism compared with, say, an atom of iron."

On the basis, then, of the theory that the atom of any element is a complex of corpuscular systems we should be able to account for the following mysteries of matter:

1. Prout's Hypothesis, pp. 19, 20.

2. Triads of Dobereiner, pp. 21, 22.

3. The Periodic Law, pp. 22-25.
4. Group Relations of the Law, pp. 30-33.

5. Series Relations, p. 29.

6. Valency, p. 37.

7. The Inert Elements of the Zero Group, pp. $36-38$.

8. The electro-chemical properties of the elements.

9. Radio-activity and the existence of unstable atoms.

We begin with a corpuscle. We know it to be a particle a thousand times smaller in mass than the smallest atom. We know it to possess a high velocity. We know it also to be charged, invariably, with a definite charge of negative electricity. But since a negative charge of electricity has always associated with it an equal positive charge, we should expect the negative charge on our corpuscle to follow the pattern of all other negative charges and to have associated with it, too, an equal charge of positive electricity. Our atom, therefore, we assume to be a sphere of positive electrification enclosing a number of negatively 
electrified corpuscles, the negative electricity of the corpuscles exactly balancing the positive electricity of the enclosing sphere.

This is all that Professor J. J. Thomson requires for his immensely important work on the theory of the structure of the atom in which the consequences of this assumption are mathematically demonstrated. He places before him the following questions for solution: (1) What would be the structure of such an atom, i. e., how would the corpuscles arrange themselves in the sphere; and, (2) what properties would this structure confer upon the atom?

The answer to the first question, how the corpuscles would arrange themselves in the sphere, depends on the number of corpuscles and their motion. If we assume that the corpuscles are at rest they will arrange themselves within the sphere so that they are in equilibrium under the attractive force of the sphere and their own mutual repulsions.

If there are two corpuscles, only, $A$ and $B$, they will be in equilibrium if placed on opposite sides of the centre of the sphere at a distance equal to one-half the radius. (Fig. 42.) If there are three corpuscles, $A, B$ and $C$, they will be in equilibrium if they form an equilateral triangle with its centres at the centre of the sphere (Fig. 43).

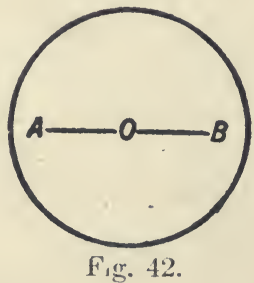

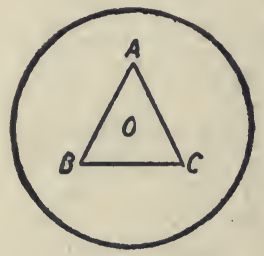

Fig. 43.

Four corpuscles will arrange themselves at the corners of a square. In all these cases the corpuscles arrange 
themselves as though they were on an inner sphere concentric with the outer one and it is natural to suppose that any number of such corpuscles could be placed over such a sphere and balanced by the attraction of the outer sphere and their own mutual repulsions. Professor Thomson has, however, shown most decidedly by mathematical calculation that such.is not the fact.

As a matter of fact he shows that unless the number of corpuscles is small, not more than five, this arrangement is unstable and consequently could never maintain itself. When the number of corpuscles exceeds five they break up into two groups. The group containing the smaller occupies the surface of an inner shell towards the centre. The others are on an outer shell concentric with the inner one, the sphere of positive electrification surrounding and balancing them all. As the number of corpuscles still further increases there comes a stage at which the equilibrium cannot be stable even with two groups and the corpuscles divide themselves into three groups on three concentric shells; and as the number increases after that, more and more groups are necessary for equilibrium. This has been neatly and elegantly shown by Professor Mayer in an experiment with a model atom in which the forces producing equilibrium are similar to those producing equilibrium among the corpuscles in the real atom as we are considering it to be in nature.

In this experiment, a number of tiny magnetized steel needles thrust through discs of cork are floated on water so that the little negative poles are all above the surface of the water while the positive poles are beneath. These little floating negative magnetic poles, just like corpuscles, repel each other with forces varying inversely with the square of the distance. In this way each little negative 
pole stands for a corpuscle. The attractive force of the sphere of positive electrification is provided for by a positive magnetic pole suspended at some distance above the surface of the water. The forces acting on these little floating magnets are thus similar to the forces acting on the corpuscle in an atom. They are free to move, they repel one another, and they are attracted by an exterior radial force. The main difference between the corpuscles and the magnets is that the corpuscles may move in any direction in space, while the floating magnets may move only in the plane of the surface of the water. The arrangements assumed by the floating magnets as the number increases from two up to nineteen are shown in Fig. 44.
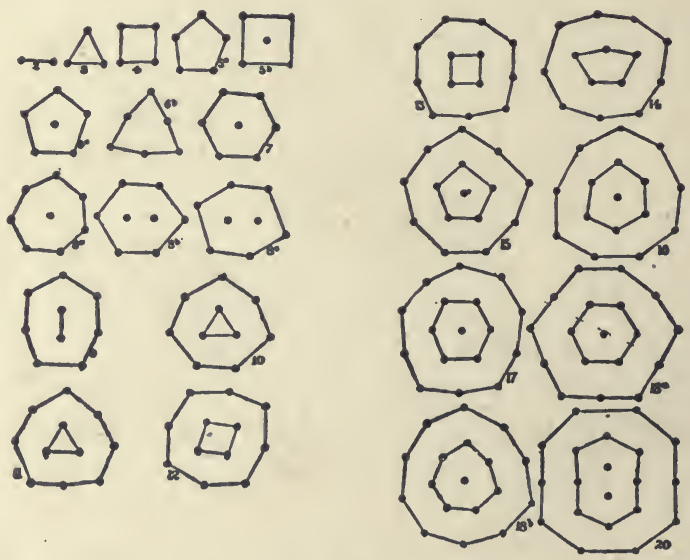

Fig. 44.

Here we see that three magnets form an equilateral triangle, four a square, five a pentagon, but that when the number exceeds five one or more of the magnets seek the centre. Thus with six magnets we have one at the centre and a pentagon of five surrounding it. With, say, ten 
magnets we have a triangular group of three within surrounded by a group of seven, and this two-group system lasts until there are fifteen magnets when it suddenly changes to a system of three groups, one at the centre surrounded by a pentagon of five which in turn is surrounded by a group of nine. This three-group arrangement lasts until the number of magnets increases to twenty-seven when the four-group arrangement comes in, one at the centre surrounded by five surrounded by nine surrounded by twelve.

This is the way our little magnets arrange themselves. It is also the way our little corpuscles would arrange themselves in the atom if these corpuscles were at rest. It is offered here as a clever experimental verification of mathematical calculation, and serves to give us confidence in the results of the mathematical reasoning we are about to consider. Our little magnets are at rest, but if they were in a state of steady motion describing in their successive rings circular orbits about the centre of the sphere the effect of the motion would simply drive them farther away from the centre without in many cases destroying the character of the configuration. The corpuscles of our atom we deem to be in such motion and they must revolve in their orbits either in concentric rings or in concentric shells. Professor Thomson has not yet succeeded in overcoming the mathematical difficulties of their distribution in shells but he is able to show that the same kind of properties would be associated with shells as with rings. On the latter basis, which is.almost as good as the former, he has for a certain number of them, solved the problem of their distribution. The following table shows the way in which the corpuscles group themselves. The numbers range downward at intervals of five. 


\begin{tabular}{|c|c|c|c|c|c|c|}
\hline Number of corpuscles. & 60 & 55 & 50 & 45 & 40 & 35 \\
\hline $\begin{array}{l}\text { Number in successive } \\
\text { rings. }\end{array}$ & $\begin{array}{r}20 \\
16 \\
13 \\
8 \\
3\end{array}$ & $\begin{array}{r}19 \\
16 \\
12 \\
7 \\
1\end{array}$ & $\begin{array}{r}18 \\
15 \\
11 \\
5 \\
1\end{array}$ & $\begin{array}{r}17 \\
14 \\
10 \\
4\end{array}$ & $\begin{array}{r}16 \\
13 \\
8 \\
3\end{array}$ & $\begin{array}{r}16 \\
12 \\
6 \\
1\end{array}$ \\
\hline Number of corpuscles. & 30 & 25 & 20 & 15 & 10 & 5 \\
\hline $\begin{array}{c}\text { Number in successive } \\
\text { rings. }\end{array}$ & $\begin{array}{r}15 \\
10 \\
5\end{array}$ & $\begin{array}{r}13 \\
9 \\
3\end{array}$ & $\begin{array}{r}12 \\
7 \\
1\end{array}$ & $\begin{array}{r}10 \\
5\end{array}$ & $\begin{array}{l}8 \\
2\end{array}$ & 5 \\
\hline
\end{tabular}

Here is, also, the entire series of arrangements for collections of corpuscles of which the outer ring consists of twenty corpuscles.

\begin{tabular}{cc|r|r|r|r|r|r|r|r|r}
\hline Number of corpuscles. & 59 & 60 & 61 & 62 & 63 & 64 & 65 & 66 & 67 \\
\hline Number $\begin{array}{c}\text { in successive } \\
\text { rings. }\end{array}$ & 20 & 20 & 20 & 20 & 20 & 20 & 20 & 20 & 20 \\
& & 16 & 16 & 16 & 17 & 17 & 17 & 17 & 17 & 17 \\
& 13 & 13 & 13 & 13 & 13 & 13 & 14 & 14 & 15 \\
8 & 8 & 9 & 9 & 10 & 10 & 10 & 10 & 10 \\
& & 3 & 3 & 3 & 3 & 4 & 4 & 5 & 5 \\
\hline
\end{tabular}

Fifty-nine is the smallest number and 67 is the largest number of corpuscles in one collection that can have an outer ring of twenty.

Let us see, now, how these corpuscles, with the configurations which collections of them must take to satisfy their attractive and repulsive forces, will answer for the One Thing which we found so necessary in Part II, for any hope of explaining the mysteries of the atoms. Will these collections of corpuscles make atoms with the properties possessed by the atoms of the chemical elements?

\section{PROUT'S HYPOTHESIS.}

The mass of the atom must be the sum of the masses of the corpuscles it contains, so that the atomic weight is a measure of the number of corpuscles in the atom. Thus, 
if the atom of hydrogen contains 1,000 corpuscles, oxygen will contain 16,000, mercury 200,000, and so on. These numbers will be whole numbers and Prout's hypothesis will be true, not in the sense that the atoms of all the elements are built up of hydrogen atoms but that they are built up of primordial atoms a thousand times smaller than the hydrogen atom.

\section{TRIADS OF DOBEREINER.}

We have stated on page 21 that out of the list of the acoms of the elements little groups of three could be chosen with strongly correlated properties and owning to a pronounced family relationship; while connected with this relationship was the curious fact that the mean of the atomic weights of the first and the third was approximately, but not exactly, equal to the atomic weight of the middle one. This previously incomprehensible fact finds ready and simple explanation on the basis of our theory in the way in which the corpuscles arrange themselves in groups to form the atoms.

Similarity of arrangement means similarity of property throughout the whole range of chemistry. Consequently, if the collections of corpuscles in the tables above constituted atoms we should not only expect, but we should be very sure, that atoms containing similar rings would possess similar properties. If we take collections containing similar rings we find the Triads of Dobereiner, thus:

\begin{tabular}{l|r|r|c}
\hline Number of corpuscles. & 60 & 15 & 5 \\
\hline Number in successive rings. & 15 & 10 & 5 \\
10 & 5 & 5 & \\
\hline Mean number of the first and third. & & $17 \cdot 5$ & \\
Number in the middle group. & & 15 & \\
\hline
\end{tabular}


If these collections of corpuscles constituted atoms, the mean of the atomic weights of the first and third would be approximately the atomic weight of the middle one.

Let us take another example:

\begin{tabular}{l|r|r|r}
\hline Number of corpuscles. & 61 & 41 & 25 \\
\hline Number in successive rings. & 20 & 16 & 13 \\
& 16 & 13 & 9 \\
& 13 & 9 & 3 \\
9 & 3 & \\
\hline Mean number of the first and thirc. & 43 & & \\
Number in tine middle group. & 41 & & \\
\hline
\end{tabular}

Again we find the same thing true. If the three collections of corpuscles constituted three atoms they would possess similar properties, and the mean of the atomic weights of the first and third would be approximately the atomic weight of the middle one. The two examples cited are like those of sulphur, selenium and tellurium, and of chlorine, bromine and iodine, page 21 , and the curious facts recited there find a simple rational explanation.

THE PERIODIC LAW.

"The properties of an element are a periodic function of its atomic weight."

This has been the great mystery of matter. If we arrange the elements of matter in the order of their atomic weights, from lowest to highest, similar properties periodically recur. For example: With the element lithium certain properties are associated. The elements immediately following lithium in the order of their atomic weights do not possess these properties. They appear again, however, when we come to sodium, then disappear until potassium 
is reached, again disappear only to reappear with rubidium, and so on. An inspection of the tables given above will show that aggregations of corpuscles as they increase in number from say five to seventy, will possess properties similar to those discovered in the periodic law. If, for example, certain properties are connected with a group of five corpuscles, these properties will appear again when the number increases to fifteen, for fifteen corpuscles consist of that same group of five with ten others surrounding it. The properties connected with these two groups of five and fifteen corpuscles will then disappear until we again come to two groups of five and ten corpuscles respectively, with still another ring surrounding it. Inspection shows that this occurs when the corpuscles number thirty, where we have a group of five, surrounded by a group of ten surrounded by a group of fifteen. For a next recurrence of these properties we must now wait until the corpuscles number forty-seven, when we again find the grouping five, ten, fifteen, this time surrounded by a group of seventeen corpuscles. The arrangement then disappears to recur again with sixty-seven corpuscles in the grouping five, ten, fifteen, seventeen, twenty. This periodic rebuilding or recurrence of the same groups as the number of corpuscles increases is wonderfully analogous to the periodic appearance and disappearance of certain properties of the elements as the atomic weight rises; and if the atomic weight is measured by the number of corpuscles the atom contains, and the properties of the atom are dependent upon the arrangement and grouping of the corpuscles within the atom, it is obvious that we have, to a reasonable degree, solved the problem of the periodic law. It means, simply, the periodic recurrence of certain groups of corpuscles as the number of corpuscles constituting the atom increases. The peri- 
odic recurrence of properties turns out to be, in fact, a necessity if the atoms are built up of corpuscles.

\section{GROUP RELATIONS OF THE LAW.}

The fact that atoms built up of corpuscles necessarily result in a periodic law has, as a further necessary consequence, the existence of natural families among the elements. If the reader will re-inspect the table of the corpuscular groupings he will find, for example, that the group of 60 corpuscles consists of the same rings of corpuscles as the group of 40, with an additional ring of 20 corpuscles around it, while the group of 40 consists of the same rings as the group of 24 , with an additional ring outside, while 24 is the group 11 with an additional ring, 11 being the group 3 with an additional ring, thus:

\begin{tabular}{c|r|r|r|r|r}
\hline Number of corpuscles. & 60 & 40 & 24 & 11 & 3 \\
\hline Number of corpuscles in successive & 20 & 16 & 13 & 8 & 3 \\
rings. & 16 & 13 & 8 & 3 & \\
(A family of five corpuscular & 13 & 8 & 3 & & \\
groupings.) & 3 & 3 & & & \\
\hline
\end{tabular}

We see, in this way, that we can divide the various groups of corpuscles into families such that each member of the family is derived from the preceding member, (the member just above it in the vertical columns of the table of the periodic law), by adding to it another ring of corpuscles.

We should expect atoms formed in this way of related groups of corpuscles to possess resembling properties; and since in the elements themselves we find such groups, it would be strange if their actual existence and the necessity for their existence on the basis of our theory had no significance or relation. Professor Thomson has recently 
shown, on mathematical grounds, that such related groups of corpuscles would of necessity possess related spectra such as have lately been discovered among the elements of certain groups in the table of the periodic law. This is a strong confirmation of our theory.

\section{SERIES RELATIONS.}

But the atoms of matter as they appear in the table of the periodic law are related not only in groups but in series, (page 29). A series is a horizontal row of elements in the table as a group is a vertical one. The gradual change in the properties of the elements which takes place as we travel along one of these horizontal rows is also illustrated in the properties possessed by these groups of corpuscles. To demonstrate this, consider, for example, the series of arrangements of the corpuscles given on page 158 , in all of which the outer ring contains 20 corpuscles. An outer ring containing 20 first occurs in a group of 59 corpuscles. Professor Thomson shows that in this case of 59 corpuscles the number of corpuscles inside is only just sufficient to make the outer ring of 20 stable; this ring will, therefore, be on the verge of instability and when its corpuscles are displaced, the forces urging them back again will be small.

For this reason, when the ring is subjected to an external disturbance, one or more corpuscles may easily be detached from it. We must remember, though, that in these collections of corpuscles, the negative electricity of the collection is exactly balanced by the sphere of positive electricity surrounding it and enclosing it; and, hence, if one negative corpuscle is lost the whole arrangement will assume a positive charge. Such an atom would behave like the atom of a strongly electro-positive or basic element. 
With the next group, 60 corpuscles, the outer ring is more stable because there is an additional corpuscle inside it. While, therefore, it may lose corpuscles it will not do so so readily as the group of 59. Hence, it will not so easily assume the positive charge of electricity, and hence, again, it will not be so electro-positive an element as the group of 59 . 61 corpuscles will be still less electro-positive than 60 , and 62 less than 61 . The addition of each successive corpuscle inside will make it more difficult to detach corpuscles from the outer ring of 20 and will, therefore, make the atom less electro-positive. Not only so, but when the total number of corpuscles increases to, say, 63 the possibility of losing corpuscles from the outer ring vanishes and, instead, another possibility creeps in. When the stability of the atom becomes extreme one or more corpuscles of the outer ring may actually lie on the surface of the atom without breaking the ring. In this case the atom would receive a charge of negative electricity and would behave like the atom of an electro-negative element. This increase in the stability of the ring, and consequently in the electro-negative character of its atom would go on growing until we had as many as 67 corpuscles where the stability of the ring would be at a maximum. Sixty-seven corpuscles would result in a strongly electro-negative element like chlorine.

A great change however in the properties of the atom takes place in the next group of 68 corpuscles for now the number of corpuscles in the outer ring increases to 21 , these 21 corpuscles are however only just stable, and would like the outer ring of 20 in the arrangement of 59 corpuscles, readily lose a corpuscle and so make the atom strongly electro-positive. An atom of 68 corpuscles would therefore strongly resemble the atom of 59 , one of 69 would resemble that of 60,70 that of 61 and so on. The properties of the 
groups of 59 and 67 corpuscles are exceedingly interesting. We have said that 59 corpuscles are on the very verge of instability and would, hence; readily lose a corpuscle and thereby acquire a positive charge. But they would not retain this charge. For when the group had lost a corpuscle 58 corpuscles would remain. But 58 corpuscles constitute the last group which has an outer ring of 19. This ring is exceedingly stable just as the ring of 67 corpuscles is stable so that no more corpuscles could escape from it, while the positive charge on it due to the escape of the 59th corpuscle would attract the surrounding corpuscles and one would immediately dart to it and become attached to it, when it would become once more 59 only to reundergo the same change over and over and over again. An atom so constituted would be neither electro-positive nor electronegative but one incapable of receiving any charge of electricity whatever. The group containing 60 corpuscles would be the most electro-positive of the series. It could lose only one corpuscle, that is, acquire a charge of only one unit of positive electricity, for if it lost two we should again have 58 corpuscles which would have double the positive charge and double the readiness to catch corpuscles which we found in the group of 59. Thus the group of 60 corpuscles would get charged with one, and one only, unit of positive electricity. It would thus behave like the atom of a monovalent electro-positive element like sodium. The group containing 61 corpuscles would not be so ready to lose its corpuscles as the group of 60 , but on the other hand it could afford to lose two for it is not until it has lost three that its corpuscles become reduced to 58 when, as we have seen, it begins to acquire fresh corpuscles. It would thus act like the divalent positive element magnesium. Similarly the group of 62 though less willing to lose its cor- 
puscles than 61 could on the other hand afford to lose three before beginning to seize more. It would thus act like, let us say, the element aluminum.

Turning now to the other interesting group, 67 corpuscles, at the end of the series, we find that its ring of 20 corpuscles is more stable than any of the others, but if the system acquires another corpuscle the 68 corpuscles would arrange themselves with a ring of 21 on the outside. This grouping as we have seen is on the very verge of instability and would readily lose its corpuscle and pass back again into its old configuration. Consequently, the group of 67 corpuscles like the group of 59 is incapable of receiving a charge at all. The group of 66 would be the most electro-negative of the series but it could afford to retain only one unit of negative electricity for if it acquired two there would be 68 a system which we have seen to be unstable. It would thus act like a very strongly electro-negative element like chlorine.

The group of 65 though less ready than 66 to retain corpuscles could, nevertheless, retain two and hence would act like a divalent negative element like sulphur. Similarly the group of 64 would act like the atom of a trivalent element after the style of phosphorus.

Thus taking those groups of corpuscles which contain 20 corpuscles in their outer rings and numbering from 59 to $6 \bar{i}$ respectively we are able to show that they would necessarily behave in their general properties like a horizontal series of elements in the periodic law.

\section{VALENCY.}

We are now able, to a reasonable extent, to explain valency, page 37 . Valency we have always defined in chemistry 
as the saturation capacity of an atom, the power possessed by an atom to unite with others, in other words, its "grabbing power." We have never known the meaning of it. We can see now that it is electrical in its origin. A univalent positive atom is one which, under the circumstances of chemical action, attains stability by losing one, and only one, corpuscle. A univalent negative atom, like chlorine, is one that will acquire one, and only one, corpuscle. A divalent positive atom is one which will lose two corpuscles and no more, and so on. The valency of the atom is thus simply a question of the number of corpuscles that can escape from or be received by the corpuscular grouping which constitutes any one kind of atom. Thus the valency as well as the other properties of elements such as neon, sodium, magnesium, aluminum, silicon, phosphorus sulphur, chlorine and argon of the $2 \mathrm{~d}$ series of the pericolic law are the properties and valencies of groups of 59 , C0, $61,62,63,64,65,66$ and 67 , corpuscles respectively.

\section{CHEMICAL ACTION.}

Chemical action can also be explained as electrical and corpuscular in its nature. Suppose that we have a number of sodium atoms which are capable of losing one corpuscle each mixed with the same number of chlorine atoms which are capable, on this theory, of acquiring one corpuscle each. Then the corpuscles which escape from the sodium atoms will find a home on the chlorine atoms which are well able to retain them.

The result of this is that all the sodium atoms will acquire their unit positive charge and all the chlorine atoms their unit negative charge. The positive atoms of sodium will then attract the negative atoms of chlorine, electrically, and we shall obtain the compound sodium chloride or com- 
mon salt. Other chemical reactions can be explained in the same way. Chemical affinity is electrical affinity.

THE INERT ELEMENTS OF THE ZERO GROUP.

The rare gases of the atmosphere, such as helium, neon and argon, which were a few years ago discovered by the masterly researches of Rayleigh, Ramsay and Travers, and which are now associated together in the zero group of the periodic law, bear out in a most interesting and remarkable way the corpuscular theory we are considering. These gases are alike in this, that they have no combining power, or valency, whatever. They combine chemically with no known element. In our study of corpuscular groupings we found that a group of 59 corpuscles and a group of 67 corpuscles were in precisely this pcsition that they were hopelessly unable to retain any electrical charge whatever, that is, unable, permanently, either to lose or to acquire a corpuscle. If; as we have said, chemical action means simply the power either to lose or to acquire corpuscles, it is obvious that atoms built up of such corpuscular groups would be quite unable to enter into chemical combination. They would, therefore, be like helium and neon. Not only so, but these groups occur at the proper intervals. They occur with seven groups in between, just as helium and neon occur with seven atoms in between.

It is very evident then that if, as we said in Part II, the rare gases of the atmosphere have found a home in the periodic law, they have also found a home in the corpuscular theory which explains that law.

RADIO-ACTIVITY AND THE EXISTENCE OF UNSTABLE ATOMS.

But the corpuscular theory of the atom must explain the transmutation of matter as it is seen to take place in 
the radio-active elements. It must also explain radio-activity in general. Any failing in this respect would be fatal to its acceptance. It was stated, page 152, that an atom of one of the radio-active elements should consist not only of corpuscles but of systems of corpuscles. This finds its explanation in the systems of rings into which we have shown the corpuscles would necessarily arrange themselves. In addition to this, however, Professor Thomson has proved that these rings of corpuscles need not be concentric. A triangular ring of three corpuscles, for example, may exist anywhere in the atomic sphere surrounded by positive electricity, and yet retain its integrity and act like one corpuscle. We see that the cvident complexity of an atom of radium need not worry the theory, for the vast number of corpuscles it would contain, about 225,000 on the basis of its atomic weight, would of course be exceedingly complex. The explanation of transmutation and radio-activity, however, lies in the energy of the corpuscles, and in the fact that the configurations adopted by the corpuscles depend in certain cases on the energy they contain. This is shown in the arrangements adopted by the little magnets, Fig. 44, where we find that five corpuscles may arrange themselves either in a pentagon or in a square with one corpuscle in the centre. Professor Thomson has demonstrated mathematically that a group of four corpussles, for example, rotating with an angular velocity greater than a certain critical value will arrange themselves at the corners of a square, but that if the velocity falls below this value they will suddenly arrange themselves this time at the corners of a tetrahedron. Let us suppose now that we have an atom containing a system of corpuscles of this kind. Suppose that the corpuscles are rotating with an angular velocity far beyond the critical velocity. The configuration is stable enough. 
But owing to the radiation of energy, the velocity is going to diminish, slowly, very slowly, but certainly. There will come a time, then, and a definite time, when this critical velocity will be reached and then, presto! there will be sudden convulsion, or explosion, and the rearrangement is accomplished.

The potential energy is decreased, the kinetic energy is increased.

This arrangement must mean the evolution of a large amount of kinetic energy, and it has been shown that it might easily be sufficient to carry the system out of the atom altogether and we should have, as in the case of radium, a part of the atom shot off with high velocity.

It is very like the case of a spinning top. The top is stable in a vertical position if the kinetic energy due to its rotation exceeds a certain value. When, however, the velocity diminishes to this critical point, the crash comes and away goes the top, helter-skelter.

This all agrees with the facts of radio-activity. The radio-activity of radium, for example, is thus an atomic cataclysm. When the point of instability is reached the explosion occurs with the projection of two kinds of particles which are sub-atoms inside the group but free atoms outside.

One of these is the alpha particle consisting of two or three thousand corpuscles and the other is the atom of the emanation which contains probably about 150,000 . The atom of the emanation is of the same type as the atom of radium. Its configuration for steady motion depends on its kinetic energy. Consequently the process is repeated for the emanation, but in a very much shorter time, and we again have the evolution of alpha particles, which seems as a matter of fact to be the atom of helium, together with the formation of another atomic system called emanation $\mathrm{X}$. 
This, too, breaks down but this time with a perfect conflagration of decomposition in which the alpha particles, the stray corpuscles, or beta-rays, and the gamma-rays all appear together.

We may, therefore, define a radio-active substance as one whose atom consists of a complex group of corpuscles the configuration of which depends for its maintenance upon a certain velocity of movement of the corpuscles comprising it and beneath which velocity the corpuscles rearrange themselves with the evolution of an amount of energy which breaks down the atom.

Our theory of an atom is that it is a sphere of positive electrification enclosing a number of negatively electrified corpuscles the negative electricity of the corpuscles exactly balancing the positive electricity of the enclosing sphere. On this theory we have been able to explain all the mysteries of matter, which it has been the function of preceding chapters to describe, in terms of what we already know.

We have been able to show, also, that these mysteries of matter inevitably result from the acceptance of the theory. 


\section{CHAPTER III.}

INTRA-ATOMIC ENERGY.

March, 1903, was an historic date for chemistry. It is, also, as we shall show, a date to which, in all probability, the men of the future will often refer as the veritable beginning of the larger powers and energies that they will control. It was in March, 1903, that Curie and Laborde announced the heat-emitting power of radium. The fact was simple of demonstration and unquestionable. They discovered that a radium compound continuously emits heat without combustion or change in its molecular structure. The heat emitted is sufficient to maintain the temperature of the radium 1.5 degrees Centigrade, or about 2.7 degrees Fahrenheit, above that of its surroundings. It is all just as surprising as though Curie had discovered a red-hot stove which required no fuel to maintain it in heat. Stated in another way, one gram of radium compound emits 100 gram-calories of heat per hour. This means that every hour it emits enough heat to raise its own weight of water from the freezing-point to the boilingpoint.

It is enough to raise its own weight of water one degree in 36 seconds. In about 40 hours sufficient heat has been evolved from the gram of radium to decompose its own weight of water completely into its constituents, hydrogen and oxygen. After the lapse of 10,000 hours (13.5 months) there has been enough heat emitted to raise the temperature of a million times its weight of water one degree. 
It is necessary to analyze out this remarkable fact. We know that the radio-activity of a mass of radium compound is complex and consists of the united activities of the radium itself and its disintegration products, the emanation, the emanation $\mathrm{X}$ and the two or three active bodies into which the emanation $\mathrm{X}$ successively breaks down. It has been determined that the heat emission is due almost entirely to the alpha-rays, the positively electrified particles of atomic dimensions. In a mass of radium nearly all the alpha-rays emitted from it are absorbed in the radium itself. The radium is thus subjected to an intense bombardment by the alpha particles projected from its own mass. It is little wonder, under the circumstances, that the radium is heated. The energy of the alpha particles is immense. These particles, small as they are, are 2,000 times the mass of a corpuscle and travel with a velocity 40,000 times that of the swiftest rifle bullet. If an alpha particle were the size of a cannon ball the heat generated by its impact on the target would be many times more than sufficient not only to melt it but to dissipate it into vapour. But the alpha particles are projected not only from radium itself but from all its disintegration products; and we discover that the heat emission is distributed thus:

Radium freed from active products. . . 25 per-cent.

Emanrition and successive active products. 75 " "

Seventy-five calories, then, of the heat emitted from a gram of radium are due to the emanation stored therein. But the volume of the emanation is infinitesimally small. From one gram of radium compound the volume of the emanation evolved would not amount to more than 1.3 of a cubic millimetre. This needle point of gas evolves enough heat per hour to raise the temperature of 75 grams of water one degree. If it were possible to obtain one cubic centimetre 
(a thimbleful) of this emanation in the form of a gas we should find that it possessed the power of emitting, altogether, over seven million calories of heat! This is more than sufficient to raise 15,000 pounds of water one degree, and all this heat from a thimbleful of an invisible gas! The important phase of this statement is that it is altogether outside of any hypothesis or theory. It is a simple straightforward fact. Now, the heat evolved by exploding the same volume of hydrogen and oxygen mixed in the proportions required to form water is about two calories. We find then that the heat evolved by the radium emanation is over three million five hundred thousand times greater than that let loose by any known chemical reaction. This seems to be an unanswerable reply to those who, would ascribe the energy of radio-activity to ordinary chemical action or, on the other hand, to those who would ascribe it, instead, to an external source which, hypothetically, the radium atom alone has the power to respond to. With the passing away of these interpretations we are locked up with the only other conclusion possible,- - that the radio-activity is due to an enormous store of energy within the radium atom itself. The energy of radio-activity is intra-atomic.

The amount of heat generated by radium gives us some additional general information. In any mass of radium not all its atoms are disintegrating at the same time. In the foregoing chapter we were led to understand that they would go to pieces only as they became unstable, and that this instability was a mere chance for an individual atom, though a constant for the average one. It is interesting to know how many atoms of radium disintegrate per second. If we ascribe the heat emission to the alpha particles we are let into the secret. In the case of radium there are at least four stages in the disintegration, each 
one of which is accompanied by the expulsion of an alpha particle. Therefore, four is the very least number produced from any one atom of disintegrating radium. On this basis, calculation leads to the conclusion that in every mass of radium, however great or however small, not more than thirteen trillionths of it is undergoing change per second, and all its radiated energy is due to this infinitesimal portion of it. Knowing the amount of radium undergoing change per second, it is possible to deduce the average life of the radium atom. This life is about 2,450 years as a minimum estimate. It is obvious from this that the radium at present existent in the world has not always been with us. It has come into existence since the formation of the world. It is also obvious that in the course of a few thousand years all the radium at present existing will be reduced to practically nothing. What we have in the world to-day has come to be, and will cease to be, within the time of man. We may ask, then, is it an unprecedented substance, the phenomenon of a day in all time?

Not likely. Certain indications point to the conclusion that radium is itself a disintegration product from the heavier, and more slowly changing, radio-active element uranium. It turns out that the relative proportion of radium to uranium in the different radio-active minerals from which radium is extracted is a constant quantity. This is just as it should be if uranium were the parent of radium. But there is contrary evidence. If uranium is the parent of radium, the actual genesis of the radium ought to be capable of detection. Soddy has tested this point by carefully extracting all the radium from a mass of uranium nitrate and testing the uranium for the growth of radium at frequent intervals throughout a year. He has been able to show that if radium is generated its quantity 
is 100,000 times less than it, theoretically, should be. The source of radium is, therefore, still an open question, though we may be fairly sure that its generation is constant from some source or other, and that its decay will be balanced 'by a constant fresh supply.

The amount of energy locked up in a gram of innocent looking radium bromide and appearing as heat on the disintegration of the whole gram, calculates out to about one billion calories, - a prodigious quantity of energy. 'ithis energy is not the total amount contained in the radium. It is only that portion which becomes manifest on the decomposition of the radium into its disintegration products. If the gram of radium could be wholly dissociated into corpuscles, the energy let loose would greatly exceed the above amount.

But radio-active substances in their normal character as chemical elements are in no way different from the inactive elements. Radium is like barium and strontium; uranium is like tungsten and molybdenum; polonium is like bismuth; and thorium is like titanium. If it were not for thcir bizarre property of radio-activity they would be in no sense remarkable. Hence, it is impossible for us to come to any other conclusion than that there is locked up in all the so-called "elements" of matter an enormous store of energy which, except in those elements of heaviest atomic weight like radium and thorium, remains latent and unknown. Professor Thomson as the result of his calculations, concludes that a gram of hydrogen has within it energy sufficient to lift a million tons through a height considerably exceeding one hundred yards; and that since the amount of energy is proportional to the number of corpuscles comprising the atom of the element, the energy of the other elements such as sulphur, iron, or lead must enor- 
mously exceed this amount. We have already shown that Professor Thomson's calculations have a habit of squaring with fact. The energy whence we obtain our manufacturing power whether derived from burning coal or gas or any other chemical reaction depends upon the action of one system of atoms upon another. - It is absolutely insignificant compared with the limitless energy. .locked up within the atoms themselves. We know that this energy exists, but, to-day, we have no control over it. We can neither set it loose nor tie it up in any way whatever. We can only observe it. But it would be rash indeed to predict that our impotence will last forever. Strange things happen nowadays and yet stranger things may, nay will, be seen by future men. We have no real warranty that this infinity of energy will be tapped by man, except this: That what man earnestly longs for he will obtain. If he knows that every breath of air he draws has contained within itself power enough to drive the workshops of the world he will find out some day, scme how, some way of tapping that energy. In looking for plausible methods of attacking the problem we find at least a hint. X-rays passing through a substance cause it to emit $\mathrm{X}$-rays. These induced X-rays are called secondary rays or the S-rays of Sagnac. They are emitted from solids, liquids and gascs whenever X-rays fall upon them, and they differ in character from the primary rays that produce them. They are not pure X-rays for they consist of corpuscles as well, and since some of the radiation is exceedingly easily absorbed, it is likely that alpha particles are present also. If this is the case it is difficult to see why we should not call a body lying under the impact of X-rays, radio-active; and if the body becomes radio-active in this way, it is a moot point, indeed, as to whether the energy of the radiating substance 
is not greater than the energy of the $\mathrm{X}$-rays falling upon it-the excess of energy being derived from re-arrangements taking place in the atoms of the body exposed to the primary X-ray bombardment. It is conceivable that some such method of attack might lead to a way of doing by external agency what radio-active bodies can do spontaneously, i. e., liberate the energy locked up in the atom. It has been playfully suggested by Professor Rutherford that some day it might be possible to construct a detonator which would send a wave of atomic disintegration through the earth and decompose the. whole round world into helium, argon, and other gases, leaving literally not one stone upon another. Without being frightened by any such humorous suggestion as this, we can easily grant that with the continuous acceleration of scientific research where one year of the present counts for a cycle of former time, there will come a day in the unending succession of days when men will look with mingled horror and amusement at the burning of coal and wood, and will date the coming in of their kingdom to the time when Curie and Laborde demonstrated the existence and extent of intra-atomic energy. 


\section{CHAPTER IV.}

\section{The Electrical Nature of Matter.}

It often happens that in inverting a problem the truth drops out. Copernicus, instead of assuming that the sun moved around the world, succeeded better by assuming that the world moved around the sun. Kant, also, instead of assuming that knowledge must conform to objects, inverted the idea by assuming that objects must conform to our knowledge. In a similar fashion it is now proposed to invert the conception of matter and electricity that we have so far gained. Instead of assuming that corpuscles are particles of matter possessing the properties of negative electricity, we shall assume, instead, that corpuscles are particles of negative electricity possessing the properties of matter. It will be seen that this new way of looking at things will lead to new knowledge. It is proposed in this chapter to show by arguments adduced from facts that Maitter is made up of Electricity and nothing but Electricity. We can best develop the thesis by comparing matter and electricity in the possession of one common property. The one sole unalterable property of matter is inertia. It requires an effort to put matter into motion when the matter is already at rest, and it requires an effort to stop matter after it has once been set in motion. Inertia is simply the Latin word for laziness, but the "laziness" of matter is exceptional and peculiar. Matter hesitates as much to stop. when once in motion as to start when once at rest.

Matter hesitates to start. Water will reflect a cannon 
ball or flatten a bullet. A dynamite charge exploded upon a stone will shatter the stone before the air has time to move away. Matter also hesitates to stop. It tends to overshoot the mark. A bullet will fly many a yard after it has left the gun. In the gun it was urged by force, but after it has left the gun it not only continues on its way without force but against force, the force of friction, until eventually it is overcome. It is sometimes asked: "Is perpetual motion possible?" It is not only possible but nccessary if there is no interfering or opposing force. The inertness, or inertia, of matter is defined in the First Law of Motion: "A body at rest remains at rest and a body in motion continues to move with a constant speed in a straight line, unless acted upon by some external unbalanced force." We may illustrate this law by the case of a body which is in motion under a pair of balanced forces. Thus, a steamship under the application of force does not instantaneously assume its full velocity; it gathers way.

After it attains a constant speed it is under the application of no resultant force whatever, the force developed by the engines simply overcoming the contrary force of the resistance of the water. It is thus obeying the first law of motion. On the cessation of the force from the engines, the hitherto balanced force of friction begins to be effectual and the ship stops, not at once but gradually. Now this property of inertia which causes the steamship to act in this way belongs, also, to electricity. The inertia of electricity is called self-induction. When a current of electricity is suddenly started in a wire it does not rise to its full strength instantaneously. Just like the steamship it requires a certain time to gather way and to rise to its full strength. Again, when the current is suddenly broken, it does not stop instantaneously but tends to persist. This tend- 
ency to persist is interesting. This sudden breaking of a current gives rise to an electrical push, or electro-motive force, far greater than that which maintained the current. The instant the circuit is broken there is a sudden lurch forward of the current which enables it to spring across the break and which gives rise to the spark seen at that point. The more sudden the break the more violent is the spark. This is very like the blow which a high-pressure service watertap experiences when the flow of water is suddenly arrested by turning the tap. The jar of the water momentum will sometimes burst the pipe. The delay of the current on making the circuit, and its tendency to persist after breaking it, prevents any very sudden change in the strength of a current. It is this that hinders telephonic communication through very long wires and renders ocean cable telegraphy a comparatively slow operation. In the past, this refusal cf an electric current to undergo any very sudden change has been called the phenomenon of self-induction or, sometimes, quasi-electrical-inertia. We propose, now, to eliminate both the quasi and electrical and to develop the idea that this unwillingness of an electrical current to start or stop is the unwillingness of matter to start or stop. That, in each case, the phenomenon is due to simple inertia, and that that inertia is purely electrical in its nature.

The idea that inertia is electrical in its origin first took form in a paper by J. J. Thomson, which appeared in the Philosophical Magazine for 1881, and which has since become classical. This paper dealt with the properties of a moving charged sphere, and in it Professor Thomson showed that an electrical charge, concentrated on such a moving sphere, must possess inertia due to the electro-magnetic field of force which it creates by its motion in the surrounding ether. In other words, it will tend to resist change of 
motion, which we understand to be inertia, and will thus behave as though its mass were increased. In order that this inertia, or increase of mass, should become perceptible, it is necessary that the sphere should be very small and that its speed should approach that of light. We can best illustrate this by appending certain calculations subsequently made by Sir Oliver Lodge, showing the extent to which the apparent mass would increase as the speed of light is approached. If 1 equals the mass measured by the inertia of the sphere under slow motions, at half the speed of light the mass becomes 1.12 ; at three-quarters, 1.37 ; at nine-tenths, 1.8 ; when the speed is 99 per cent. of that of light the mass is 3.28 ; at 99.5 per cent., 5; while between this last value and that of light the mass increases to infinity. It is plain, then, that no substance can move faster than light; and it is interesting to note how very near the speed of light must be approached before the mass becomes increased to an enormous extent. Now, this paper of Thomson's, at the time of its publication, excited but little comment because of the fact that at that time no bodies were known which were sufficiently small and sufficiently swift in their velocity to make this increase in mass experimentally demonstrable. The paper belonged to mathematical academics. It was not practically important. With the coming, however, of corpuscles, the paper assumed a very different aspect. We have in corpuscles particles very much smaller and very much lighter than the smallest and lightest atom; and, moreover, we have shown that in the case of radium these particles are shot off with velocities approaching that of light. We have, then, in the corpuscle a means of verifying this mathematics and of determining, as a matter of material fact, whether or not the mass measured by the 
inertia of a body increases with its velocity. This investigation has been carried out by Kaufmann with the most interesting results. These results are shown in the following table. The first column expresses the relative velocitias of the particle, and the second column the value of the fraction $e / m$, where $e$ is the charge on the particle and $m$ is its mass.

$\begin{array}{cc}\text { Value of } v . & \text { Value of } e / m \\ 2.83 & .62 \\ 2.72 & .77 \\ 2.59 & .975 \\ 2.48 & 1.17 \\ 2.36 & 1.31\end{array}$

We see by this table, reading from bottom to top, that the value of $e / m$ diminishes as the velocity increases. We learned in Part III, page 65, that the value of $e$ remains constant. Hence this table indicates that the mass increases with the velocity. Kaufmann's work, therefore, demonstrates, experimentally, the truth of Thomson's mathematics. Not only so but it affords Professor Thomson the opportunity of still further extending the scope of his mathematical conclusions. In a word, Thomson calculates the ratio of the masses of the rapidly moving corpuscles given out by radium to the mass of the same particles when at rest, on the assumption that the whole of the mass is due to the electrical charge upon it; and he compares these results with the values as determined by Kaufmann's experiments. The comparison is shown in the following table, where the first column contains the velocities as determined by Kaufmann, the second column the mathematical determination of the number of times the mass of a particle moving with the given velocity ex- 
ceeds the mass of the particle when at rest, and the third column the same values as found by Kaufmann experimentally:

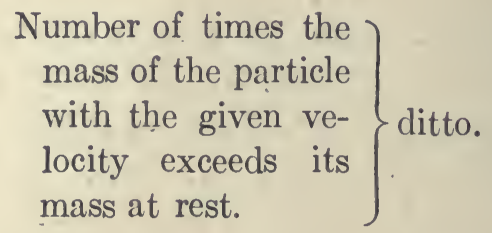

Velocity of the particles.

2.85

2.72

2.59

2.48

2.36
Mathematically determined.

3.1

2.42

2.0

1.66

1.5
Found by experiment.

3.09

2.43

2.04

1.83

1.65

We see from these results that the calculated and the experimental results practically agree, and we are, therefore, entitled to believe, if we like, that the whole mass of the corpuscle arises from its electrical charge. But the corpuscle we deem to be the constituent of an atom, the atom the constituent of a molecule, and a molecule the constituent of a mass of matter, such as a table or a chair. Hence, on this view, the inertia of any material body, and the mass of it as measured by the inertia, is due simply to electrical charges in motion. On this view, then, the to-and-fro motion of a pendulum and the electrical oscillations of the spark from a Leyden jar, are simply two manifestations of an identical thing, the inertia of a charged body.

But what do we mean by saying that the mass of a body depends simply on an electric charge? By mass is meant quantity of matter, and the idea that the quantity 
of matter in a body depends on the speed with which an electric charge 'moves, is difficult to grasp concretely; for we are accustomed to think that the quantity of any given object is invariable. We may, however, obtain a concrete representation of the idea by considering the analogical case of a sphere moving through a frictionless liquid. In such a case, when the sphere moves, it sats the liquid around it moving with a velocity proportioned to its own, so that the sphere is accompanied by a definite volume of the liquid. This volume is one-half the volume of the sphere and the sphere, therefore, behaves as though its mass were increased by that amount. In the case of a cylinder moving at right angles to its length, the mass of the cylinder is increased by the mass of an equal volume of the liquid. Now the cylinder in our case is the electric charge and the frictionless liquid is the ether. The electric. charge possesses no mass at all, and the total mass, therefore, is due to the bound ether carried along by the charge ir its motion, the total anount of the bound ether depending on the velocity of the charge. On this view of "the electronic theory of matter," all mass is the mass of the ether, all momentum, whether clectrical or mechanical, the momentum of the ether, and all kinetic energy the kinetic energy of the ether.

The electronic theory of matter may be used, as we l, to account for certain properties of electricity. Corpuscles, used in this connection, are generally given another name; they are called electrons. Since we have used the word corpuscles throughout we shall continue to use it in this connection, remembering, however, that the two words, corpuscle and electron, stand for the same thing precisely. An electric current, for example, is easily explained on the corpuscular theory. Electricity may be conducted through 
gases, liquids and solids. In gases the electricity is conveyed by free corpuscles, flying bullet-like, and with velocities amounting, sometimes, to a hundred thousand miles a second. In liquids the velocity is more nearly an inch an hour. In liquids, the corpuscles travel with the atoms, and for this reason travel slowly. Liquid conduction is what Sir Oliver Lodge calls "the bird-seed method of conduction;" for the corpuscle travels through the liquid from one electrode to the other much as a bird carries a seed. It moves slowly because it must jostle its way through the throng of other atoms, and also because of the load of the heavy atom it conveys. In the case of solids, or metallic conduction, the atoms are fixed in their places relatively to one another. Their only power is that of vibration. The corpuscles, therefore, can go from one end of the wire to the other, only by being handed on. Each atom in the string along the wire receives one and passes it, or another like it, on to the next, so that for every corpuscle that starts at one end of the wire, another like it passes out at the other end.

Magnetism, on the basis of the electronic theory, is a force developed at right angles to the moving charge. This magnetism may be seen in the free corpuscles flying through a Crookes' tube where they may be bent up and down by a magnet; in the beta-rays from radium where they also fly free; or in the magnetism developed in a wire when corpuscles are being handed on through it and constituting what we call a current. Light, Röntgen rays and all other radiations result, and must result, from disturbances, in the surrounding ether whenever the velocity of the electric charge is accelerated, diminished, stopped or changed in direction.

The electronic theory teaches us: 
1. That negative electricity is made up of unit charges called corpuscles, or electrons.

2. That static electricity is due to the action of these corpuscles at rest.

3. That current electricity is due to nothing but these corpuscles in motion, whether through gases, liquids or solids.

4. That magnetism is a force developed in the ether as right angles to the direction 'of motion of the corpuscles.

5. That light and other radiations are due to disturbances in the surrounding ether caused by a change in the motions of the corpuscles.

6. That the self-induction of an electric current and the mechanical inertia of matter are identical, and that they are due to the electric charge, or corpuscle, in motion.

7. That mass, or quantity of matter, is simply the ether carried along by the corpuscle in its motion, that it is by no means a constant quantity but depends upon the velocity of motion of the corpuscle.

8. That the atoms of matter, themselves, are made up of the same negative charges or corpuscles, each aggregation of corpuscles being surrounded by a sphere of positive electricity.

9. That, consequently, matter, in its last analysis, is identical with electricity.

We see, then, that the electronic theory accounts for static electricity, current electricity, magnetism, the radiations of light, X-rays, etc., inertia, chemical action, the atoms of matter and their peculiar properties as exemplified in the periodic law, and the phenomena of radic. activity. 
We must now ask ourselves the questions: 1 . Is it proved? 2. Are there any phenomena that the theory will not account for?

With regard to the first question, we may say at once, the theory is not proved. It is an hypothesis which accounts in a beautiful way for the phenomena enumerated above. It finds its chief acceptance, outside of this, in the fact determined by Thomson that the whole mass of matter may be accounted for on the supposition that it is electrical in origin. But between the fact that it, and all these other matters, may be accounted for, and the fact that there is nothing else in heaven and earth that will account for it instead, there is a great gulf fixed. The acceptibility of the hypothesis depends on the extent of its exclusive power to account for things; the more exclusive it becomes the more we shall believe it. In the meantime, while it is certainly extraordinary in its power to explain, the answer to our second question bids us be cautious. There are phenomena which the theory does not yet explain. For example what is positive electricity, as distinguished from negative which consists of these corpuscles? The answer is, we do not know. We conceive of an atom as an aggregation of negative corpuscles arranged in a certain number in a certain way, and surrounded by a sphere of positive electricity which balances the negative electricity of the corpuscles within it. We can account for positive electrification as distinct from positive electricity on the supposition that a positively electrified body is one which has lost some of its corpuscles while a negatively electrified body is one which has gained corpuscles. But this does not tell us what positive electricity actually is. If it is made up of particles, these particles must either have no mass at all, or very little, for the mass of the whole atom seems to be simply the sum of the 
masses of its negative corpuscles. Positive electricity as apart from an atom does not seem to exist. It never seems to fly free as the corpuscle does. Its nature is, to-day, a mystery.

What is gravitation? Again, the answer is not forthcoming. The force of gravitation is minute and it is only apparent to us because of the nearness to us of the overwhelming mass of the earth. Still it ought to be capable of explanation and the explanation has not yet arrived.

Still, again, what are Life and Mind? There is nothing in the foregoing pages to give us even the glimpse of an idea of the physical basis of Life. It is unreasonable, however, to expect too much for a theory still in its infancy, and we can afford to marvel at the mysteries which it does explain, and to give it on this account a large measure of acceptance.

It ought to be rointed out at the end of this chapter that the theory of atomic disintegration is quite independent of the electronic theory we have been considering. Atomic disintegration postulates nothing beyond the conception, familiar to chemists for the last hundred years, that atoms exist. Once grant the existence of the chemist's atom and the disintegration of the atom necessarily follows. Neither has it any necessary connection with the facts of radio-activity, the transmutation of the elements, or the vast stores of intra-elemental energy. 



\section{PART VI.}

\section{INORGANIC EVOLUTION.}





\section{PART VI.}

INORGANIC EVOLUTION.

\section{CHAPTER I.}

\section{Celestial Dissociation.}

The products of the dissociation of the heavy atoms such as radium and uranium render the air a conductor of electricity and this conductivity, and hence the dissociation which causes the conductivity, is measurable by the electroscope. The electroscope is hundreds of thousands of times more sensitive than the most refined type of spectroscope in existence. This, however, should not detract from the admiration which is due to the spectroscope. In the same measure that the electroscope exceeds in sensitiveness the spectroscope so does the spectroscope exceed any other known instrument for the detection and mensuration of minute quantities of matter. Besides, the electroscope is exceedingly limited in its application while the range of the spectroscope is as wide as the universe. That the spectroscope will detect the millionth of a milligram of matter, and on that account has discovered new elements, commands our admiration; but when we find, in addition, that it will detect the nature of forms of matter billions of miles away and, moreover, that it will measure the velocities with which these forms of matter are moving, with an absurdly small per cent. of possible error, we can easily acquiesce in the statement that it is the greatest instrument 
ever devised by the brain and hand of man; and that if we are to win additional knowledge of elemental dissociation as it exists in the sun and stars, the spectroscope is our one sole means to that end.

On a priori grounds we should rather expect to find this dissociation. For the elements which dissociate on earth, thorium for example, are in their normal chemistry, in no wise remarkable or particularly distinguished from other elements. The other elements, therefore, ought to dissociate under favorable conditions. Now, it is in the sun and stars that we shall find these favorable conditions if anywhere; for they constitute furnaces with temperatures enormously high and transcendental so far as man may hope to attain. The spectroscope with which we shall search for this celestial dissociation is, in its essentials, simple in the extreme. The fundamental part of the instrument is a prism of glass or a grating. The light from the body under examination is passed through a fine slit and hence through the prism. The prism sifts out the light so that the longest or "red" waves go to one side and the shortest or "violet" waves to the other. Each kind of light thus yields its own individual image of the slit in the form of a fine line. All incandescent solids, liquids, and some dense gases on becoming incandescent give out white light consisting of waves of every conceivable length and hence instead of separate little line-like images there results an infinity of images all blended together into a broad band ranging by imperceptible gradations through red, orange, yellow, green, blue and violet. Such a band of color is called a continuous spectrum. Fig. 45. If, now, we pass from incandescent solids and liquids to substances which easily volatilize, the light from their flames presents a very different appearance. We find, in fact, that it consists of a 
copious emission of light of a few wave-lengths only, the others being missing. The result of this is that instead of

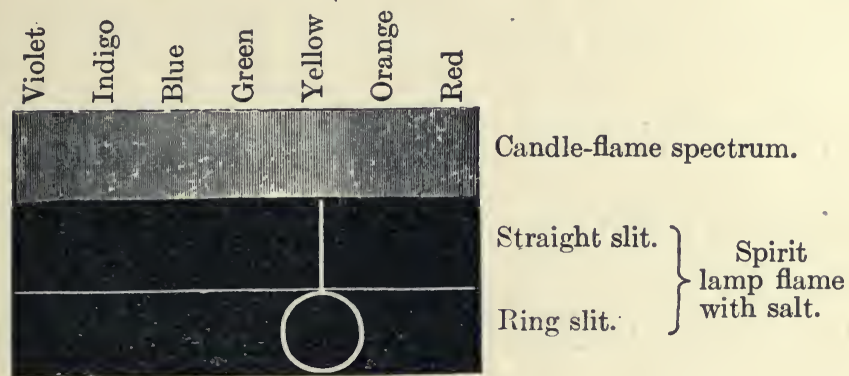

Fig. 45. A continuous and a discontinuous spectrum.

a broad band of colour, we see a series of lines of definite colour and separated by definite spaces. Such a series of definite lines is called a discontinuous or line spectrum. No two elements emit the same light, and hence no two elements yield the same line spectrum. It is therefore possible to recognise each element by the spectrum of its lines when sifted out by the prism and this process is called spectrum analysis. It makes no manner of difference whether the element exists on the earth, in the sun or in the farthest "fixed" star. Its existence may be recognised beyond dispute wherever light shines from it to us. Fig. 46. In the

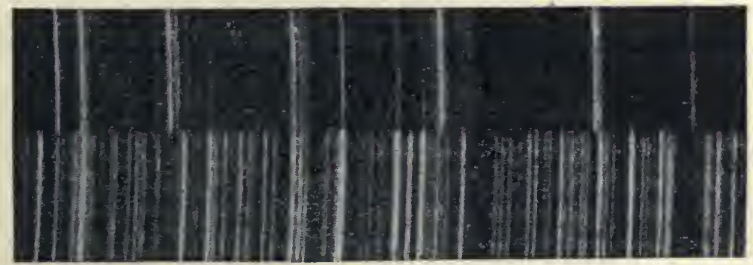

A

B

Fig. 46. Parts of the spectra of (A) barium and (B) iron (from a photograph). 
case of some elements, the lines of the spectrum, instead of being irregularly distributed, are arranged rythmically so that in appearance they strongly resemble a Corinthian column seen under a strong side light. Such line spectra are called fluted spectra. The spectrum of carbon is a beautiful and typical example of fluted spectra. Fig. 47.

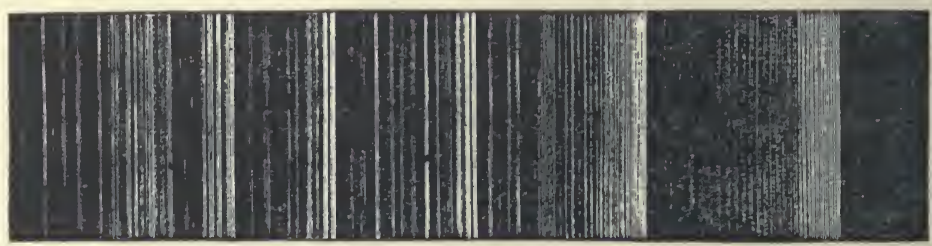

Fig. 47. Fluting of carbon.

In the case of certain elements, again, the lines arrange themselves in accordance with a beautiful law in such a fashion that they constitute a sequence numerically related to one another. Such a sequence of rythmically related lines is called $a$ series. Fig. 48.

Violet

Red

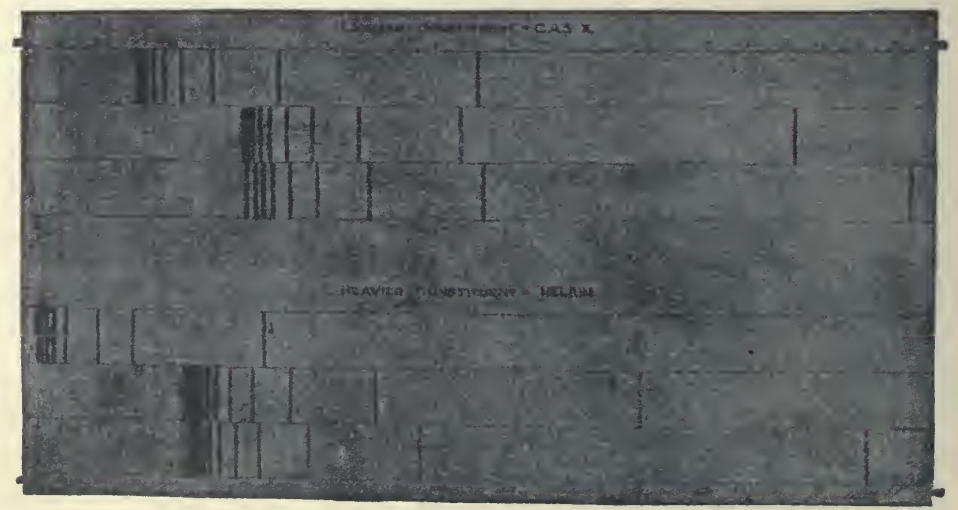

Fig. 48. The series in the cleveite gases. 
The lines constituting the discontinuous spectrum of an element, as normally produced, are bright lines; that is, they have definite colours. In the beginning of the last century Fraunhofer discovered that the continuous band of color constituting the spectrum of sunlight was broken by a great number of lines as in the case of a discontinuous spectrum, but that these lines were dark instead of light. The explanation of this lay in the fact that the great mass of the highly heated interior of the sun gives rise to light of every ccnceiyable wave-length constituting the continuous spectrum, and that the incandescent gases surrounding this heated interior have the selective power of absorbing the very light-waves they themselves emit and thus give rise to dark lines which, if it were not for the heated interior of the sun, would be bright. These dark line spectra are called Fraunhofer's lines. Fig. 49. They constitute the spectra of all the incandescent gaseous substances existing in the atmosphere of the sun. Lines of the spectrum of any one substance in this atmosphere occupy the same relative positions as they do upon earth and hence the substance may be recognized with as much certainty as though it existed in the laboratory instead of 93,000,000 miles away.

With these definitions we are now in a position to take up the business of our subject-the question as to whether or not the elements exist in decomposed simpler forms in the sun and stars. The work done on this subject comprises forty years of the life of Sir Norman Lockyer. Other men have made their contributions, both directly and indirectly, but Lockyer has been the foremost champion of the idea and to him alone belongs the chaplet of the victor. One of the first tasks put before Lockyer in the pioneering stage of his work was the removal from the mind of science of a serious misconception. Men were 


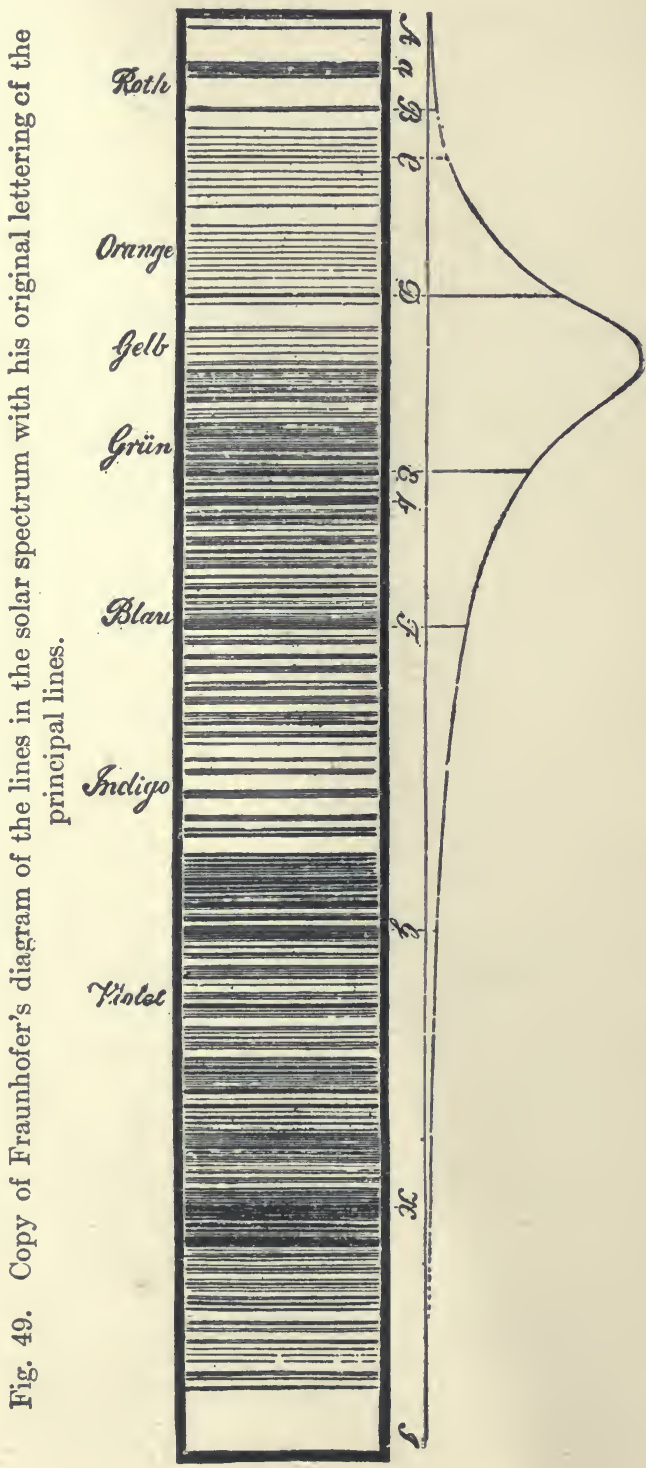


deeply imbued with the idea that an element could have one, and only one, spectrum. They held this idea because, while not formally saying so, they believed that the atom which caused the spectrum was a simple undecomposable thing. This idea of one element-one spectrum was a serious mistake, for it has been possible to show that an element may have two or three spectra under different conditions,-though each spectrum is characteristic for that substance. Thus, Plucker and Hittorf in 1865 announced that " there is a certain number of elementary substances which when differently treated furnish two kinds of spectra of quite a different character, not having any line or band in common." This was the first blow to the current conception though it took many more before the fact won the concensus of scientific belief. The conditions under which a substance must be placed in order that its spectrum may change from one form to another are as follows:

a. The temperature of a flame.

$b$. The temperature of the electric arc.

$c$. The vibration due to an electric spark of very high potential.

These three conditions, which amount to three stages in temperature, give rise, in the case of many elements, to three or more different spectra.

Let us take the case of iron, according to Lockyer:

1. The flame spectrum consists of a few lines and flutings, only, including several well-marked lines, some of them arranged in triplets.

2. The arc spectrum consists, according to Rowland, of 2,000 lines or more.

3 . The spark spectrum differs from the are spectrum in the enhancement of some of the short lines and in the reduced relative brightness of others. 
4. A spectrum consisting of a relatively very wmall number of lines which are intensified in the spark.

We see, thus, that the spectrum of an element depends upon the temperature to which it is subjected, and if we ask ourselves the meaning of the change which the spectrum undergoes, it is difficult to imagine any other efficient cause than elemental dissociation with increasing temperature to account for it. But other explanations, more or less specious, may be assigned, and as the dissociation, if it exists, exists for the briefest possible time under the innmediate influence of the arc or spark, it is impossible to prove it. Help, however, is found in another direction. As Lockyer says:

"For twenty years I longed for an incandescent bottle in which to store what the centre of the spark produces. The stars have provided it."

The sun and stars really constitute so many "incandescent bottles" in which to study the variations of spectra under different conditions and afford, as we shall see, proof of the most reasonable sort of the dissociation of the elements.

\section{THE CASE OF IRON IN THE SUN.}

-In one part of the sun, called the " reversing layer," the spectrum of iron is represented by nearly a thousand lines. In another part of the sun, called the "chromosphere,"

- which is apparently at a much higher temperature, the spectrum of iron is reduced to two lines only. It is difficult to see what other explanation we can assign to this remarkable fact than that at the higher temperature of the chromosphere the atom of iron is decomposed or dissociated into some simpler constituent which appears at that point. This explanation is rendered additionally valid by the 
further fact that in sun-spots one set of iron lines is found, and in this chromosphere, quite another.

Furthermore, at the maximum sun-spot period the widened sun-spot lines are nearly all unknown; at the minimum sun-spot period they consist of iron and other well-known substances, a fact only to be explained on the assumption that the increased energy at the maximum sunspot period is adequate to break the "iron and other" well-known substances." into finer things. The most interesting evidence, however, of the decomposition of iron under the fervent heat of the sun is adduced from the fact that while some of the "iron" lines in the sun show that the substance giving rise to them is in rapid motion, other different and adjacent "iron" lines show that the substance in causal connection with them is at rest. Now, if the "up-rush" and "down-rush" of incandescent gas in the sun were caused by iron vapour as iron, it should be registered equally by all the iron lines alike. The fact that it is not gives us every reason to suppose that in the sun, "we are not dealing with iron itself, but with primitive forms of matter contained in iron which are capable of withstanding the high temperature of the sun, after the iron observed as such has been broken up."

Fig. 50, according to Lockyer, shows the variations, in the line spectrum of iron as they existed in the reversing layer of the sun, the electric arc, the high-potential electric spark, in sun-spots observed at Kensington, and in solar prominences observed at Palermo. It will be observed that the normal Fraunhofer's lines of iron in the sun correspond to the spectrum of iron as obtained at the temperature of the arc, while the iron spectrum in sun-spots or solar storms corresponds to the more strenuous conditions of the highpotential spark. 
THE NEW KNOWLEDGE.

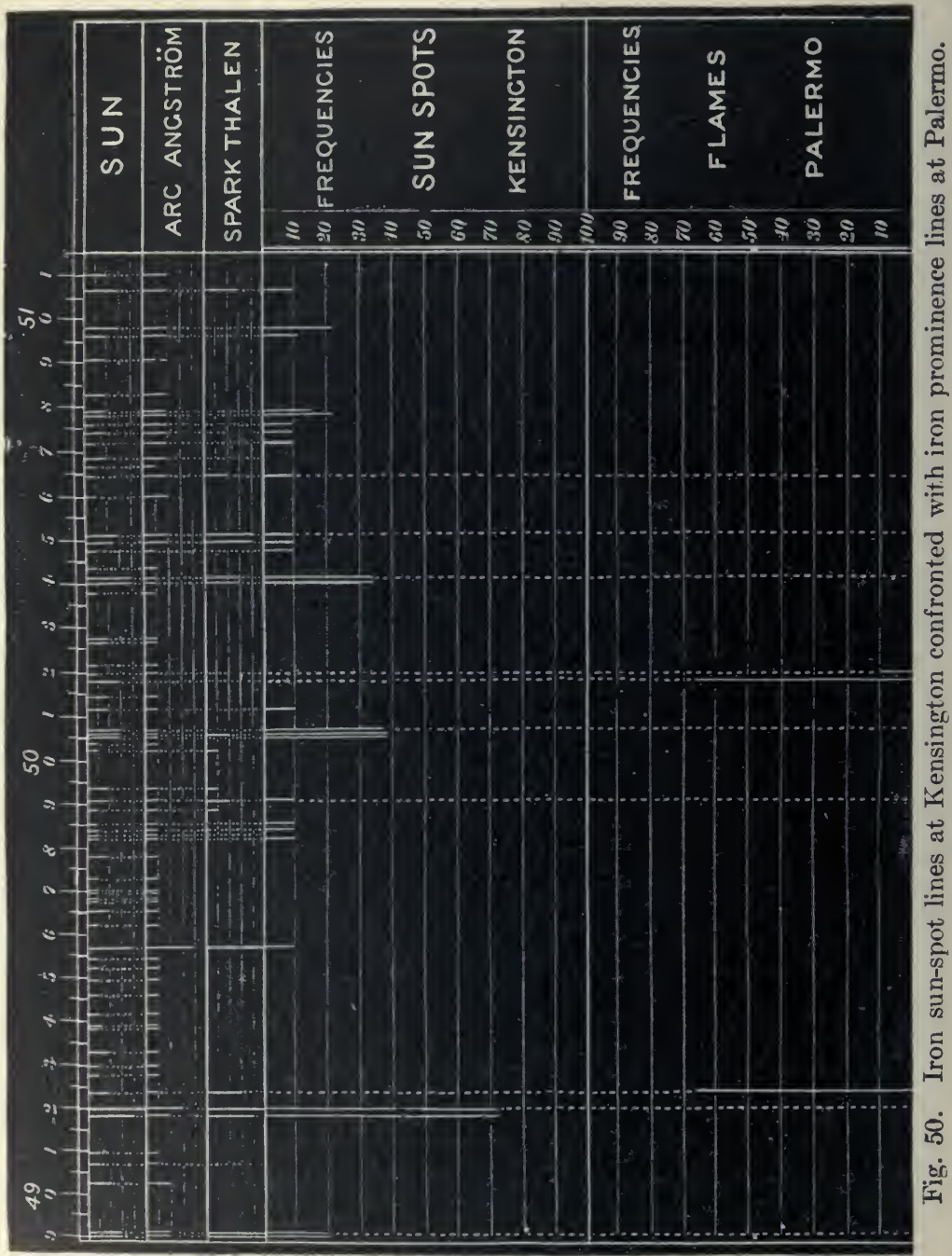


Fig. 51, according to the same authority, shows the different rates of motion registered by different and adjacent iron lines in the sun.

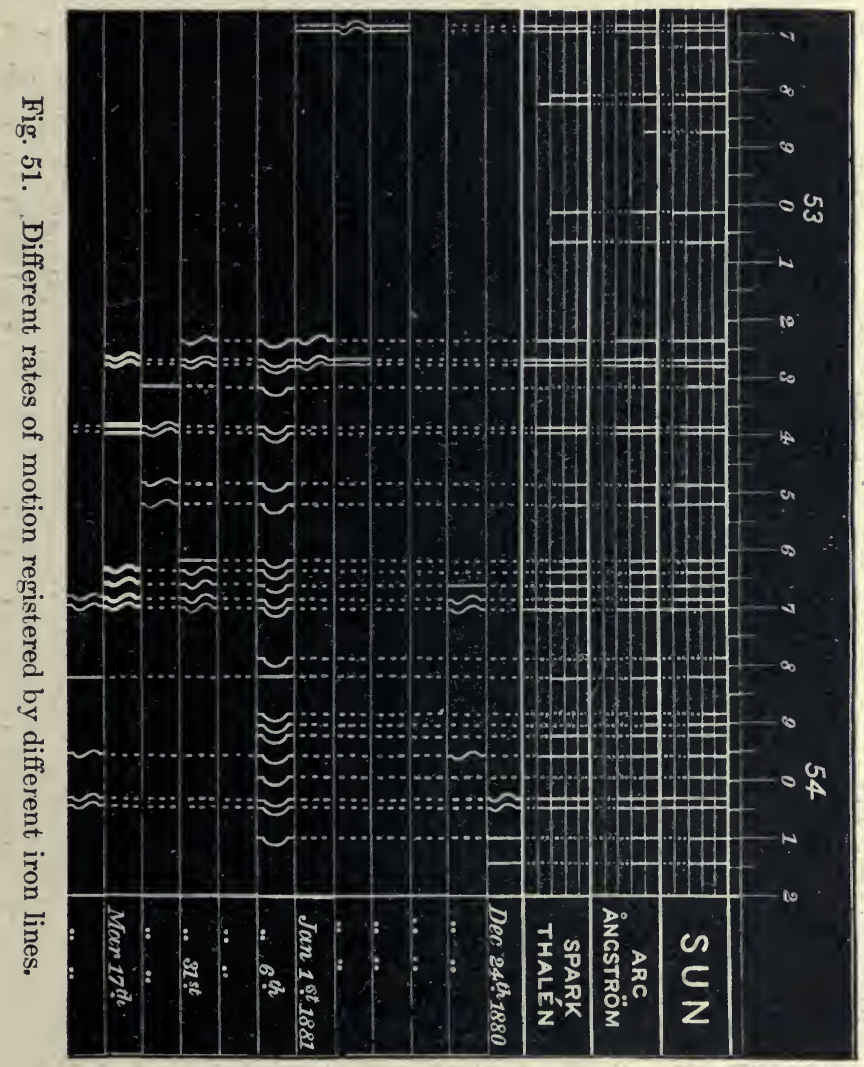

THE CASE OF MAGNESIUM.

The difference between the flame spectrum of magnesium and the spark spectrum is marked. Some of the flame lines disappear altogether, and two new lines make their appear- 
ance in the spark. Turning to the sun, we find that the lines characteristic of the flame spectrum do not appear, while some of the spark lines do. Magnesium, therefore, takes its place beside iron as an element which, in the sun, exists in a dissociated form; or, at any rate, that is the only explanation which will render the results consistent with reason.

\section{THE CASE OF CALCIUM.}

The evidence of dissociation in the sun afforded by calcium is interesting. In the electric-arc spectrum of calcium, a certain blue line is particularly prominent, while two other lines, named $\mathrm{H}$ and $\mathrm{K}$ respectively, are thin. In the solar spectrum, on the other hand, the $\mathrm{H}$ and $\mathrm{K}$ lines of calcium are particularly thick, while the blue line is thin. Again, in solar storms the blue line of calcium is always absent, while the $\mathrm{H}$ and $\mathrm{K}$ lines of the element are almost always seen. Still again, the blue line is absent in eclipses, while the $\mathrm{H}$ and $\mathrm{K}$ lines are the brightest seen or photographed. Finally, in photographing the spectra of sun-spots it was discovered that the $\mathrm{H}$ and $\mathrm{K}$ lines of calcium are reversed or darkened, while the blue line is not reversed. It must be obvious, then, from this evidence that the calcium which on earth yields all three lines, must in the sun be decomposed into at least two sub-substances, one of which is in causal connection with the blue line and the other with the $\mathrm{H}$ and $\mathrm{K}$ lines.

\section{STELLAR EVIDENCE.}

But evidence is found in other suns. The spectra of the stars afford in many cases the same simplified spectra observed in the sun, of iron, magnesium and calcium. In addition, simplified spectra of other metals are discovered, such as titanium, copper, manganese, nickel, chromium, 
vanadium and strontium. To these supposably brokendown metals the prefix proto is applied. By proto-iron, proto-copper and proto-nickel, for example, is meant the constituents of iron, copper and nickel as they exist in the sun or hottest stars. A very important proto-element is proto-hydrogen, discovered some time ago by Professor Pickering of Harvard University, in the star named zetaPuppis in the constellation Argo. The spectral lines representing this substance Pickering at first supposed to signify a new element; but he was able to show, later, that they belonged to a new series of hydrogen lines constituting a form of hydrogen unknown on earth. Subsequently, this same proto-hydrogen was discovered in the stars 29 Canis Major and gamma-Argus. It is interesting to note that this broken-down, or proto-hydrogen, is con'fined to the very hottest stars known.

If we accept the dissociation hypothesis, these curious proto-spectra are naturally, simply, and sufficiently explained. If we reject it, we shall look in vain for any other present-day explanation which will co-ordinate and harmonize the observed results.

In our studies of the periodic law and radio-activity, we found reason to believe that the elements were not by any means the simple bodies formerly believed in, but that the atoms of these elements were highly complex and were built up of particles finer still. We saw reason to believe that in the solar and stellar furnaces, if anywhere, we should find these sub-elemental forms of matter existing in a stable form, and that we do find a series of remarkable phenomena which can be explained only on the supposition that we previously had every reasonable reason to believe, surely strengthens and rivets tight the whole hypothesis of the resolution of the atom. 


\section{CHAPTER II.}

INORGANic Evolution.

In the preceding chapter we attempted to show by a brief exposition of the work of Sir Norman Lockyer that many of the elements of matter as they exist in the sun and stars are different from, and simpler than, these same elements as we know them on earth. These simplified substances are called proto-elements and the process by which they are produced is dissociation owing to the super-intensity of the solar and stellar heat.

We now propose to show in accordance with the work of the same investigator that this dissociation according to temperature results in a stupendous evolution of inorganic matter, besides which organic evolution is the affair of a day, and to which it is a mere appendix.

By organic evolution we mean that the vast multitudes of plants and animals as they exist to-day are not specially created but that they have all resulted from older, simpler forms, and these from simpler still, and these again from still simpler, down and down to some ancient simple type from which they have all probably evolved. So by inorganic evolution, we mean that the eighty odd elements of matter as we know them on earth to-day were not specially created, but that like the plants and animals, they have truly evolved, from simpler, and still simpler, types back to some really simple element from which they have all evolved through infinite æons gone by. Futhermore we wish to show that (206) 
the evolution of living things is not parallel to, but the continuation and end of, the inorganic evolution. We deem that the governor of this inorganic evolution is temperature, and that the evolution itself results from a running down of temperature. Before proceeding to the evidence for this statement we must first present the basis upon which rests the whole building of Lockyer's proof. Before speaking of "hottest suns" and "cooler suns" we must have some system of celestial thermometry by which we may compare beyond peradventure their relative temperatures. The basis upon which this rests is strong and simple. We know from actual observation that on heating an iron rod, let us say, it first becomes red hot and then proceeds gradually up to whiteness. Now, if we examine with a spectroscope the light from the rod in its progression to white heat, we find first that only the red end of the spectrum is seen; on further heating, the orange and yellow portions of the spectrum appear and, finally, at a white heat, we have the whole visible spectrum from red to violet. Not only so, but by the aid of photography we discover that as the rod grows still hotter the spectrum proceeds farther and farther into the invisible portion of the spectrum beyond the violet. We can, thus, make this general statement, that the hotter a body is the more does its spectrum lengthen out, the more does it extend from red into the ultra violet, and this is as true of a star as a poker.

Lockyer first divides the stars into three main groups:

Gaseous stars . . . . . Longest Spectrum.

Metallic stars . . . . Medium Spectrum.

Carbon stars . . . . . Shortest Spectrum.

And on the basis of the foregoing fact he draws the following deduction: 
Gaseous stars . . . . . Highest temperature. Metallic stars ... . . Medium temperature. Carbon stars ...... Lowest temperature.

Next, on examining the chemical constitution of these three groups, he is able to still further extend our knowledge and the foregoing scheme.

Gaseous stars . . Highest temperature .... Strong gas of the Helium family and faint enhanced lines.

Metallic stars .. Medium temperature.. $\begin{aligned} & \text { Feeble gas of } \\ & \text { Helium family } \\ & \text { and strong en- } \\ & \text { hanced lines. } \\ & \text { No gas of } \\ & \text { Helium family } \\ & \text { and strong } \\ & \text { arc lines. }\end{aligned}$

Carbon stars.. Lowest temperature .... Faintarclines.

The meaning of the foregoing table is briefly this: In the very hottest stars we find almost exclusively the gases hydrogen, helium, and the gas asterium, which is, so far, unknown on earth.

In the stars of medium temperature, these gases become replaced by metals in the dissociated state in which they exist in an electric spark of extremely high potential. In the stars of the lowest temperature the gases disappear almost entirely and the metals exist in the state produced by the electric arc. So rigourous is this division that Lockyer has been able to construct a relative temperature table of stars in which the stars are arranged in the order of de- 
scending temperatures, and which constitutes a veritable stellar thermometer which he can use to test the temperature of the stars.

Hottest stars.

1. Two in Argo (zeta Puppis and gamma Argus).

2. Alnitam (epsilon Orionis).

Stars of intermediate temperature.

3. Achernar.

4. Algol.

5. Markab.

6. (

7. Sirius.

8. Procyon.

9. Arcturus.

Stars of lowest temperature.

10. 19 Piscium.

Considering this star table from hottest to coldest in relation to the chemical nature of the stars comprising it the evolution of matter drops into evidence.

1. Argonian Stars.

Predominant.-Hydrogen and proto-hydrogen.

Fainter.- Helium, unknown substance, proto-magnesium, proto-calcium, asterium.

2. Alnitamiam Stars.

Predominant.-Hydrogen, helium, proto-silicon, unknown substance.

Fainter.- Asterium, proto-hydrogen, proto-magnesium, proto-calcium, oxygen, nitrogen, carbon. 
3. Achernian Stars.

Predominant.-Hydrogen, helium, asterium, oxygen, nitrogen, carbon.

Fainter.- Proto-magnesium, proto-calcium, proto-sili4. Algolian Stars. con, unknown substance, silicon.

Predominant.-Hydrogen, proto-magnesium, proto-calcium, helium, silicon.

Fainter.- Proto-iron, asterium, carbon, proto-titanium, proto-copper, proto-manganese,

5. Markabian Stars. proto-nickel.

Predominant.-Hydrogen, proto-calcium, proto-magnesium, silicon.

Fainter.- Proto-iron, helium, asterium, proto-titanium, proto-copper, proto-manganese, proto-nickel, proto-chromium.

6. ( ).

7. Sirian Stars.

Predominant.-Hydrogen, proto-calcium, proto-magnesium, proto-iron, silicon.

Fainter.- The lines of the other proto-metals and the arc lines of iron, calcium and manganese.

8. Procyonian Stars.

Predominant.-Proto-calcium, proto-titanium, hydrogen, proto-magnesium, proto-iron, and arc lines of calcium, iron and manganese.

Fainter.- The other proto-metals and metals occur9. Arcturian Stars.

Predominant.-Proto-calcium, arc lines of iron, calcium, and manganese, proto-strontium, hydrogen. 
Fainter.- Proto-iron and proto-titanium.

10. Piscian Stars.

Predominant.-Flutings of carbon.

Fainter.- Arc lines of metallic elements.

A glance at the foregoing table shows us the following facts:

1. That beginning with the hottest stars known, which are composed almost altogether of hydrogen and dissociated hydrogen we find that as the temperature decreases one after another of the chemical elements makes its appearance until, when we arrive at 9 , the Arcturian Stars, the elements rival in their number those existing in our own sun.

Now, since a star has but few elements when it is hot and many when it is cold, the natural and reasonable explanation is that the many have evolved from the few.

2. Next, we find that the metallic elements appear first in the dissociated condition and afterwards in their normal form. Thus, in Group 1 we have proto-calcium which after existing in the intervening groups appears finally in Group 7 in its normal condition as the calcium which we know on earth. Again, silicon appears in the proto-form in Group 2 , in both the proto and normal forms in Group 3, and in the normal form alone in Group 4. Iron appears in the proto form in Group 4, faintly in the normal form in Group 7, and predominantly in the normal form in Group 8.

It is evident that this fact greatly strengthens the validity of our explanation. For if with decrease of temperature the elements are evolved out of simpler substances, of course the dissociated forms would appear first. It would be a serious blow to the whole hypothesis were we to find 
an element appearing first in the normal form and afterwards in the dissociated form. Such, however, we do not find to be the case.

3. Finally, we discover that as a general rule the elements of lightest atomic weight appear first. This, also, is quite in accordance with what we should expect on the dissociation hypothesis. We have had reason to believe that the atoms are built up of nothing but corpuscles, and these corpuscles would naturally form larger and larger aggregations as the temperature sinks. Furthermore, in the periodic law we saw that the elements of the same family behaved just as though the heavier atoms had evolved from the lighter. That the elements do not appear with sinking temperature strictly in the order of their atomic weights, need not discompose us, for we have seen that a corpuscular aggregation constituting an atom depends for its stability not only on the number cf corpuscles constituting the atom, but upon their arrangement. Consequently, it might easily be possible' for an aggregation of $X$ corpuscles with a certain stable configuration to exist before an aggregation of $X-1000$ in a configuration less stable. This might explain why we find calcium in the stars with an atomic weight of 40 , before we find sodium with a less atomic weight of 23. Though we should expect, nevertheless, as we find to be the case, that as a general rule the elements would put in their appearance in the order of their atomic weights. Taking it altogether the evidence for an inorganic evolution of the elements seems every whit as conclusive as the evidence for an organic evolution.

The geologist from an examination of the earth's strata from lowermost to highest finds an ever-increasing complexity in the organic remains which the rocks contain. The astronomer from an examination of the stars from 
hottest to coldest finds an ever-increasing complexity in the so-called elements which they contain.

They both deduce an evolution of simpler forms to more complex, and their deductions are equally valid. We accept the organic evolution; we must accept the inorganic evolution. Organic evolution is measured by millions of years; inorganic evolution is measured, probablý, in billions. This need not affright us for we have seen ample demonstration in this book that with God there is neither great nor small in size, nor long nor short in either distance or time.

But are the organic and inorganic evolutions parallel processes, or does one follow upon the heels of the other? We conceive of inorganic evolution as the existence first of the atoms of the dissociated simplest elements followed by the appearance of the atoms of the elements more and more complex as the temperature diminishes. From our knowledge of every-day chemistry we can easily see that the stellar bodies comprising these atoms would eventually sink to a temperature so low that the atoms of the elements formed could associate into the molecules of compounds, and that the complexity of these compounds would continually increase until, at about the temperature of the earth, we should find, as to-day, that they existed in tens of thousands. But where does life come in?

The great law of continuity forbids us to assume that life suddenly made its appearance out of nothing, and tells us that. we must look for the element of life in the very elements of matter, for the potentiality of life should exist in every atom.

The biologists and geologists tell us that life originated in the sea. If that is the case, then the constituents of living bodies should be the constituents of the sea-water and the air above it. 
The constituents of sea-water are:

Chloride of sodium

$$
\text { " " magnesium }
$$

- Sulphate of magnesium

$$
\text { "6 }
$$

"6

"calcium.

"potassium

Bromide of magnesium

Carbonate of calcium
77.75

10.87

4.73

- 3.60

2.46

0.21

0.34

The main constituents of the air are nitrogen, oxygen and carbonic acid.

The elements constituting sea-water and air are thus:

Oxygen, nitrogen, carbon, hydrogen, sodium, magnesium, potassium, calcium, chlorine, sulphur and bromine.

Let us now examine the constituents of the living being. We find on an ultimate analysis that they comprise: Oxygen, nitrogen, carbon, hydrogen, sodium, potassium, phosphorus, sulphur, calcium, magnesium, iron and silicon. We see, thus, as a matter of fact, that the elements constituting living beings are almost exclusively the elements contained in sea-water and air. And not only so, for the elements constituting sea-water and air are the first elements created in the process of inorganic evolution. This is easily determined by an examination of the stellar temperature table, page 209. This table shows us that the hydrogen, oxygen, nitrogen, carbon, calcium, magnesium, iron, sodium and silicon that constitute sea-water and the substances of our own bodies are the first born elements of the hottest stars. More and more do we see that we are the last result of a series of consecutive changes running back without any sudden break in continuity to a time when the stars were young. Organic evolution is the last stage in inorganic evolution and we are akin to the stars. It is inter- 
esting to notice the relation of organic evolution to inorganic evolution in the scale of time as illustrated by Sir Norman Lockyer. Fig. 52.

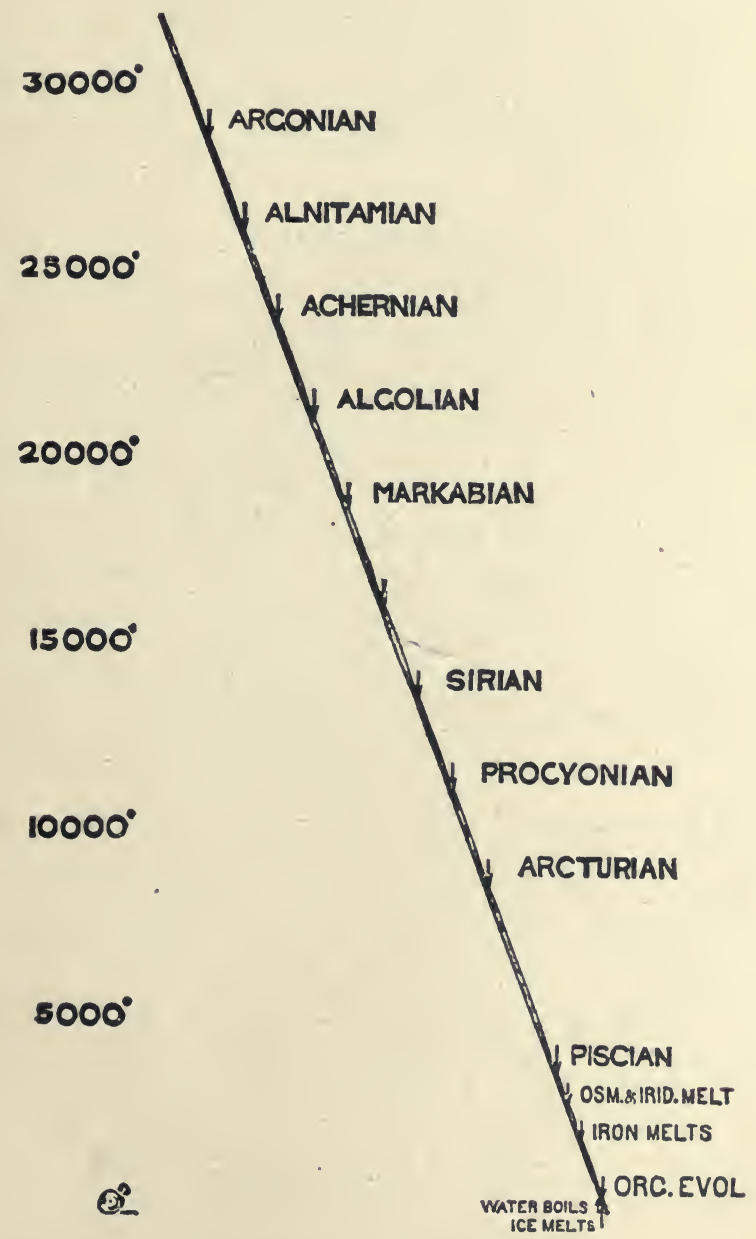

Fig. 52. Diagram showing that organic evolution occupies only a point in the line representing the time and temperature range required by inorganic evolution. 
This diagram informs us that in the running down of temperature from the 30,000 degrees Centigrade, which is estimated as the temperature of the hottest stars, to the average temperature of the earth, that the position of organic evolution is a mere point in the scale somewhere between the temperature at which water boils and ice melts, and yet we measure that point by many millions of years. 


\section{CHAPTER III.}

\section{Inorganic Devolution.}

And so we are akin to the stars, and untold millions of years ago the tiny particles of the materia prima, the corpuscles, electrons, or what not, began the mazy configurations which evolved into the atoms which constitute us. We began so long ago that the imagination feels almost willing to rest satisfied and satiated with a conception so immense,-almost, but not quite. There is a disturbing question. Did God, however long ago, start the circling particles with the full plentitude of His energy, and then leave them to waste their energy in ever multiplying configurations down to what, however far removed it may be, must be a state of rest and death, or did He give them this energy in perpetuity? Put in another way, is the universe a clock wound up by the Maker and left to run itself down or has it within itself the elements of its own regeneration? The definite answer to this great question is hardly for our day but we have evidence which anticipates the answer, evidence which is strong and good so far as it goes and which leads to the conclusion that there is a compensating devolution of the universe which, for all we know, may balance its evolution.

Our belief in inorganic evolution rests upon the apparent fact that with a running-down of temperature in the stars we have a continual increase in the number of elements 
contained in them, and the running-down of temperature is measured by the progressive contraction of the spectra of the stars towards the red end of the spectrum. The chemical constitution of the stars is thus correlated with their temperature, and the stillar thermometer, page 209, is an expression of this correlation. But when Lockyer had sorted out his stars into equal-temperature groups in accordance with this table, he discovered a fact of the utmost importance and significance. He discovered, indeed, that the constituent stars of each one of these groups having among themselves the same elements, the same length of spectrum and, consequently, the same temperature, differed in this, that while some of them had thick hydrogen lines and thin metallic lines in their spectra, in others the relative thickness and thinness of the lines was reversed. The different intensities of the hydrogen lines in stars of practically identical temperature and constitution is shown in the accompanying Fig. 53 in the case of Sirius and alpha-Cygni together with the differences in width and intensities of the enhanced metallic lines in two other similar stars Procyon and gamma-Cygni.

For the full bearing of this fact the reader is referred to Lockyer's "The Meteoritic Hypothesis." Here it will suffice to say that this fundamental difference of intensity in the spectral lines of stars of the same temperature and constitution leads logically to the conclusion that while those stars having thick hydrogen lines and thin metallic lines are decreasing in temperature others in which the relative intensities of the lines are reversed are on the con. trary increasing in temperature.

In other words, while some of the stars are growing cooler and more complex, and are undergoing an evolution, others are growing hotter and less complex and are under- 
INORGANIC DEVOLUTION.

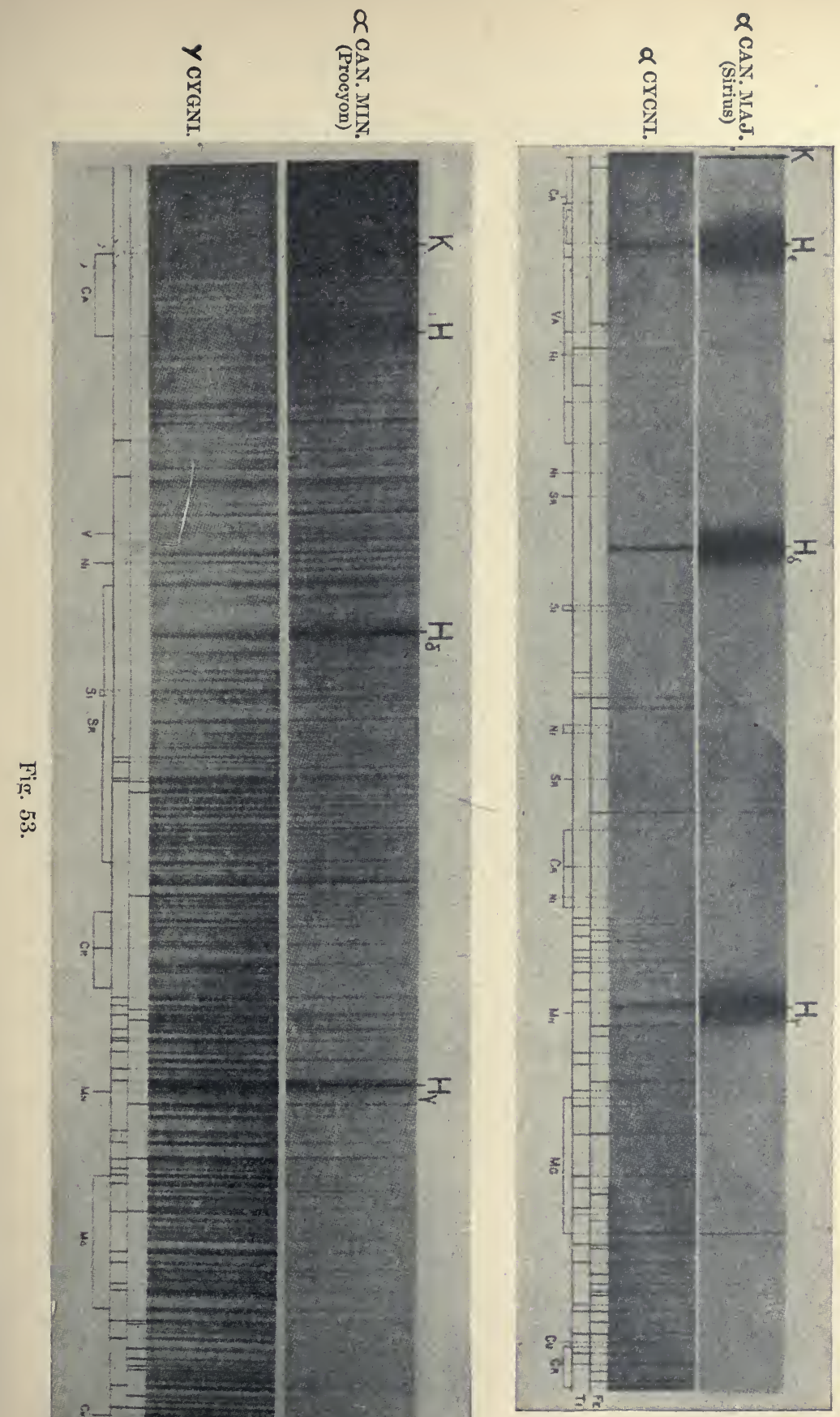


going a devolution. Lockyer has found himself able to construct a table similar to, and numbered like, that of the stellar thermometer, page 209, in which the stars are placed in the order of their intensity of temperature, and in which every star is growing hotter. We present this table of stars together with the elemental substances composing them.

1. Antares.

Predominant.-Flutings of manganese.

Fainter.- Are lines of metallic elements.

2. Aldebaran.

Predominant.-Proto-calcium, are lines of iron, calcium and manganese, proto-strontium, hydrogen.

Fainter.- Proto-iron, proto-tintanium.

3. Polaris.

Predominant.-Proto-calcium, proto-titanium, hydrogen, proto-magnesium, proto-iron, and are lines of calcium, iron and manganese.

Fainter.- The other proto-metals and metals occurring in the Sirian genus.

4. ( ) .

5. alpha-Cygni.

Predominant.-Hydrogen, proto-calcium, proto-magnesium, proto-iron, silicon, proto-titanium, protocopper, proto-chromium.

Fainter.- Proto-nickel, proto-vanadium, proto-manga-

6. Rigel. nese, proto-strontium, iron.

Predominant.-Hydrogen, proto-calcium, proto-magnesium, helium, silicon.

Fainter.- Asterium, proto-iron, nitrogen, carbon, proto-titanium. 
7. zeta-Tauri.

Predominant.-Hydrogen, helium, proto-magnesium, asterium.

Fainter.- Proto-calcium, silicon, nitrogen, carbon,

8. beta-Crucis. oxygen, proto-iron, proto-titanium.

Predominant.-Hydrogen, helium, asterium, oxygen, nitrogen, carbon.

Fainter.- Proto-magnesium, proto-calcium, proto-silicon, unknown, silicon.

9. Alnitam.

Predominant.-Hydrogen, helium, proto-silicon, unknown substance.

Fainter.- Asterium, proto-hydrogen, proto-magnesium, proto-calcium, oxygen, nitrogen, carbon.

10. Argo.

Predominant.-Hydrogen and proto-hydrogen.

Fainter.- Helium, unknown substance, proto-magnesium, proto-calcium, asterium.

A comparison will show that Group 1 of this table corresponds in chemical constitution with Group 10 of the other, Group 6 with Group 5, Group 8 with Group 3. The bottom of this stellar table is the top of the other. The hottest stars of the Argonian type are the culminating point of a star's growth in temperature and simplicity. They are also the point of departure in the star's decay in temperature and growth in complexity. The course of a star's history is a curve.

We thus see that the magnificent inorganic evolution which we described in the foregoing chapter is by no means the final expression of the working of the universe. It is 
but the last phase, the fall of the ascended rocket and its bursting into the pyrotechnics of our chemical elements. Taking some one star as typical of all, we may trace its history in accordance with the hypothesis devised by Lockyer. The history of a star begins with a nebula. A nebula is a vast swarm of meteorites colliding together. The meteorites are cold lumps of matter containing the chemical elements as we know them on earth. These meteorites in accordance with their gravitational attraction seek the contre of the swarm, collisions result, heat is evolved, and the temperature gradually rises.

Owing to the meteoritic bombardment, the condensing and colliding mass becomes first so hot that the low-temperature arc lines begin to appear in the spectrum of the mass and we have such a star as Antares in Group 1 of the table above. But the bombardment and condensation continues, and the temperature increases to such a point that the arc lines now begin to disappear and the enhanced lines of dissociated elements begin to take their place. The star thus passes progressively through the conditions exemplified in Groups 2, 3, 4 and 5. Next, many of the proto-elements, themselves, disappear and others, fewer in number, take their place; proto-nickel, proto-manganese, proto-vanadium, pass away and elements like proto-magnesium, silicon, oxygen take their place. Finally, these elements themselves disappear and the star eventually arrives at the condition shown in Group 10 in the naked simplicity of nothing but hydrogen and dissociated hydrogen together with small quantities of helium, proto-magnesium, protocalcium and asterium.

It is now completely converted into an incandescent gas at the highest attainable temperature. The progressive decomposition into simplicity ceases for want of meteorites to 
continue the bombardment and the future history of the incandescent gas is that of a cooling body.

Step by step it passes back through the various groups as in the table, page 209, ever decreasing in temperature and increasing in complexity, until it arrives at Group 10, into

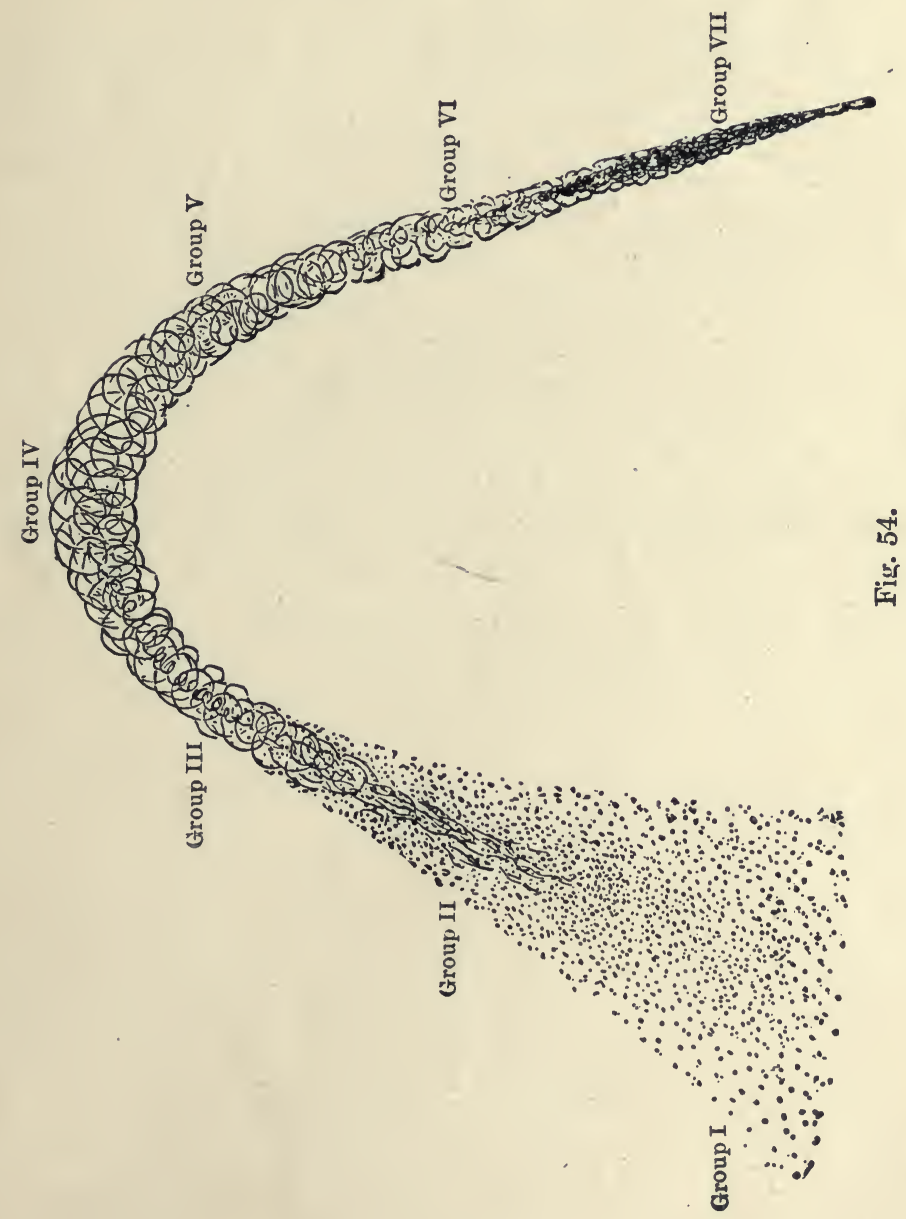


the condition of our own sun and Arcturus in the full possession of most of the elements we find on earth, and, eventually, into the condition of a dark star, extinct and dead, like our earth itself. This progress of a nebulous swarm of meteorites to a dark star, is illustrated, diagrammatically, by Lockyer in the accompanying temperature curve. Fig. 54.

But the interesting question yet remains. Is this curve of ascent and descent, which is deemed to be common to every star in the universe, open or closed ? What is the relation between the dark stars at the end of the process and the meteorites at the beginning. If the swarms of complex meteorites pass up into the simplicity of the hottest stars and back again to the complexity of the dark stars and common earth, do the dark stars become meteorites again and continue the process infinitely in a circle of change, or, to revert to the question at the head of the chapter, is the universe a clock running down? We see, at any rate, evidence of a regenerating influence at work, and that if we have an inorganic evolution we also have an inorganic devolution, but in the light of this present chapter that is all that can be said. We shall discuss this question from a totally different point of view in Chapter III Part VII. 


\section{PART VII.}

THE NEW KNOWLEDGE AND OLD PROBLEMS 



\section{PART VII.}

THE NEW KNOWLEDGE AND OLD PROBLEMS.

\section{CHAPTER I.}

Cosmical Problems and Radio-activity.

\section{The Sun's Heat.}

How does the sun maintain its heat? This has always been a problem of intense interest to the human mind. It was at first supposed, naïvely, that the sun's heat was maintained by ordinary chemical combustion; that the sun was a burning fire, and that when the coal, or what not, of which the sun was composed, was consumed, there would be an end of light and heat and life. This belief was shown to be untenable, among 'others by Professor Tait who said: "Take (in mass equal to the sun's mass) the most energetic chemicaly known to us and the proper proportion for giving the gratest amount of heat by actual chemical combination ard, so far as we yet know their properties, we cannot see the means of supplying the sun's present waste for eveñ 5,000 years. ... It is quite obvious that the heat of the sun cannot possibly be supplied by any chemical process of which we have, the slightest conception. ... This question is quite unanswerable, unless there be chemical agencies at work in the sun of a far more powerful order than anything we meet with on the earth's surface." 
Next, it was supposed that the meteorites falling into the sun could generate heat sufficient to maintain its energy. This also was disproved. Finally then came Helmholtz's theory, based upon the nebular hypothesis, that the heat of the sun might be maintained by its own contraction from a nebular condition. It is not too much to say that in recent years this has been the accepted thecry of science. It has always been burdened, however, by the fact that, on this basis, the sun could not have maintained its energy and have illuminated the earth in the past for a time sufficient to account for the observed geological changes. Professor Young says in his "General Astronomy," "No conclusion of geometry is more certain than this that the contraction of the sun to its present size, from a diameter even many times greater than Neptune's orbit cannot have been emitting heat at its present rate for more than $18,000,000$ years, if its heat has really been generated in this manner."

Finally, Lord Kelvin has calculated the energy lost in the concentration of the sun from a condition of infinite dispersion with the conclusion that it is "on the whole probable that the sun has not illuminated the earth for $100,000,000$ years and almost certain that he has not done so for $500,000,000$ years. As for the future we may say with equal certainty that inhabitants of the earth cannot continue to enjoy the light and heat essential to their life for many million years longer, unless sources now unknown to us are prepared in the great store-houses of creation."

We shall see that in radio-activity we have, probably, an additional store of energy. We know that there exists in the sun enormous quantities of the element helium. We know, also, that helium is a decomposition product from radio-active substances, - and finally we know that radioactive substances generate enormous quantities of heat. It 
is, therefore, possible, and even likely, that there exists in the sun's mass large quantities of radio-active matter, and on this supposition it is easily possible to increase to an enormous extent the duration of the sun's age and heat in the past, and its maintenance for untold millions of years in the future.

It may be shown that the presence of 3.6 grams of radium in each cubic metre of the sun's mass is sufficient to account for its present rate of emission of energy, or; calculated in another way, that 2.5 parts by weight of radioactive matter in a million would keep the sun going. Rutherford concludes that if the energy resident in the atoms of the elements is available in the sun that the time during which the sun may continue to radiate at its present rate may be as much as 500 times longer than the maximum limit afforded by Lord Kelvin.

We see thus that the depressing conclusion of the older science that the earth must come to an end in a time short in comparison with its past duration, was unwarranted. It may, however, be objected to this conclusion that if the sun possesses radio-activity, this radio-activity ought to be perceptible on earth. But this is not so, for even the most penetrating rays, the gamma-rays, would be practically stopped and absorbed by the earth's atmosphere which is equivalent to 30 inches of mercury.

THE AGE OF THE EARTH.

For the last fifty years the age of the earth as a habitable planet has been a subject of bitter debate between the physicists on the one hand and the biologists and geologists on the other. The physicists would not grant the time demanded by the geologists and biologists; for whereas the physicists would grant ten million years, the geologists 
refused to be content with less than a thousand million. The claims of each party to the controversy seemed to be irrefragable and yet irreconcilable. As an example of the physical method of calculation we may cite the method of Lord Kelvin who deduced the age of the earth by a consideration of the interior heat of the earth and the rise of temperature as one descends beneath the surface.

This rise in temperature amounts to about one degree," Centigrade, for every one hundred feet of descent, and taking the average heat conductivity of the earth as .004 (C. G. S. Units) this leads to the conclusion that ten million years ago the surface of the earth was still molten,-a conclusion absolutely unacceptable to the natural scientists. This conclusion of the physicists rests on a certain assumption which, however, at the time, seemed no assumption at all. In a word they assumed that the earth was a self-cooling body; they did not imagine that it was a self-heating one as well. We shall see that as a matter of fact the earth is self-heating.

One gram of radium yields about 100 calories of heat per hour, or 864,000 gram-calories per year. Consequently, the presence of $2.6 \times 10^{-13}$ of radium per unit volume or $4.6 \times 10^{14}$ per unit mass would compensate for the heat which the earth loses by conduction. Or, taking the case of uranium, which probably does not evolve more that a millionth of the heat of radium, it may be shown that the presence of a very small fraction of this substance scattered throughout the earth would be sufficient not only to keep the earth's temperature constant but actually to raise it from a cold condition to a hot one. But do we actually find in the ordinary earth a radio-activity adequate to furnish heat sufficient to balance the earth's loss by conduction? We certainly do. We have shown, pages 133 et seq., that all 
matter is radio-active, including the soil, water, air, and indeed practically all earthly substances. It has been convincingly shown by Rutherford that this radio-activity of ordinary substances is in the right order of magnitude to balance the loss of the earth's heat into space. It seems, then, that the physicists were right only so far as they went, the trouble being that they did not take into account the possibility of the earth being a self-heating body. The geologists and biologists were also right-and they may have the thousand million years for the earth as a habitable planet, if they desire it. 


\section{CHAPTER II. \\ The Mechanical Pressure of Light and its Consequences.}

To the reader who has not followed, particularly, the course of scientific advance during the last ten years, the heading of this chapter must seem upsetting to all accepted notions as to the nature of light. By light is meant undulations in the omnipresent ether and it seems odd to attribute mechanical pressure to such an immaterial thing. Yet in 1873 Clerk-Maxwell, in one of his prescient mathematical inspirations showed that such a pressure should exist, and his conclusion was mathematically borne out in 1876 by Bartoli on totally different grounds. Briefly it may be stated that this light pressure $p$ is determined if we know the amount of energy $E$ in the light, the reflecting power of the substance that receives it $r$, and $v$ the velocity of light, for then

$$
\mathrm{p}=\frac{\mathrm{E}}{v}(1 \times \mathrm{r})
$$

The experimental verification, as is of ten the case, lagged long behind the mathematical prediction. In 1901, however, Peter Lebedew actually proved and measured the mechanical pressure of light. The pressure discovered was small, but the smallness of a thing is often an inverse measure of its importance, and as this light pressure has been found adequate to the task of explaining some of earth's greatest mysteries we shall indicate his method here. Briefly, he allowed a beam of light to fall on a sus(232) 
pended disc in a bulb containing a vacuum. This vacuum was attained with the greatest care by first exhausting the bulb to the highest degree possible and then freezing out the residue of mercury vapour. In such a vacuum the disc was repelled on the impact of the light-beam and its repulsion was measured by its torsional effect on the suspending wire. This repulsive pressure of the light was found very nearly equal to that calculated so long in advance by ClerkMaxwell. Since Lebedew's demonstration, Nichols and Hull have repeated his work with greater exactness and there is now no shadow of doubt as to the fact that it has Maxwell's value. This light pressure at the distance of the earth from the sun is small, not quite a milligram per square metre of the earth's surface, or, put roughly, 70,000 tons on the whole earth. Were we to consider only the effect of the impact on large bodies our interest would not proceed very far, but things take on a different complexion when we notice the remarkable effect of size on the relation between the light pressure and weight or gravitational attraction. The light pressure is applied only on the surface and is proportional to the surface while weight or the pull of gravitation, on the other hand, affects the whole body.

Suppose we divided a sphere, such as a cannon ball, into eight equal spheres. The sum of the surfaces of these eight spheres would be twice that of the original sphere while the weight of gravitative pull would remain the same. If we continued the process of division until the spheres were the size of the smallest shot, the total sum of their surfaces would be enormous compared with the original sphere while the weight would again be equal to that of the cannon ball. If we continued the division on and on we should eventually come to a body so small that the ratio of its 
surface to its weight would be enormous, - it would be almost all surface. Now the greater the surface the greater the effect of the light pressure and hence without going down, by any means, into infinitesimals the process of division carries us to a particle so fine that the light pressure will exactly balance its weight. This is the case with a particle of earth $1 / 100,000$ of an inch in diameter. Such a particle would neither be attracted nor repelled from the sun, for the sun's pull upon it is exactly balanced by the repulsive force of the sun's light. If the particle is smaller still it is repelled from the sun and, in fact, if the particle is exceedingly small the light-push may enormously exceed its weight. But $1 / 100,000$ of an inch is not in itself very small. We know many bodies smaller than this, without considering the atoms and corpuscles of preceding chapters.

\section{COMETS' TAILS AND THEIR EXPLANATION.}

One of the greatest mysteries in astronomical science has been the comet's tail and why it points away from the sun. The facts are generally known. The tail of a comet may be any length up to $100,000,000$ miles. It develops and grows larger as the comet approaches the sun, proceeding back from the direction of motion of the comet like the smoke from a steamer; but unlike the steamer-smoke, as the comet rounds the sun and flies away; the tail now precedes the head. It is precisely as though there was a strong repulsive wind blowing away from the sun and sufficing to keep the comet's tail pointed away from it. The nature of this repulsive force has been the mystery of astronomy. Now, however, we may consider ourselves acquainted with its cause.

The whole comet has a spectrum practically identical with that of a bunsen burner consuming ordinary gas, and, hence, evidently consists of hydrocarbons. In addi- 
tion, as the head approaches the sun evidence of iron, magnesium and other metals becomes apparent. We can easily see that as the comet approaches the sun the hydrocarbons must break up into hydrogen gas and other hydrocarbons of higher boiling point. Finally as the sun is approached and the heat becomes intense these hydrocarbons themselves will break up into free carbon in the form of soot. The whole process is analogous to that which takes place in an ordinary gas flame with the exception that since there is no air, the soot formed cannot burn into gas but must exist in the form of small particles. These small particles whether in the form of a mist of liquid hydrocarbons, or in the form of a carbon soot, must fall under the sway of the mechanical pressue of light. If they are so small that the light-pressure overbalances the forces of the sun's gravitative pull they will be driven back from the comet with a speed depending on their size and will constitute the ordinary comet's tail. If these small particles vary in size, as would naturally be the case, the rate at which the light drives them will vary and the resulting tail will be curved.

Since the material composing the comet is heterogeneous, one constituent after another will decompose and several tails will be formed successively with curvatures depending on the size of the particles. If the particles are larger than can be repelled by the sunlight they will form a tail pointing towards the sun, which is a rare phenomenon, but occasionally observed. The sizes of the mist particles of the comets' tails necessary to account for their obsarved length and curvature have been calculated, and are quite in the order of particles we are familiar with on earth in the early stages of combustion. They vary in diameter from $1 / 10,000$ to $6 / 1,000$ of a millimetre. Now a particle one-half the 
"weight" which the sunlight can balance, about half the thousandth of a millimetre, would travel under the pressure of light more that 865,000 miles an hour. In comets' tails we probably have particles whose diameter is less than oneeighteenth of this. Such particles would travel the same distance in less than four minutes.

It is not surprising, then, that "the tail of the great comet of 1680 was found by Newton to have been no less than $20,000,000$ leagues in length and to have occupied only two days in its emission from the comet's body, - a decisivo proof this of its being darted forth by some active force, the origin of which, to judge, by the direction of the tail, must be sought in the sun itself." The whole matter is accounted for by the mechanical pressure of light,- $-\mathrm{a}$ force in the universe hitherto unsuspected.

\section{THE SOLAR PROMINENCES AND THE CORONA.}

In a solar eclipse, at the precise moment when the moon blots out the sun's disc there becomes visible around the edge of the sun a number of magnificent scarlet steamers, or clouds, some of them 60,000 miles in height and held suspended over the sun. These are the solar "prominences."

In addition to these fiery streams there exists also a beautiful halo or "glory" of a greenish or pearly lustre which contrasts finely with the scarlet hue of the prominences. This "halo" has been called the "corona."

Both the prominences and corona consist of matter in a highly rarefied condition and the so-far unanswered question of the astronomers has been, "How is this matter held up?" The complete answer seems to be, "It is held up by the pressure of the sun's own light." The sun must project vapours into space. These vapours will condense into drops where they meet the cold of outer space. These drops, if 
MECHANICAL PRESSURE OF LIGHT; ITS CONSEQUENCES. 237

larger than the critical size, will fall slowly back towards the sun constituting the prominences; if smaller than the critical value, they will be driven away from the sun forming the curious streams of the corona. If they are, practically, just the size which the light can support they will float permanently suspended and will constitute the main body of the corona. Even the mysterious "hairy structure" of the corona is explicable as due to the supporting power of light on particles of different sizes.

\section{THE ZODIACAL LIGHT.}

Just after twilight on any clear evening in winter or spring there may be seen on the western horizon a faint soft beam of light. This beam seems to proceed out from each side of the sun to some distance beyond the earth's orbit. It is called the zodiacal light. Its cause has been another of the "mysteries" of astronomy, though it finds an easy present-day explanation in terms of our theory. It was shown, page 51, that incandescent carbon and metals gave off negatively electrified particles or corpuscles a thousand times smaller than the smallest atom. We know that enormous quantities of carbon exist in the photosphere of the sun, and exist, moreover, at a temperature vastly greater than any known on earth. This carbon must emit corpuscles, and, since the corpuscles are almost infinitely small, the effect upon them of the mechanical pressure of light must be extreme. The sun must, therefore, bombard all space with corpuscles travelling with an immense velocity. These corpuscles, which it should be remembered are negatively electrified, when they strike the outer regions of the earth's atmosphere will charge it also negatively, and when this charge reaches a certain value the oncoming rush of corpuscles will be deflected by the similar electrification 
of the atmosphere so that it will stream past the earth on each side in a hyperbolic orbit. Far out in space on the side away from the sun they will meet with other particles. We have shown, page 63, that corpuscles are remarkable in being able to act as nuclei about which other corpuscles and atoms and molecules will collect. When they meet, therefore, with other particles back of the earth, this condensation will take place and if the particles formed are greater than the critical diameter which the pressure of light can control they will drift back with increasing velocity past the earth and towards the sun. If we could take our stand on the moon we should probably see the earth attended by a faint double tail the more conspicuous one pointing away from the sun and a fainter one pointing toward him. It is this sheaf of light on each side of the earth, due to a corpuscular bombardment from the sun, which, in the opinion of Arrhenius, is the cause of the zodiacal light. It should be stated here that Arrhenius is the father of nearly all this theoretical interpretation of the observed mechanical pressure of light.

\section{THE AURORA BOREALIS.}

The Aurora Borealis has been still another mystery. We shall see that the new knowledge has something to say as to its elucidation. In Part III it was shown that the corpuscles from red-hot carbon, Crookes' tubes and the beta-rays of radium are deflected by a magnet in such a way that they describe helices around the lines of magnetic force. If the magnetic field is strong enough they may be bent into a complete circle inside a moderately large tube, page 57. If there is such a thing as the continuity of natural law, the earth should be bombarded by these corpuscles projected from the sun. But the earth is a magnet, 
MECHANICAL PRESSURE OF LIGHT; ITS CONSEQULNCES. 239

and the lines of force proceed from pole to pole. Now the corpuscles must arrive most thickly over the equatorial region of the earth where the earth is directly exposed to them. They must be at once caught by the lines of force and must travel along them in winding helices ever coming closer and closer and farther and farther down into the atmosphere as they approach the poles. At a certain distance from the poles they find themselves in an atmosphere comparable with our high vacua and they then begin to give out the shifting and darting lights of the cathode rays, though this can be only at the cost of their existence for their energy is absorbed in causing the luminosity. These "darting and shifting lights of the cathode rays" in accordance with this speculation account for the Aurora Borealis as well as for " the dark circles around the magnetic poles from which, as from behind a curtain, the leaping pillars of the Aurora rise." If the theory is true, there should be some connection between the earth's magnetic field and the Aurora and since they are both due to solar influence they should be related, as well, to the sun's activity as revealed in the number of sun spots.

In fact, the Aurora Borealis, the earth's magnetism and sun spots should all vary together. It has long been known that they all do vary together in a very remarkable way.

\section{ATMOSPHERIC ELECTRICITY.}

Another peculiarity possessed by corpuscles travelling with high velocity is their ability to knock to pieces or ionize a gas through which they pass, and that these ions act as nuclei of condensation of clouds. If, therefore, the earth is bombarded by solar corpuscles they should ionize the air in the upper regions and this should result in the formation of clouds. We have here a beautiful 
explanation of the hitherto inexplicable fact that cloudformation in the upper air varies with the frequency of auroræ.

\section{METEORITES AND NEBULE.}

The number of corpuscles intercepted by the earth is of course infinitesimal compared with those that miss the earth altogether and continue on through interstellar space. Through their immense velocity under the pressure of light we can easily see how they would overcome their electrical repulsions, clash together, condense and form the meteorites which flame through the upper air and occasionally reach the earth itself as "thunder-bolts." We are not even yet at the end of the functional power of the corpuscle. Many of them will escape these traps to strike the nebulæ and comets. The fact that both nebulæ and comets are cold bodies and yet shine with their own light has always been a perplexing matter. It need be so no longer, for on the impact of a rain of corpuscles the tenuous gaseous mass of a nebula or a comet's tail would of very necessity shine with the same light that we see in the Aurora or a Crookes' tube on earth.

It is a highly interesting and significant fact that these corpuscles found in candle flames, hot metals, Crookes' tubes and radium, which apparently constitute the very essence of matter and electricity, should also serve to explain, reasonably and adequately, some of the most perplexing phenomena in the whole range of natural knowledge. 


\section{CHAPTER III.}

\section{On the Reconstruction of a Universe.}

It is now possible to renew the discussion postponed from page 224 as to whether or not the universe is losing its available energy and is going steadily to a condition of rest and extinction; whether or not the universe is a clock running down. Only yesterday, practically, the affirmative side of this question seemed to be one of the safest and surest conclusions of modern science. But we have seen more than one of these long-accepted generalizations seriously impugned and it may be that, in the light of this new knowledge, we shall find that this widely accepted dictum of science, that the universe is proceeding fatally to the extinction of its available energy, is also a legitimate matter of deliberate question.

The reasons for this current conception have seemed, until recently, irrefragable. In the words of Mr. A. Daniell; "In every Transformation of Energy we find that some Energy is wasted through conversion into Heat, the result, direct or indirect, of friction, noise, flashes of light, and so on. This heat is presently distributed pretty uniformly among its surrounding objects, and can no more be made use of by us for the sake of producing work. A large quantity of the Energy of the Universe must have already assumed this relatively useless condition, and in the course of time the whole of the Energy in the Universe will have assumed it. The Energy of the Universe is a constant amount, some of 
it is available, some is non-available: the former is in every phenomenon somewhat diminished but never increased: the non-available energy is constantly increasing: hence the Available Energy of the Universe tends to Zero." Again, Professors Stewart and Tait say: ". . . it is absolutely certain that age after age the possibility of such transformations (of energy) is becoming less and less; and, so far as we yet know, the final state of the present Universe must be an aggregation into one mass of all the matter it contains, i. e., the potential energy gone, and a practically useless state of kinetic energy, i. e., uniform temperature throughout that mass."

Is such a conclusion absolutely certain? It all depends upon the validity of the Second Law of Thermodynamics. This "law" states that "one part of a body of uniform temperature cannot grow hotter at the expense of the heat of the remainder unless work is performed upon it," consequently, if the energy of the universe is being continuously degraded into heat of equal temperature it will eventually be a dead universe. That this "law" however has limitations has been recognised since the time of ClerkMaxwell. The kinetic theory of gases teaches us that in a gas of uniform temperature, while the average velocity of the molecules comprising the gas must be a constant quantity the individual velocities of the molecules must vary to a great degree, some of them possessing velocities higher and others lower than the average.

Clerk-Maxwell imagined a firm partition, full of little doors, to be placed so as to divide the vessel into two, and to each door he placed an intelligent little demon with precise instructions to open the door whenever he saw a quick moving molecule approach in such a way that it could get through from the first compartment 
into the second, and whenever he saw, also, that he could allow a slow-moving molecule to escape from the second compartment into the first. It is obvious that the demon would eventually succeed in dividing the molecules of the gas into two groups, one group of which would possess greater kinetic energy than the other and would be capable of doing work, say, in moving the dividing partition, and all this without the performance of work upon it. The second law would thus be contravened. The only reason that this contravention of the "law" is not possible in a practical sense is the exceedingly small size of the gaseous molecules and their immense number.

The great question for us is this: Is the "law" which we see has its limitations in the case of gases also limited in the case of sub-atomic change? Throughout this book we have had evidence, and, in fact, demonstrations, of the continuous disintegration of the heavy atoms into subatoms. The heavy elements of matter are undergoing a steady and inevitable decomposition with the continuous production of inter-elemental energy. Now, if the lighter elements were at the same time undergoing the reverse process, were, in fact, synthesizing themselves into the heavy elements with the absorption of energy so that as much energy was collected up by them in their growth as was "wasted" by the decomposition of the heavy elements in their decay, the universe of matter would keep its available energy constant; it would constitute a conservative system having neither beginning nor end. It is true that the energy evolved in atomic disintegration is enormous in amount, page 176, and that the energy absorbed in atomic synthesis must be equal to it; but that does not constitute a valid reason why our atoms, which we consider to be aggregations of corpuscles, should not continuously grow by the 
gradual accretion of other corpuscles and the storage of the requisite energy through vast stretches of time. An objection has been urged against the possibility of the growth of atoms on the ground that if the lightest atoms gradually grew into the heaviest there should be an infinite number of transitionforms from hydrogen to uranium, and we find, on the contrary, that the 70 odd elements are sharply defined. This objection, however, does not hold good. While it is not necessary to assume that intermediate elemental forms may not exist to some extent, their amount would be insignificant. The atoms of the periodic table on the basis of Thomson's theory are aggregations of corpuscles representing collections of maximum stability, and, hence, a transition collection would hasten to these points, and we should neither find them existing in notable quantity or be able to conserve them any more than we can conserve the transition products of atomic disintegration like thorium $\mathrm{X}$ or the emanation $\mathrm{X}$ of radium. There is, therefore, no known impossibility inherent in the conception of a conservative universe. Have we any positive reason for believing in it? It must be confessed, at the present time, not much. In Chapter III, Part VI, we discovered that there is, apparently, a regenerating influence at work in the stars by which the cold complex nebulæ of meteorites become converted gradually into the hottest stars of simple chemical constitution whence they again fall into coldness and complexity; and, very recently, Sir William Ramsay announced that he believes himself to have synthesized one element into another; but this is all, and it does not suffice by any means to prove that the universe of matter is building up its available energy as fast as it dissipates it.

The hypothesis of the reconstruction of the universe of matter is therefore, at the present time, a pure specula- 
tion but it is a speculation which may be, as Mr. Soddy says, "one of those coming events which cast their shadows before." It is discussed here because of its extreme importance. If the universe is running down its available energy into uselessness, there must have been a precise moment of time, however far back we may place it, when the energy was all available and when it was initiated in a sudden beginning by a single creative act. Consequently, there must have been a time behind which our present laws did not operate. Also, there must be a time in the future when the universe will have grown to a definite exhaustion and death. The death will come gradually but the beginning must have been sudden and due to a creative act.

If on the contrary, the waste of energy is replaced by growth, the universe is immortal or eternal both in the future and in the past. If the old conception is true, it is necessary to say, "God made it and started it at a definite time to run its course." If the second conception is true, we may say: "The Universe is God in one phase of Him and it possesses His attribute of eternal duration." This, to most people of scientific training, is the more acceptable conclusion. The solution of this great problem seems now, at any rate, a legitimate aspiration of science and, for the present, if the new knowledge has not proved positively that the past and future of the universe is infinite, it has, beyond all question, enormously increased its boundary in time. 


\section{CHAPTER IV.}

\section{The Definitions of Science Re-Defined.}

The summation of what the new philosophy has to say with regard to the older science is best expressed, synoptically, in the form of tentative and supplementary definitions. These "definitions" will be enunciated in the order of their simplicity so that they may-afford a concise synthesis of the views of the new philosophy in their relation to the great fundamental problems of the universe. It is understood that the new philosophy is very new, and that its definitions are wholly provisional. They represent the author's interpretation of the teaching of radio-activity as he has gleaned it from a worker here and a worker there. The "definitions" are virtually "propasitions" to stand or fall as they may.

\section{Electricity:}

Positive Electricity:

What. positive electricity is, nobody knows; unless the statement that it is a mode of manifestation of the allpervading ether constitutes knowledge, though even this we do not certainly know. It has either no mass, or very little. It seems to exist in the form of particles the size of atoms. In fact, the size of the atom seems to determine the size of the positive electricity connected with it. Positive electricity is never obtained free from atoms.

Negative electricity: Page 185.

Negative electricity is particulate in character; that is, it (246) 
consists of separate definite units. These units, if they could be obtained in a state of rest, would, it is deemed, have no mass whatever. Whether, under these conditions they would have spatial dimension is not known.

Mass: Page 184.

A unit of negative electricity in motion carries along or drags with it a portion of the surrounding ether. This "bound" ether carried by the moving negative unit is what we call mass. The mass of all matter is believed to be due solely to the amount of ether dragged along by the moving electrical units.

Corpuscle: Pages 65 and 184.

A moving unit of negative electricity together with its bound ether is a corpuscle. The mass of a corpuscle depends upon the amount of bound ether connected with the moving unit and this depends on the velocity. The average mass of a corpuscle is about one one-thousandth of that of a hydrogen atom. Corpuscles may exist free from matter.

Atom: Pages 10 and 171.

A congeries of corpuscles surrounded and balanced by a sphere of positive electricity is an atom. The weight of the atom is due to the weight of the constituent corpuscles, and the properties of the atom are due to their number and arrangement. Since it takes a large number of corpuscles to constitute an atom its structure is thus extremely complex.

Chemical Union: Page 167.

Certain corpuscular aggregations will hold in an unstable condition a few more corpuscles than exactly suffices to balance the surrounding sphere of positive electricity. The atom consisting of them is thus as a whole negatively electrified. Other arrangements will hold a few less corpuscles than suffices to balance the positive electricity. This leaves the atom positively electrified. If these two 
types of atoms are free to move they unite together and neutralize each other electrically. This union is chemical union. Chemical union is thus nothing but electrical union. Chemical valency is simply a measure of the corpuscles more, or the corpuscles less, than the atom will hold in a stable condition.

Molecule: Pages 9 and 167.

A group of atoms united electrically constitutes a molecule.

Matter: Pages 2 and 184.

Any mass of matter is $x$ molecules, a molecule is $y$ atoms, an atom is $z$ corpuscles surrounded by positive electricity and a corpuscle comprises a unit of negative electricity. Matter is thus explained away as being electricity and nothing but electricity.

Radio-activity: Page 169.

Certain vast assemblages of corpuscles comprising the heaviest atoms are somewhat unstable. As their kinetic energy decreases the aggregation "explodes" and the cor." puscles re-arrange themselves with the evolution of energy" and the projection of some of the products of the re-arrang:ment. This is radio-activity.

The alpha-rays from a radio-active body are simplific ? arrangements of corpuscles resulting from the explosior. They are positively electrified sub-atoms.

The beta-rays are free corpuscles let loose from the ex. plosion.

The gamma-rays are probably identical in nature with $\mathrm{X}$-rays and are probably pulses in the ether set up by the explosion.

Inertia: Page 179.

The only inertia known is the inertia of the "bound" ether carried along by the moving negative electrical units. 
The inertia of any mass of matter is thus electrical inertia. Current Electricity: Page 186.

An electrical current is nothing but a series of corpuscles "handed along" from one atom to another through the wire. At the beginning of their course there is a deficiency of corpuscles and the positive electricity of the atoms thus appears. At the end there is a gain in corpuscles and the negative electricity is manifested.

Electrical Self-induction: Page 181.

The tendency of corpuscles to maintain their state of motion which we know in matter as inertia is the same tendency expressed as they are handed on through a wire or in the oscillations of an electric spark. Electrical selfinduction and the inertia of matter are thus identical phenomena.

Radiation: Page 186.

Whenever the velocity of a corpuscle is changed it causes ripples in the surrounding ether. These etherial ripples constitute radiation, whether of light, heat, Hertzian waves or what not.

Magnetism: Page 186.

Magnetism is a force developed at right angles to the direction of motion of the moving corpuscle.

Gravitation: Page 189.

We do not, as yet, know what gravitation is. Possibly, it depends on some interaction between the positive electricity and the negative electricity of the corpuscles when they come together to form an atom. It is certainly an extremely small effect and is appreciable to us only on account of the enormous masses of the bodies giving rise to it.

Conservation of Mass: Page 3.

Is the law of the conservation of mass the expression of an absolute truth? It does not seem so, at any rate in the 
case of radio-active bodies. We have learned that the mass of a corpuscle is dependent on its velocity and this indicates that the mass of the radium atom before its explosive rearrangement would not be the same as the mass of the products of its disintegration for the velocities of its corpuscles have changed. This can only be determined by looking for a change of weight in a quantity of radium kept under such conditions that the products of disintegration cannot escape. It will take time to determine this question.

Since all atoms are corpuscular aggregates and are therefore liable to changes of energy we should expect to find minute changes of weight in ordinary materials and this expectation is borne out by certain researches notably those of Heydweiler and Wallace.

Heydweiler claims that copper sulphate and water do not have the same collective weight before and after solution. Wallace claims that a mass of water does not have the same weight before and after freezing. Altogether, both from theoretical and experimental considerations the absolute validity of the law of the conservation of mass is certainly challenged.

\section{The Ether: Page 4.}

The ether is what it was-the hypothetical, but none the less believed in, medium of extreme tenuity and elasticity diffused throughout all space, the medium for the transmission of radiant energy. Recently, however, Mendeléeff, the doyen of chemical science, has originated the conception that the ether instead of being some mysterious form of non-matter as generally believed is actually the lightest and the simplest of the elements, and a definite form of matter. He believes it to be one of the inactive gases of the Argon family of elements and he assigns to it the position $x$ in the Zero Group of his revised periodic arrangement of the 
elements. Fig. 5, Page 28. The atomic weight of the ether he concludes to be nearly one-millionth of that of hydrogen and its atoms consequently travel with enormous velocities. This extreme velocity explains the all-pervading character of the substance. It may be said that, on this hypothesis, Mendlejeff accounts fairly well for the properties of the ether, and his speculations are deserving of more credit and attention than they at present receive. 


\section{CHAPTER V.}

\section{The Validity of the New Knowledge.}

We began our present work by attempting to show the need felt by men of science of reducing the physical universe to a condition of "Oneness" - of finding some One Thing out of whose qualities or properties might proceed all that is. We have not done this, quite. By means of theoretical speculations based upon scientific experimentation, we have shown how it may be true that all bodily existence is but the manifestation of units of negative electricity lying embosomed in an omnipresent ether of which these units are, probably, a conditioned part. Matter has disappeared as a fundamental existence, or at any rate it is explained as a manifestation of electricity. Mass, a supposedly indestructible thing, has disappeared with matter and comes into existence only as the negative electron, assuming motion, carries with it a bound portion of the ether in which it is bathed; and furthermore this mass which we thought so invariable depends solely upon the velocity with which the negative unit moves.

Our negative unit on receiving mass becomes a "corpuscle" endowed with the primary qualities of matter super-imposed upon those of electricity. Corpuscles congregating into groups or various configurations constitute essentially the atoms of the chemical elements, locking up in these configurations super-terrific energies and leaving but "a slight residual effect" as chemical affinity or gravitation with which we attempt to carry on the work 
of the world. These atoms, congregating in their turn as nebulæ and under the slight residual force of gravitation condense into blazing suns. The sun sdecay in their temperature and become ever more and more complex in their constitution as the atoms lock themselves into multiple forms. We then see these multiple atoms developing up into the molecules of matter to form a world. We see the molecules growing ever more and more complex as the world grows colder until we attain to organic compounds. We see these organic compounds united to form living beings and we see these living beings developing into countless forms and, after æons of time, evolving into a dominant race which is us.

Of this attempt on the part of science to unify physical nature, the Hon. A. J. Balfour said in his presidential address before the British Association, it "excites feelings of the most acute intellectual gratification. The satisfaction it gives is almost æsthetic in its intensity and quality. We feel the same sort of pleasurable shock as when from the crest of some melancholy pass we first see far below us the sudden glory of plain, river and mountain."

But is this glorious view of plain, river and mountain a veritable reality, or is it some mocking illusive mirage spread out before men thirsty for a consistent world? Is it true? Now, without repeating the jest of Pilate, we may ask ourselves, is there any criterion of truth by which we judge this wonderful system, to accept or condemn?

It has been said that "truth consists in an 'agreement' or 'correspondence' of thought with its object, viz.: reality." But this is impossible with a system of this kind. The definition is applicable enough when we wish to compare a theoretical determination with a "reality" experimentally obtained. But, here, we cannot get at the "reality" to 
compare it with the theoretical interpretation. We know "reality" only as it is expressed in our thought and consequently this "correspondence" can have no meaning. Again, truth is conceived as "systematic coherence." A system is "true" if it is entirely consistent and coherent, if it is completely inter-explanatory. The system we have presented is beautitully consistent with the observed facts of the universe as we see them. It is not complete, far from it, but incompleteness does not necessarily mean error. Is it therefore "true"?

Let us go farther. Suppose that we had actually resolved the whole physical scheme of things into modes, or manifestations, of a single simple ether, so that every action of every thing was a necessary consequence of the postulated properties of this fundamental substance and that all phenomena on this basis were perfectly coherent and consistent. Would we then have attained to the actual absolute truth? The answer to this question raises another. Is it not possible that there may be a perfectly consistent and coherent falsehood or error, and, if so, should we be able to recognize it and to know it from truth? Probably not, but is a system of falsehood or of error ever perfectly coherent and consistent? Is there not always discovered, sooner or later, a rift in the lute and a false note in the harmony? Still, this does not extricate us from our difficulty. Even if we had a perfectly inter-explanatory system we should not be able to know beyond peradventure that it was an expression of "reality." There is no criterion of absolute truth, there is no way of attaining to absolute truth, and we may as well acknowledge it. Should we therefore abandon the world-riddle? Assuredly not. If we may never know a system to be true, we may believe it to be true. We may not have a knowledge of truth but we may have a recognition of it. 
This recognition of truth depends, seemingly, on psychological considerations. If we have a beautiful building of systematized perceptions and conceptions all dovetailing into one another into the complete expression of an idea, we say the idea is true because we see in it a perfect harmony, and this harmony pleases us and gives us a feeling of the recognition of truth. But the statement: "This scheme is faultless in its consistency and is therefore true" is not logic; it is an act of pure faith. This unlogical faith which permeates science is very plain to see. Why should there be a system at all? Why should we feel that the universe must be a perfect harmony? Why should there not be seventy or eighty elements as well as one only? The answer is not forthcoming. It is a matter of faith bred in the bone of science. The little systems have their day, one after another, and cease to be. But out of each system rises another, not as a revolution but as an evolution. The second system takes in all the "facts" of the first accounts for all its inconsistencies and embraces a wider scope. The third bears a similar relation to the second. Hence the evolution of systems is like a series of concentric ever-widening circles covering ever larger areas of knowledge, and we believe purely as an act of faith and not at all of logic that the universe is eventually determinable, thousands of years hence, into some one system which will account for everything and which will be the truth.

Meanwhile, this system of the new knowledge, as we have attempted to outline it, is simply the outermost circle covering the greatest area of knowledge, and while its diameter is by no means infinite, it is the truest expression of the truth attainable at.this time and as such is vastly useful. Its utility in the evolution of knowledge is its sole apology for existence. Outside, however, of the 
theoretical interpretations of the new knowledge there is a great body of newly perceived phenomena called "facts." These "facts," independently of any theory connecting them, are also useful, so useful, indeed, that they will never be forgotten nor neglected so long as thought endures. Such are the ascertained facts of, and measurements of, radioactivity, of the new physics, the new chemistry, and the new astronomy-new pawns on the chessboard of man's struggle with nature and forever useful.

In addition, there are certain new conceptions which while we can hardly say they are ascertained truths, shadow themselves as such.

It is in the realization of two of these conceptions that during the next two hundred years the great work of the world will lie.

The first is the transmutability of the elements. Our reason bids us assent to its actual accomplishment, not with our aid but in spite of it, in the case of the heavy elements. Our hopes lead us to feel that we may aspire to accomplish it for ourselves. In this connection Sir William Ramsay's speech at the Waldorf-Astoria banquet is significant.

"Experiments are in progress with radio-active substances the resul's of which seem to show that we are on the brink of discovering the synthesis of atoms. This may lead us to the discovery of the ordinary elements." A record of his experiments certainly confirms his hopeful attitude. Having accompished atomic synthesis we shall then strive to subordinate it to our needs, and having done this we shall be well on our way to a transformed world.

Still another conception of the new knowledge is that of the vast stores of inter-elemental energy of which we live but on the fringe-a store of energy so great that every breath we draw has within it sufficient power to drive the work- 
shops of the world. Man will tap this energy some day, some how.

Of course we do not know this, but we believe it. We believe it because we believe that Creation means something and means it intensely. We have not come up through Paleozoic, Mesozoic and Cenozoic times for nothing. If all the anguish of all the lives of all the past were to find one common vocal expression what a cry to God there would be! Are we to believe that the butcher, the baker and the candlestick maker, to say nothing of the great masses of men beneath them are worth all that? No. It is all a promise. There must be a result in the world that is worth all the world. It has been impossible in the past to even glimpse this result. It was an action of pure faith to believe in it. But now that we know, or think we know, of this infinite treasure-house of inter-elemental energy lying latent for the hand of future man to use, it is neither difficult nor fanatical to believe that "beings who are now latent in our thoughts and hidden in our loins shall stand upon this earth as one stands upon a foot-stool, and shall laugh and reach out their hands amidst the stars."

Meanwhile, we feel that we know this: "In the beginning God created" and in the midst of His creation He set down man with a little spark of the Godhead in him to make him strive to know,-and in the striving, to grow and to progress to some great, worthy, unknown end in this world. He gave him hands to do, a will to drive, and seven senses to apprehend,--just a working equipment; and so he has won his way, so far, out of the horrible conditions of pre-history.

To know, is to work and to do; and a new thing done is forever a rung in the ladder by which man climbs,-necessary and good for all generations, until the summit is attained and the ladder can be cast aside. 



\section{INDEX.}

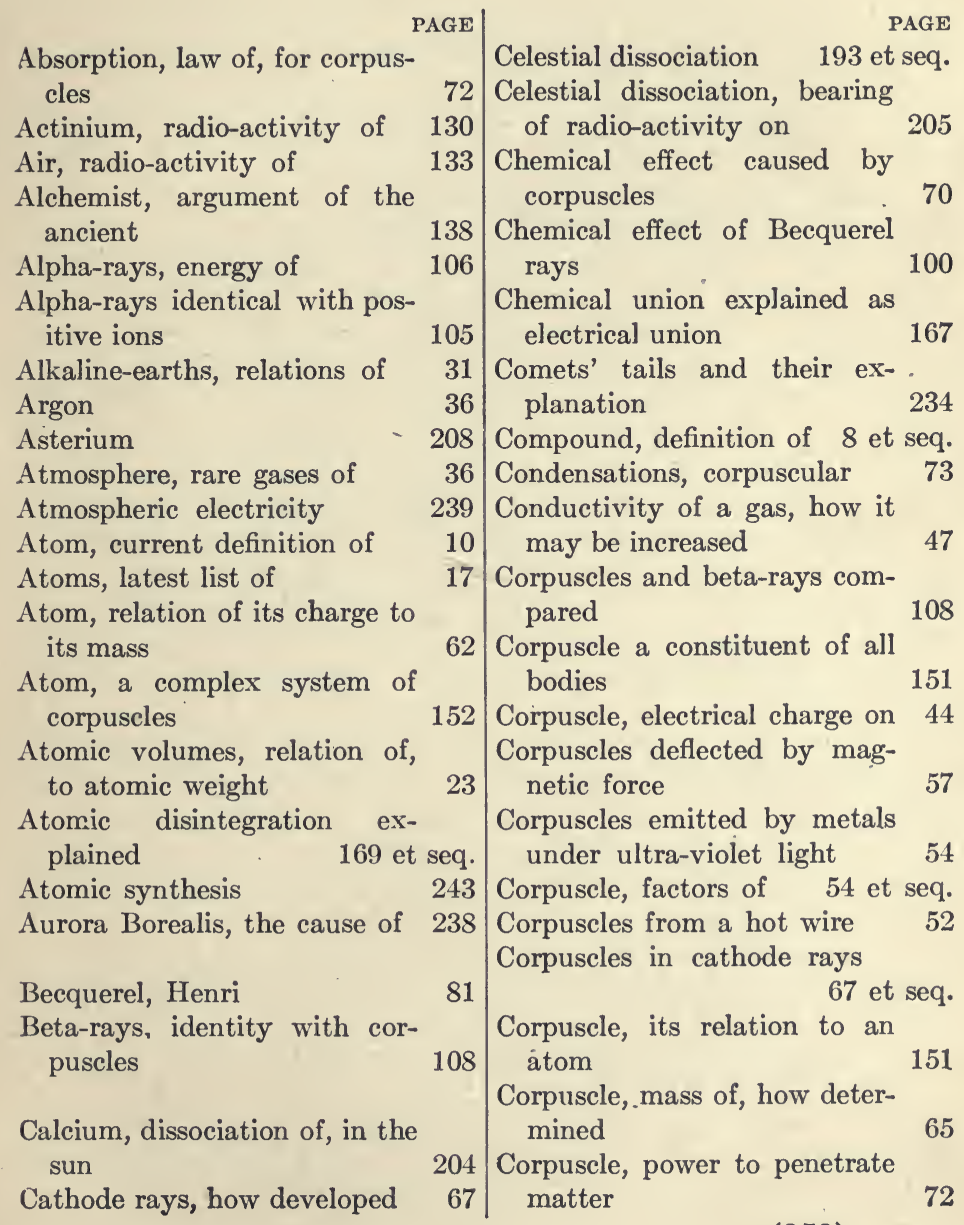


Corpuscles, speed of

Corpuscles, résumé of properties of

Corpuscle, relation of its charge to its mass

Corpuscles, velocity of, how determined 56 et seq.

Corpuscular arrangement in the atom 154 et seq.

Curie, M. et Mde.

Curves, illustrating decay and restoration of activity

Curves illustrating the decay and recovery of thorium radio-activity

Dark stars, relation of, to meteorites

Davy on elemental transmutation

De-emanated radium, a restoration of activity

Disintegration, atomic 150 et seq.

Earth, the age of the

Earth, the, a self-heating body 230

Eka-aluminum

Eka-boron, identity with scandium of

Eka-silicon

Electrical conduction explained by corpuscles

Electrical self-induction

Electron identical with corpuscle

Electrotonic theory of matter

Electrotonic theory, teachings of

Electrotonic theory distinguished from atomic disintegration

Electroscope, simple

59 Electroscope for the study of radio-activity

74 Electroscope, sensitiveness of 117 Element, definition of 8 et seq. Elements, relation of temperature to, in stars

Elements, undiscovered, successful prediction of 34 et seq. Elements, radio-active, discovery of 90 et seq. Elemental transmutation is atomic 152

Emanations, discovery of $\quad 114$

Emanation from radium, properties of 116

Emanation, decay of activity of

Emanation, amount stored in solid radium compound 121

140 Emanation, heat emitted by 174 Emanation from thorium 128 Emanation, rays emitted by 119 Emanation, energy of 118 Emanation X, properties of

Emanation X, energy of $\quad 123$

34 Energy, definition of 5 Energy, forms of 6

35 Energy as an entity 7

34 Energy, law of the conservation of 6

186 Energy, inter-elemental, its

180 importance 257

Energy, interatomic, amount of 176

185 Energy, interatomic, possibility

185 of utilizing 177

Ether, preliminary definition of $\quad 4$

187 Ether, the, according to Mendeléeff 250

Ether, the, its position in the

189 periodic table 250

47 Evolution, inorganic 206 et seq. 
Excited activity

Exradio

Faraday on transmutation

Fraunhofer's lines

Gallium, successful prediction of

Gamma-rays, properties of

Gamma-rays compared with $\mathrm{X}$-rays

Gases, conductivity of

Germanium, successful prediction of

Gravitation

Halogens, relations of

Helium, a decomposition product of radium

Helium, discovery of

Helium in radio-active minerals 124

Helium from radium

Helium, its existence in the stars

Helium, position of, in periodic table

Helium, the possible substance of the alpha-rays

Helium, spectrum of

Heating effect caused by corpuscles

Heat emitted by radium

Induced radio-activity

Inert elements, position of, in periodic law

Inert elements, corpuscular explanation of

Inertia of matter

Inertia of electricity

Inorganic evolution indicated in periodic law

110

189

124

124

124
122 Inorganic evolution, relation

147 of, to organic evolution

213

Inorganic devolution 217 et seq.

140 Inorganic devolution, evidence

198 for

Inorganic devolution, its relation to inorganic evolution 222

34 Interatomic energy, discovery

110 of 172 et seq.

Ionisation, definition of $\quad 50$

Ions, gaseous

48 et seq.

Iron, spectrum of, in the sun 200

Iron, spectrum of, in the sun

Knowledge, the new, the valid-

ity of

252 et seq.

Lenard rays

72

Light, the mechanical pressure of 232

Light, undulatory theory of Lockyer, Sir Norman

Magnesium, spectrum of, in the

Magnetism

203

Mass, law of the conservation

Mass, conservation of, reconsidered

Mass electrical in its origin 184

Mass, increase of, with velocity 182

Mass, the increase of, with velocity; experimental verification

Matter, preliminary definition of

Matter, the mystery of

180 Matter, electrical nature of

41 Matter, transmutation of 137 et seq. 
PAGE

Mayer's model atom 155 et seq.

Mechanical effect caused by corpuscles

Melting-point of the elements, relation of, to atomic weight

Meteorites, the light of

Molecule, definition of

Nebula, stellar

Nebulæ, the light of

Niewenglowski's experiment

83 et seq.

Nuclei caused by corpuscles

Octaves of Newlands

Periodic law, corpuscular explanation of group relations of

Periodic law, corpuscular ex-

planation of series relation of 163

Periodic law, definition of

Periodic law, description of

26 et seq.

Periodic law explained in terms of corpuscles

Periodic law, group relations of

Periodic law, latest table of

Periodic law, regularities of

Periodic law, significance of

39 et seq.

Phosphorescence caused by Cathode rays

Phosphorescence caused by Becquerel rays

Polonium, radio-activity of

Positive ions, properties of

Positive electricity

Prout's hypothesis

'Prout's hypothesis explained in terms of corpuscles
Rays, Becquerel, effect of a magnet on

Rays, Becquerel, electrical effects of

Rays, Becquerel, existence of three types of 102 et seq.

Radio-activity, acquired

PAGE

Radio-activity, antecedent discovery

81 et seq.

Radio-activity and unstable atoms explained by corpuscles

Radio-activity, definition of 111

Radio-activity, discovery of 86

Radio-active elements, radioactive changes in

Radium, activity of, compared with uranium

Radium as a test of the periodic law

Radium, discovery of, in pitchblende

Radium, its supposed relation to uranium

Radium emanation, condensation of

Radium, life of

Radium; position of, in periodic law

Radium, rarity of

94

Radium, spectrum of

Ramsay, Sir William, on atomic synthesis

Rays, Becquerel, continuous emission of 87

Rays, Becquerel, genealogy of 82

Rays, Becquerel, law of absorption of

Rays, Becquerel, photographic power of

Rays, Becquerel, physiological 


\section{PAGE}

Scandium, successful prediction of

Science, definitions of, redefined 246 et seq.

Series, definition of, in periodic law

Solar corona

Solar prominences and their. cause

Spectra, fluted

Spectra, variable

Spectroscope, the philosophy of

Spectrum, discontinuous

Spectrum series

Spinthariscope

Stellar evidence of dissociation 204

Stellar thermometer, teachings of

Sub-atomicity indicated in periodic law

Substances, radio-activity of ordinary

Sun, helium in the

Sun, the heat of the

Sun, the life of the

Table of atomic weights

Table of transmuted elements 148

Thermodynamics, second law of

Thermometer, stellar

Thomson, Professor J. J., on the structure of the atom 154 et seq.

Thorium emanation, condensation of
Thorium emanation obeys

Boyles' law

PAGE

Thorium, radio-activity of

Thorium emanation $\mathrm{X} \quad 128$

Thorium X, discovery of $\quad 126$

Triads of Dobereiner 21

Triads of Dobereiner explained in terms of corpuscles

Truth, definitions of 253 et seq.

Uranium compounds, radioactivity of

Uranium, radio-activity of 129

Uranium, transmutation into

Uranium X

Uranium $\mathrm{X}$ distinguished from uranium

Uranium $\mathrm{X}$, radio-activity

Universe, $\mathrm{a}$, the reconstruction of

280 et seq.

Universe, the, a conservative system

Universe, the, available energy of

Valency

Valency, corpuscular explanation of

Water, radio-activity of

$\mathrm{X}$-rays, possible nature of $\quad 111$

$\mathrm{X}$-rays, their relation to corpuscles

Zero group 





\section{a.n.B. $23: 6192$ \\ M.H. 19/4/44}

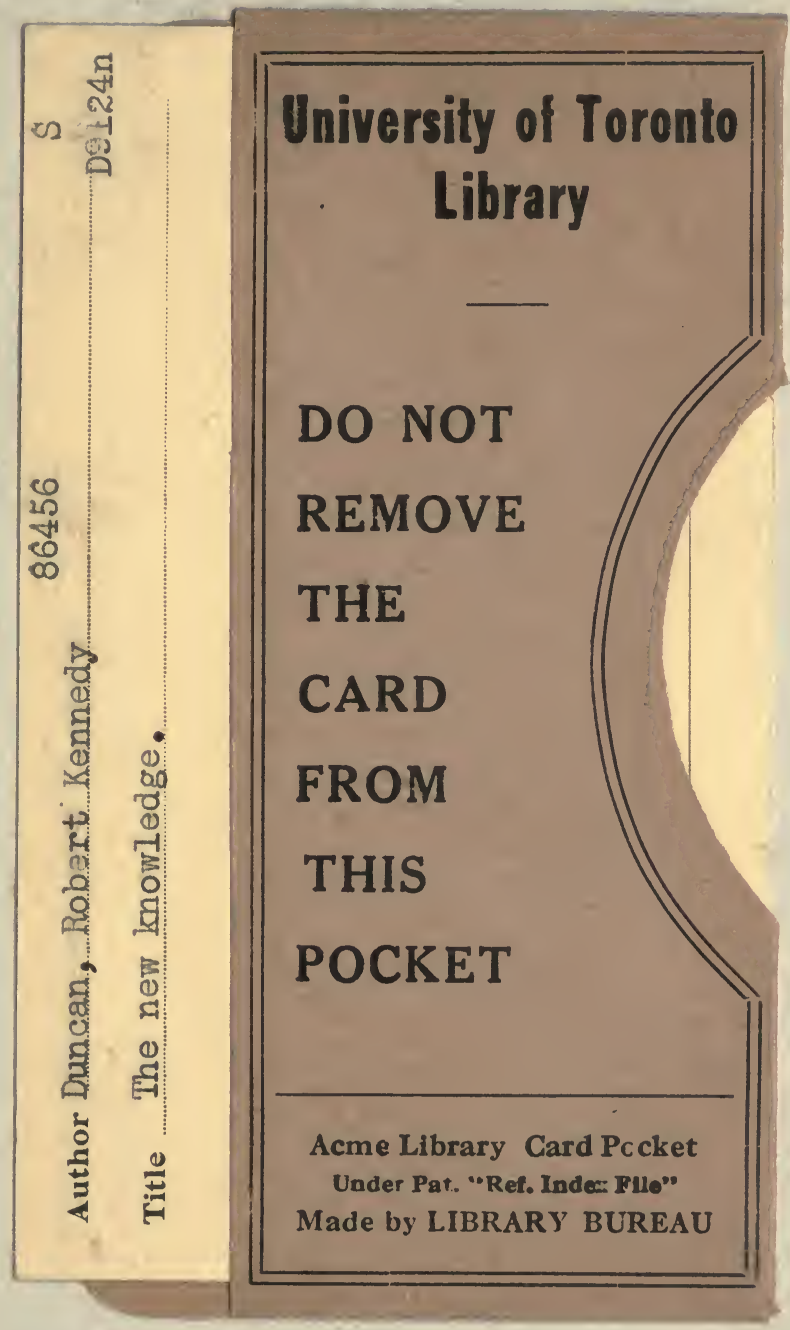


